\title{
The global aerosol-climate model ECHAM-HAM, version 2: sensitivity to improvements in process representations
}

\author{
K. Zhang ${ }^{1,6}$, D. O'Donnell ${ }^{1, *}$, J. Kazil ${ }^{2,7}$, P. Stier ${ }^{3}$, S. Kinne ${ }^{1}$, U. Lohmann ${ }^{4}$, S. Ferrachat ${ }^{4}$, B. Croft ${ }^{5}$, J. Quaas ${ }^{1,{ }^{* *}}$, \\ H. Wan ${ }^{6}$, S. Rast ${ }^{1}$, and J. Feichter ${ }^{1}$ \\ ${ }^{1}$ Max Planck Institute for Meteorology, Hamburg, Germany \\ ${ }^{2}$ Cooperative Institute for Research in Environmental Sciences (CIRES), University of Colorado, Boulder, Colorado, USA \\ ${ }^{3}$ University of Oxford, Oxford, UK \\ ${ }^{4}$ Institute of Atmospheric and Climate Science, ETH Zürich, Switzerland \\ ${ }^{5}$ Department of Physics and Atmospheric Science, Dalhousie University, Halifax, Canada \\ ${ }^{6}$ Pacific Northwest National Laboratory, Richland, WA, USA \\ ${ }^{7}$ NOAA Earth System Research Laboratory (ESRL), Boulder, Colorado, USA \\ * now at: Finnish Meteorological Institute, Helsinki, Finland \\ ** now at: University of Leipzig, Leipzig, Germany
}

Correspondence to: K. Zhang (kai.zhang@pnnl.gov)

Received: 13 February 2012 - Published in Atmos. Chem. Phys. Discuss.: 16 March 2012

Revised: 31 August 2012 - Accepted: 17 September 2012 - Published: 1 October 2012

\begin{abstract}
This paper introduces and evaluates the second version of the global aerosol-climate model ECHAM-HAM. Major changes have been brought into the model, including new parameterizations for aerosol nucleation and water uptake, an explicit treatment of secondary organic aerosols, modified emission calculations for sea salt and mineral dust, the coupling of aerosol microphysics to a two-moment stratiform cloud microphysics scheme, and alternative wet scavenging parameterizations. These revisions extend the model's capability to represent details of the aerosol lifecycle and its interaction with climate. Nudged simulations of the year 2000 are carried out to compare the aerosol properties and global distribution in HAM1 and HAM2, and to evaluate them against various observations. Sensitivity experiments are performed to help identify the impact of each individual update in model formulation.

Results indicate that from HAM1 to HAM2 there is a marked weakening of aerosol water uptake in the lower troposphere, reducing the total aerosol water burden from $75 \mathrm{Tg}$ to $51 \mathrm{Tg}$. The main reason is the newly introduced $\kappa$-Köhlertheory-based water uptake scheme uses a lower value for the maximum relative humidity cutoff. Particulate organic matter loading in HAM2 is considerably higher in the upper troposphere, because the explicit treatment of secondary organic
\end{abstract}

aerosols allows highly volatile oxidation products of the precursors to be vertically transported to regions of very low temperature and to form aerosols there. Sulfate, black carbon, particulate organic matter and mineral dust in HAM2 have longer lifetimes than in HAM1 because of weaker incloud scavenging, which is in turn related to lower autoconversion efficiency in the newly introduced two-moment cloud microphysics scheme. Modification in the sea salt emission scheme causes a significant increase in the ratio (from 1.6 to 7.7) between accumulation mode and coarse mode emission fluxes of aerosol number concentration. This leads to a general increase in the number concentration of smaller particles over the oceans in HAM2, as reflected by the higher Ångström parameters.

Evaluation against observation reveals that in terms of model performance, main improvements in HAM2 include a marked decrease of the systematic negative bias in the absorption aerosol optical depth, as well as smaller biases over the oceans in Angström parameter and in the accumulation mode number concentration. The simulated geographical distribution of aerosol optical depth (AOD) is better correlated with the MODIS data, while the surface aerosol mass concentrations are very similar to those in the old version. The total aerosol water content in HAM2 is considerably 
closer to the multi-model average from Phase I of the AeroCom intercomparison project. Model deficiencies that require further efforts in the future include (i) positive biases in AOD over the ocean, (ii) negative biases in AOD and aerosol mass concentration in high-latitude regions, and (iii) negative biases in particle number concentration, especially that of the Aitken mode, in the lower troposphere in heavily polluted regions.

\section{Introduction}

Although it is widely believed that natural and anthropogenic aerosols play an important role in determining the current state and future changes of the Earth's climate, various physical processes in the aerosol lifecycle are not yet understood with certainty. Quantifications of the climatic effects of aerosols, particularly through their impacts on clouds, remain insufficient. Numerical models, together with observational data from a variety of sources, provide a powerful tool for advancing our understanding of the complex interactions between aerosols and climate. Lessons learnt from earlier studies using simple bulk methods (e.g. Langner and Rodhe, 1991; Feichter et al., 1996) gradually led to appreciation of the importance of microphysics in aerosol modelling. The newer models have thus included more detailed descriptions of aerosol composition and size distribution, using different approaches (Wilson et al., 2001; Jacobson, 2001; Vignati et al., 2004; Easter et al., 2004; Stier et al., 2005; Spracklen et al., 2005; Liu et al., 2005; Bauer et al., 2008; Liu et al., 2012).

The ECHAM5-HAM model (Stier et al., 2005) developed at the Max Planck Institute for Meteorology was one of the earlier examples of a global atmospheric general circulation model that can dynamically predict the composition and size distribution of aerosols by taking into account the most important chemical and physical processes ranging from the micro- to the global scale, and in return, calculate the radiative effects of aerosols on the atmospheric dynamics. In addition to the evaluation presented by Stier et al. (2005), the model has been compared with other models and with observations through participation in the AeroCom (Aerosol Comparisons between Observations and Models) model intercomparison project (http://aerocom.met.no), as well as the EUCAARI (European Integrated project on Aerosol Cloud Climate and Air Quality interactions) model intercomparison (Kulmala et al., 2011). The simulated aerosol mass budget, residence time, and optical properties are within the ranges of multi-model spread (Textor et al., 2006, 2007; Kinne et al., 2006). The estimated direct forcing of aerosols is close to the multi-model mean (Schulz et al., 2006).

Since first released in 2005 , the model has been widely used in process studies (e.g. Hoose et al., 2008; Croft et al., 2009; Makkonen et al., 2009) and for investigations in the climate impact of aerosols (e.g. Roeckner et al., 2006b; Stier et al., 2006; Kloster et al., 2008; Lohmann and Hoose, 2009; Fischer-Bruns et al., 2010; Folini and Wild, 2011; Kazil et al., 2012). The first released version, designed with a focus on tropospheric aerosols, has been extended into the stratosphere and used in volcanic eruption and geoengineering studies (e.g. Niemeier et al., 2009; Timmreck et al., 2010; Niemeier et al., 2011). Apart from being coupled with ECHAM5 (Roeckner et al., 2003, 2006a), the complete aerosol module HAM, or substantial parts of it, has been implemented in several other model systems, for example by Mashayekhi et al. (2009), Pringle et al. (2010), Zhang et al. (2010), and Bergman et al. (2012).

In the past years, through further evaluation as well as various applications, several biases in ECHAM-HAM have been brought to attention. For example, the simulated aerosol absorption featured negative biases (Stier et al., 2007). In comparison to aircraft measurements, the Aitken mode particle number concentration was underestimated in the lower troposphere over the industrial regions (Stier et al., 2005; Zhang et al., 2010). According to ship measurements, the accumulation mode number concentration over the ocean was also underestimated (Hoose et al., 2008). The simulated aerosol optical depth (AOD) and extinction profiles had systematic negative biases in high-latitude regions (Koch et al., 2009; Bourgeois and Bey, 2011) and positive biases over the open oceans (Croft et al., 2009). The Ångström parameter over the ocean was on the large large side compared to the Moderate Resolution Imaging Spectroradiometer (MODIS) satellite retrieval. These issues, together with the simplifications made for secondary organic aerosols (SOA) and the lack of physically-based coupling between aerosols and clouds, motivated further improvement of ECHAM-HAM.

A series of attempts have been made to identify the sources of these errors and to improve model performance. The refractive index for black carbon has been updated to reduce the negative bias of absorption aerosol optical depth (Stier et al., 2007). The four-band shortwave radiative transfer scheme in the atmospheric model has been extended with two more bands (Cagnazzo et al., 2007). A newer aerosol nucleation parameterization has been adopted, and additional mechanisms included (Kazil et al., 2010). A more detailed and explicit treatment of SOA was implemented (O'Donnell et al., 2011), as well as a new scheme for calculating the hygroscopic growth of aerosol particles. The wet scavenging schemes have been updated (Croft et al., 2009, and this work). A two-moment cloud microphysics scheme is implemented and coupled with aerosol microphysics (Lohmann et al., 2007). The on-line calculation of dust and sea salt emissions have also been modified (Cheng et al., 2008, and this work). A satellite simulator (Quaas et al., 2004, see also http://www.euclipse.eu/downloads/D1. 2_euclipse_modissimulator.pdf) is implemented in the model which diagnoses cloud quantities consistently with passive satellite retrievals as from the MODIS instrument, and 
samples the spatial and temporal incidences of the overpasses of polar-orbiting satellites. This facilitates the comparison between model results and the observations from spaceborne instruments. These revisions have brought us to the point where a second version of this aerosol-climate model is ready for release. This new version, referred to as ECHAM-HAM2 (or simply HAM2), participated in phase II of the AeroCom model intercomparison (Schulz et al., 2009).

The main objective of the present paper is to analyse and quantify the effects of improvements in the process representation on the simulated aerosol properties, global distribution, and radiative effects. Although some of the new features have already been discussed in the publications cited above, the authors therein mainly concentrated on specific schemes for individual processes. The model evaluation was often limited to aspects most closely related to the process in question. Furthermore, some of the above-cited studies with ECHAM-HAM were based on intermediate (unreleased) code versions that included incremental changes in model configuration. As the aerosol processes and their interactions with each other and with model meteorology are often nonlinear, it is not always easy to draw conclusions on the effect of a particular modification by intercomparing results reported in these publications. An important part of the present paper is a series of sensitivity simulations that are all performed with the "official" HAM2 as reference, and with a single aspect of the model updates reverted to the HAM1 configuration. In this way we attempt to provide a clean evaluation of the impact of each individual modification. These sensitivity simulations are discussed in Sect. 4 . The combined effects are analysed in Sect. 5, in which the HAM2 results are compared with those from the previous version, as well as against observation. Before showing these results, we provide a summary of the basic features of the ECHAMHAM model in Sect. 2, and describe the simulation design in Sect. 3. Conclusions drawn from this work are presented in Sect. 6. As in the paper by Stier et al. (2005), we concentrate our analysis on aerosols in the troposphere. There are some additional model updates related to stratospheric aerosols which have not yet been included in the code used in this study. These developments were presented in Niemeier et al. (2009).

\section{Model overview}

The aerosol module HAM (Stier et al., 2005) was designed as a component of the global climate model ECHAM5 (Roeckner et al., 2003, 2006a) for the purpose of investigating aerosol-climate interactions. The host model ECHAM5 employs a spectral transform dynamical core inherited from the European Centre for Medium-range Weather Forecasts (ECMWF), and a flux-form semi-Langrangian tracer transport algorithm of Lin and Rood (1996) with piecewise parabolic sub-grid distribution. As for the parameterized physics, cumulus convection and convective tracer transport are represented by the mass-flux scheme of Tiedtke (1989) with further modifications by Nordeng (1994). Turbulent transport of momentum, heat, moisture and passive tracers is described by the eddy diffusivity theory (Louis, 1979), with the vertical diffusion coefficient computed as functions of atmospheric stability and the turbulent kinetic energy (Brinkop and Roeckner, 1995). Shortwave and longwave radiative transfer calculations follow the methods of Fouquart and Bonnel (1980) and Mlawer et al. (1997), respectively. The longwave scheme considers 16 spectral bands. The shortwave scheme has 4 or 6 bands depending on model version. The 6-band version adapted from the ECMWF model by Cagnazzo et al. (2007) has the $250-690 \mathrm{~nm}$ interval subdivided to better consider the absorption by water vapor at $440-690 \mathrm{~nm}$. In addition, an ultra-violet band is added to consider the absorption by ozone, resulting in a total of 3 bands in the ultra-violet and visible range $(185-250 \mathrm{~nm}, 250$ $440 \mathrm{~nm}$ and $440-690 \mathrm{~nm}$ ).

The tropospheric version of ECHAM5 is most often used at T63 resolution (approximately $2^{\circ}$ latitude $\times 2^{\circ}$ longitude grid spacing), with 31 vertical levels up to $10 \mathrm{hPa}$ and a default time step of $12 \mathrm{~min}$. This is also the configuration used in this study. Most of the AeroCom Phase I models (Textor et al., 2006) used resolutions between $1.1^{\circ} \times 1.1^{\circ}$ to $5^{\circ} \times 4^{\circ}$, except ULAQ which was $22.5^{\circ} \times 10^{\circ}$. The T63 resolution we are using in this study is similar to the GOCART $\left(2.5^{\circ} \times 2.0^{\circ}\right.$, Chin et al., 2000), MATCH $\left(1.9^{\circ} \times 1.9^{\circ}\right.$, Barth et al., 2000), MOZGN $\left(1.9^{\circ} \times 1.9^{\circ}\right.$, Tie et al., 2001), UMI $\left(2.5^{\circ} \times 2^{\circ}\right.$, Liu and Penner, 2002), and PNNL $\left(2.5^{\circ} \times 2.0^{\circ}\right.$, Easter et al., 2004) models.

ECHAM drives the aerosol module by providing meteorological conditions such as horizontal wind, temperature, pressure, humidity. The large-scale, convective, and turbulent transport of aerosols and their precursors are handled in the same way as other passive tracers in the host model (e.g. water vapor and hydrometeors). The aerosol module provides feedback to ECHAM by affecting the radiative transfer (Sect. 2.6) and cloud microphysics (Sect. 2.7).

In the remainder of this section the main components of the aerosol module HAM are described. To avoid repeating the details already provided by Stier et al. (2005), we restrict ourselves to an extended summary of the modeling concept, and provide the references when necessary. Note that this section focuses on the aspects that remain unchanged since 2005. Later in the paper, when mentioning these features, or the model development effort in general, we use the term "ECHAM-HAM" or simply "HAM". When it is necessary to distinguish, "HAM1" refers to the specific model configuration described by Stier et al. (2005), and "HAM2" the new version presented in this paper. An overview of the updates in HAM2 with respect to HAM1 is provided by Table 1. Further details and the impacts on aerosol simulation are discussed in Sect. 4. 
Table 1. An overview of the main differences between HAM1 and HAM2 in model configuration.

\begin{tabular}{|c|c|c|c|}
\hline & HAM1 and HAM2 shared features & HAM1 specifics & HAM2 specifics \\
\hline $\begin{array}{l}\text { Atmospheric dynamics } \\
\text { and physics }\end{array}$ & $\begin{array}{l}\text { ECHAM5 (Roeckner et al., 2003, } \\
\text { 2006a) }\end{array}$ & $\begin{array}{l}\text { Stratiform cloud microphysics scheme by } \\
\text { Lohmann and Roeckner (1996); Solar ra- } \\
\text { diation scheme with four bands (Fouquart } \\
\text { and Bonnel, 1980). }\end{array}$ & $\begin{array}{l}\text { Two-moment stratiform cloud microphysics } \\
\text { scheme by Lohmann et al. (2007); So- } \\
\text { lar radiation scheme extended to six bands } \\
\text { (Cagnazzo et al., 2007) }\end{array}$ \\
\hline Sulfuric acid gas & $\begin{array}{l}\text { Sources and sinks include transport, } \\
\text { chemical production, condensation, } \\
\text { and aerosol nucleation. }\end{array}$ & $\begin{array}{l}\text { Concentration equation is solved with } \\
\text { three-step sequential operator splitting us- } \\
\text { ing explicit time stepping scheme; No dis- } \\
\text { tinction between cloudy and cloud-free } \\
\text { parts of a model grid box. }\end{array}$ & $\begin{array}{l}\text { Concentration equation is solved by a two- } \\
\text { step operator splitting scheme with analyti- } \\
\text { cal solution for production and condensation } \\
\text { (Kokkola et al., 2009); Complete removal of } \\
\text { sulfuric acid gas from the air is assumed in } \\
\text { the cloudy part of a model grid box (Kazil } \\
\text { et al., 2010). }\end{array}$ \\
\hline Aerosol nucleation & $\begin{array}{l}\text { Vehkamäki et al. (2002) or Kulmala } \\
\text { et al. (1998) }\end{array}$ & Vehkamäki et al. (2002) as default & $\begin{array}{l}\text { New scheme by Kazil et al. (2010) as de- } \\
\text { fault, with optional } \mathrm{H}_{2} \mathrm{SO}_{4} \text {-organic nucle- } \\
\text { ation based on the kinetic nucleation the- } \\
\text { ory (Kuang et al., 2008) or cluster activa- } \\
\text { tion (Kulmala et al., 2006; Riipinen et al., } \\
2007 \text {; Kazil et al., 2010). Old schemes by } \\
\text { Vehkamäki et al. (2002) and by Kulmala } \\
\text { et al. (1998) are still optional. }\end{array}$ \\
\hline
\end{tabular}

Aerosol water uptake Dependent on the chemical compositions of aerosol particles and ambient relative humidity (with respect to water).

Secondary organic

aerosol (SOA)

Sea salt emission

Interactive calculation based on

Monahan et al. (1986) and Smith and Harrison (1998)

Dust emission Interactive calculation using the Tegen et al. (2002) scheme

Aerosol radiative effects

Optical properties of aerosols are first calculated mode by mode assuming different compositions in a mode are internally mixed. Synthesized parameters are then derived for the radiative transfer calculation, assuming external mixing of different modes.

In-cloud scavenging of Prescribed scavenging coefficient aerosols for each aerosol mode and cloud type (Stier et al., 2005).

\section{Below-cloud} scavenging of aerosols
Considered only for non-organic aerosols, based on Zeleznik (1991), Zdanovskii (1948) and Stokes and Robinson (1966)

SOA is approximated as $15 \%$ of monoterpene emissions at surface (Dentener et al., 2006) and is assumed to condense immediately on existing aerosol particles and to have identical properties to primary organic aerosols (Stier et al., 2005).

Smooth merging of emission functions in the particle radius range of $2-4 \mu \mathrm{m}$ (Stier et al., 2005)
Considered for non-organic and organic aerosols, based on the $\kappa$-Köhler theory (Petters and Kreidenweis, 2007; O’Donnell et al., 2011)

The lifecycle of SOA is explicitly simulated; Emissions of biogenic precursors are computed interactively; Anthropogenic precursor emissions are prescribed (O'Donnell et al., 2011).

Monahan et al. (1986) formula for the radius range of $2-4 \mu \mathrm{m}$ (cf. Sect. 4.1.4)

East Asia soil properties updated by Cheng et al. (2008)

Aerosol effects considered only for shortwave radiation.

Aerosol effects are considered for both shortwave and longwave radiation; Refractive indices of $\mathrm{BC}$ updated by Stier et al. (2007).
Scavenging parameters are prescribed for three ambient temperature ranges (liquid cloud: $T>273 \mathrm{~K}$, mixed-phase cloud: $238 \mathrm{~K}<T<273 \mathrm{~K}$, and ice cloud: $T<$ $238 \mathrm{~K})$.

Prescribed, mode dependent impaction scavenging coefficients for rain; One fixed coefficient for snow (Stier et al., 2005)
Option to use temperature denpendent scavenging parameters for mixed-phase stratiform clouds based on a relationship from (Verheggen et al., 2007).

Optional scheme by Croft et al. (2009): Impaction scavenging coefficients for rain depend on the size distributions of aerosols and collectors; The coefficients for snow depend on aerosol size. 


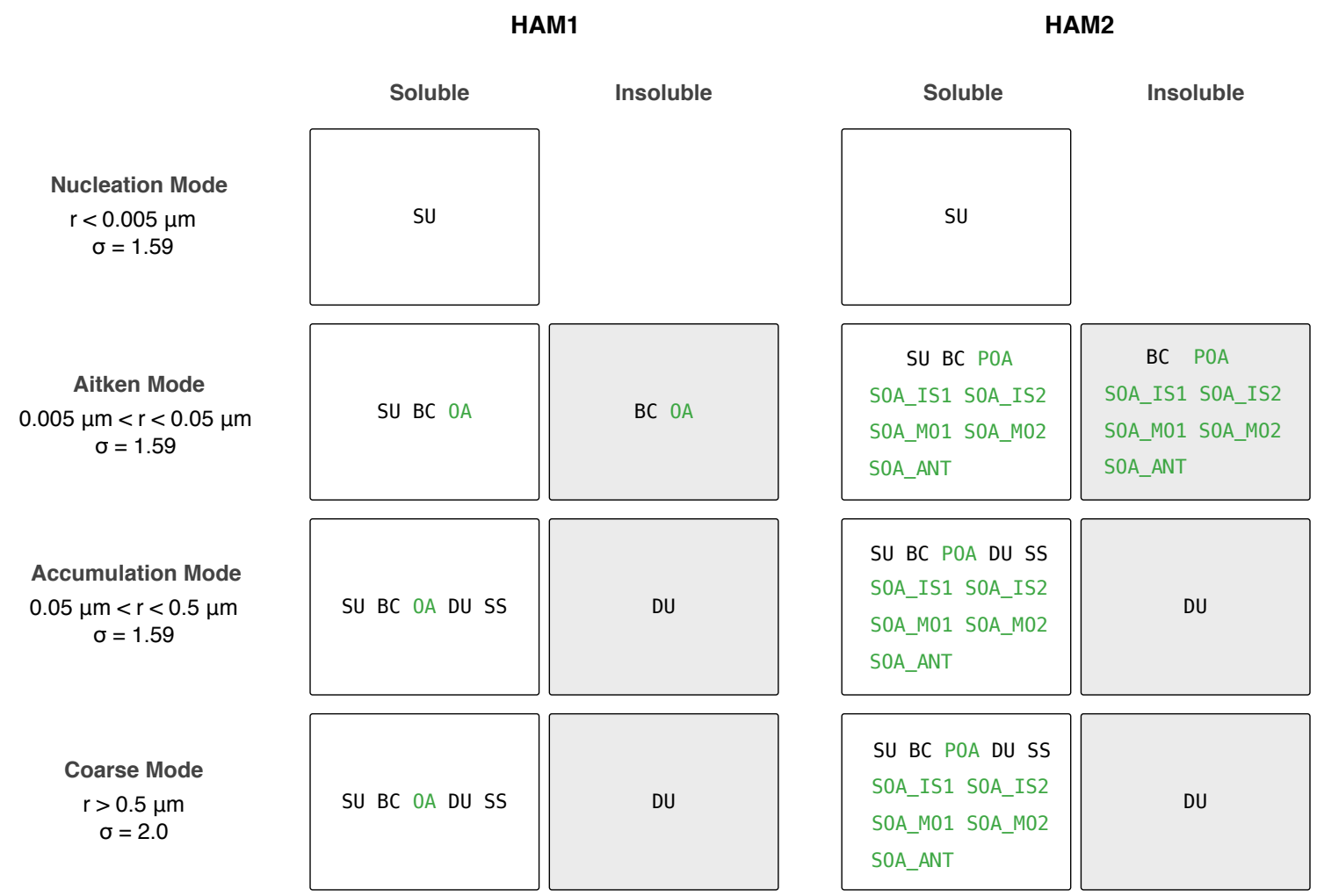

Fig. 1. Aerosol modes and compositions considered in HAM1 and HAM2. The chemical compositions include sulfate (SU), black carbon (BC), primary organic aerosol (POA), mineral dust (DU), sea salt (SS), and secondary organic aerosol (SOA). SOA can be further divided into different products from isoprene oxidation (SOA_IS1 and SOA_IS2), from monoterpene oxidation (SOA_MO1 and SOA_MO2), and from the oxidation of anthropogenic precursors (SOA_ANT). In HAM1, SOA and POA are assumed to have the same properties, thus are denoted collectively by OA in the diagram. The text in green highlights differences between the two model versions. As for the mode parameters, $r$ stands for the number median radius, and $\sigma$ the prescribed standard deviation. Modified from Table 1 in Stier et al. (2005).

\subsection{Aerosol composition and size distribution}

The aerosol module HAM predicts the evolution of an aerosol ensemble of five compositions: sulfate (SU), black carbon (BC), particulate organic matter (POM), sea salt (SS), and mineral dust (DU). The size distribution of this aerosol population is described by 7 log-normal modes with prescribed variance. A schematic is shown in Fig. 1. The detailed mathematical formulation can be found in Stier et al. (2005, Eq. (1) therein). Different compositions within a mode are assumed to be internally mixed, meaning that each particle consists of multiple compositions. Aerosols of different modes are externally mixed, meaning that they coexist in the atmosphere as independent particles. Four of the modes contain at least one soluble composition, thus the particles can take up water. These are referred to as soluble modes. The other three modes consist of insoluble species only. Through the aging processes, insoluble particles can become soluble (explained in Sect. 2.4).

The HAM module predicts the particle number concentration of each mode, as well as the mass concentration of the compositions present in that mode. Not counting the sec- ondary organic aerosol (SOA), there are 25 aerosol tracers in the model that are affected by large-scale, convective and turbulent transport. The 3 precursor gases of sulfate, namely $\mathrm{SO}_{2}$, dimethyl sulfide and sulfuric acid gas, are also transported. In HAM1, SOA was considered to have the same properties as POA (primary organic aerosol). They are denoted collectively by OA in Fig. 1, implying there is no additional tracer for SOA. In HAM2, different SOA species are distinguished according to their sources (anthropogenic, isoprene-derived and terpene-derived). The actual number of SOA-related tracers (including precursors and semi- and non-volatile secondary organics) depends on the lumping assumption. In this study we have 13 transported tracers in the SOA module. The details are explained in Sect. 4.1.2.

\subsection{Emissions of aerosols and their precursors}

The emissions of sea salt and dust are computed interactively for each mode that contains these compositions, based on the work of Monahan et al. (1986), Smith and Harrison (1998), and Tegen et al. (2002). The number and mass fluxes of sea salt are parameterized as functions of the $10 \mathrm{~m}$ wind speed 
Table 2. Partitioning (mass fraction) of the primary aerosol emissions of sulfate, black carbon (BC) and organic aerosols (POA and SOA) among different modes in ECHAM-HAM. $r_{\mathrm{m}}$ and $\sigma$ are the median radius and standard deviation of the emitted particles. Note that SOA emissions are considered as primary emissions in HAM1, while in HAM2 the formation of SOA via chemical production is explicitly represented.

\begin{tabular}{|c|c|c|c|c|c|}
\hline Composition & Emission type & $\begin{array}{c}\text { Insoluble Aitken } \\
r_{\mathrm{m}}=0.03 \mu \mathrm{m} \\
\sigma=1.59\end{array}$ & $\begin{array}{c}\text { Soluble Aitken } \\
r_{\mathrm{m}}=0.03 \mu \mathrm{m} \\
\sigma=1.59\end{array}$ & $\begin{array}{c}\text { Soluble accumulation } \\
\qquad \begin{array}{c}r_{\mathrm{m}}=0.075 \mu \mathrm{m} \\
\sigma=1.59\end{array}\end{array}$ & $\begin{array}{c}\text { Soluble coarse } \\
r_{\mathrm{m}}=0.75 \mu \mathrm{m} \\
\sigma=2.00\end{array}$ \\
\hline \multirow{3}{*}{$\mathrm{BC}$} & bio-fuel & $100 \%$ & & & \\
\hline & fossil fuel & $100 \%$ & & & \\
\hline & biomass burning & $100 \%$ & & & \\
\hline \multirow{3}{*}{ POA } & fossil fuel & $100 \%$ & & & \\
\hline & bio-fuel & $35 \%$ & $65 \%$ & & \\
\hline & biomass burning & $35 \%$ & $65 \%$ & & \\
\hline $\mathrm{SOA}^{*}$ & biogenic & $35 \%$ & $32.5 \%$ & $32.5 \%$ & \\
\hline \multirow{9}{*}{ Sulfate } & off-road & & $50 \%$ & $50 \%$ & \\
\hline & road transport & & $50 \%$ & $50 \%$ & \\
\hline & domestic & & $50 \%$ & $50 \%$ & \\
\hline & international shipping & & & $50 \%$ & $50 \%$ \\
\hline & industry & & & $50 \%$ & $50 \%$ \\
\hline & power plant & & & $50 \%$ & $50 \%$ \\
\hline & biomass burning & & $50 \%$ & $50 \%$ & \\
\hline & continuous volcano & & $50 \%$ & $50 \%$ & \\
\hline & eruptive volcano & & $50 \%$ & $50 \%$ & \\
\hline
\end{tabular}

(cf. Table 1). The dust fluxes depend on wind speed and soil properties.

Natural emissions of dimethyl sulfide (DMS) from the marine biosphere are calculated online following Nightingale et al. (2000). The fluxes depend on the model-calculated air-sea exchange rate as well as the DMS seawater concentration. The monthly mean DMS seawater concentrations are prescribed according to the work of Kettle and Andreae (2000). Terrestial DMS emissions are prescribed according to Pham et al. (1995).

Emissions of sulfur dioxide $\left(\mathrm{SO}_{2}\right)$ and particulate sulfate, black carbon and primary organic aerosols (POA) are prescribed following the year 2000 specifications of AeroCom (Dentener et al., 2006): non-eruptive volcanic $\mathrm{SO}_{2}$ emissions are taken from Andres and Kasgnoc (1998). Locations of eruptive emissions are from Halmer et al. (2002). The total strength of volcanic $\mathrm{SO}_{2}$ emission follows the recommendation of the GEIA inventory (http://www.geiacenter.org). Anthropogenically modified sources of $\mathrm{SO}_{2}, \mathrm{BC}$ and POA include wild-land fire, biofuel emissions and fossil-fuel emissions. Wild-land fire emissions are based on the Global Fire Emission Database inventory (van der Werf et al., 2004). Biofuel and fossil-fuel emissions of BC and POA are prescribed according to the Speciated Particulate Emissions Wizard inventory (Bond et al., 2004). Biofuel and fossil-fuel emissions of $\mathrm{SO}_{2}$ (including off-road, road transport, domestic, international shipping, industry, and power plant emissions) are based on Cofala et al. (2005) and EDGAR (Olivier et al., 2005a). The injection heights follow Table 1 in Dentener et al. (2006).
Primary aerosol emissions are distributed to different aerosol modes according to the emission type and the assumed soluble fraction. For sulfur emissions except DMS, $2.5 \%$ of the emission is assumed to be in the form of primary sulfate aerosols. For POA, $65 \%$ of the biomass burning and biogenic emissions are assumed to be soluble. Table 2 summarizes the partitioning mass fraction of the primary aerosol emissions among different modes in ECHAM-HAM. Further implementation details can be found in Sects. 2.3.1 and 2.3.2 of Stier et al. (2005).

The SOA emissions are treated differently in HAM1 and HAM2 due to the implementation of an explicit SOA module in the new version. This is explained later in Sect. 4.1.2. A brief summary can be found in Table 1 .

\subsection{Sulfur chemistry}

The sulfur chemistry module is based on the work by Feichter et al. (1996). Prognostic variables include concentrations of DMS, $\mathrm{SO}_{2}$ and gas- and aqueous-phase sulfate. Oxidant fields, including hydroxyl radical $(\mathrm{OH})$, hydrogen peroxide $\left(\mathrm{H}_{2} \mathrm{O}_{2}\right)$, nitrogen dioxide $\left(\mathrm{NO}_{2}\right)$, and ozone $\left(\mathrm{O}_{3}\right)$, are prescribed using three-dimensional monthly mean model output for present-day condition from the MOZART model (Horowitz et al., 2003). Sulfuric acid gas produced from gasphase chemistry can either condense on existing aerosol particles or nucleate to form new particles. Sulfate produced from aqueous phase chemistry is distributed to pre-existing soluble accumulation mode and coarse mode aerosol particles. 


\subsection{Aerosol microphysics}

The aerosol microphysics sub-module M7 of Vignati et al. (2004) simulates the formation and growth of aerosol particles due to nucleation and condensation of sulfuric acid gas, coagulation of particles, and aerosol water uptake. These processes lead to re-distribution of particle number and mass among different modes.

In the model the sulfuric acid gas concentration is affected by emission, chemical production, and large-scale and subgrid-scale transport. It can also form new aerosol particles (i.e. nucleation), or condense on particle surfaces. Condensation can happen on pre-existing particles of all sizes. The first-order mass transfer coefficient is computed following Fuchs (1959). Different accommodation coefficients are assumed for insoluble (0.3) and soluble (1.0) particles (Vignati et al., 2004). The numerical method used to solve the sulfuric acid gas evolution equation is updated in HAM2. This is noted in Table 1 and further explained in Sect. 4.1.1.

The coagulation rate is parameterized as a function of particle number concentration and a coefficient that depends on particle size and the thermodynamic state of air. Calculation of the coefficient follows Fuchs (1964). Both intramodal and intermodal coagulations are considered, although intramodal coagulation is neglected for the accumulation insoluble mode and the two (soluble and insoluble) coarse modes.

Coagulation of insoluble particles with soluble ones, as well as the condensation of sulfuric acid gas, can lead to addition of soluble mass (sulfate) to insoluble particles. When the amount of soluble composition is sufficient to form a monolayer coating, the particles becomes soluble. In M7, the number of converted (i.e. aged) particles during each time step is computed from the newly attached sulfate mass and the averaged surface area of particles in each insoluble mode (Vignati et al., 2004).

The water content of aerosols in each mode is calculated from their chemical composition and the ambient relative humidity. Different parameterization schemes are used in HAM1 and HAM2. Further details are given in Table 1 and Sect. 4.1.3.

\subsection{Removal processes}

Sink processes of aerosols, namely dry deposition, sedimentation and wet deposition, are parameterized as functions of particle size, composition and mixing state, as well as the meteorological conditions.

The loss of aerosol particles due to their role as cloud condensation nuclei or ice nuclei and due to collisions with cloud droplets or ice crystals is parameterized via a scavenging coefficient. This coefficient denotes the fraction of the available aerosols in the cloudy part of a grid box that is embedded in the cloud droplets and ice crystals. Different values of the scavenging coefficient are prescribed for different aerosol modes and cloud types, as documented in Table
3 of Stier et al. (2005). Because interstitial and cloud-born aerosols are not distinguished in our model, the particles embedded in cloud water/ice are considered as removed from the atmosphere only when the condensate is converted into precipitation.

Below-cloud scavenging describes the removal of aerosols due to collection by rain or snow. The removal rate depends on the precipitation rate and area, as well as the collection efficiency (Seinfeld and Pandis, 1998; Stier et al., 2005). Different collection efficiencies are assumed for rain and snow.

Turbulent dry deposition of aerosols is considered for all modes except for the nucleation mode, following Ganzeveld et al. (1998). The deposition flux is computed as the product of tracer concentration, air density and deposition velocity, first calculated for each of the surface types considered by the ECHAM5 model (snow/ice, bare soil, vegetation, wet skin, open water, and sea ice), and subsequently summed up using the fractional surface area. Deposition velocity is obtained from the aerodynamic resistance and surface resistance which in turn depend on particle size and density, properties of the Earth's surface, and characteristics of atmospheric turbulence.

Gravitational sedimentation of a single aerosol particle is described by the Stokes theory (Seinfeld and Pandis, 1998). The correction of Slinn and Slinn (1980) is applied to get the sedimentation velocity of a log-normal mode. To avoid violation of the Courant-Friedrich-Lewy stability criterion, the sedimentation velocity is limited to $V_{\mathrm{s}} \leq \frac{\Delta z}{\Delta t}$ where $\Delta z$ and $\Delta t$ are the model layer thickness and time step, respectively. In our model, sedimentation is considered only for the larger particles, i.e. the accumulation and coarse modes.

For precursor gases, in-cloud and below-cloud scavenging are calculated according to Henry's law (Seinfeld and Pandis, 1998). The dry deposition velocity is calculated with the big leaf approach, as a function of aerodynamic resistance, quasi-laminar boundary layer resistance, and surface resistance (Ganzeveld and Lelieveld, 1995; Ganzeveld et al., 1998). Gravitational sedimentation is ignored for gases.

\subsection{Aerosol optical properties and radiative effects}

Radiative properties of aerosols are dynamically computed in the model. From the chemical composition (including water content) and particle size, the Mie-scattering size parameter and volume-averaged refractive indices are derived for each aerosol mode assuming internal mixing of different chemical compositions. They are passed on to a look-up table that provides the extinction cross-section $\varphi$, single scattering albedo $\omega$ and asymmetry parameter $\gamma$. The look-up table is established using the Mie theory assuming 24 spectral bands for shortwave and 16 bands for longwave radiation. The $\varphi, \omega, \gamma$ parameters are then re-mapped to the bands of the ECHAM radiation scheme. For each band, the $\varphi, \omega, \gamma$ parameters of different modes are synthesized into a single triplet for the 
Table 3. References for the shortwave and longwave refractive indices for each aerosol composition in the HAM model. For the shortwave part, the refractive index at $550 \mathrm{~nm}$ wavelength is listed, in which $i$ denotes the imaginary unit. After Stier et al. (2005), Stier et al. (2007), and O'Donnell et al. (2011).

\begin{tabular}{llll}
\hline Species & Refractive index at $550 \mathrm{~nm}$ & Shortwave Reference & Longwave Reference \\
\hline HAM1 & & & \\
Sulfate & $1.43+1.0 \times 10^{-8} i$ & Hess et al. (1998) & \\
Black carbon & $1.75+4.4 \times 10^{-1} i$ & Hess et al. (1998) & \\
POM & $1.53+5.5 \times 10^{-3} i$ & Koepke et al. (1997) & \\
Sea Salt & $1.49+1.0 \times 10^{-3} i$ & Shettle and Fenn (1979) & \\
Mineral dust & $1.52+1.1 \times 10^{-3} i$ & Kinne et al. (2003) & \\
Aerosol water & $1.33+2.0 \times 10^{-7} i$ & Downing and Williams (1975) & \\
\hline HAM2 & & & \\
Sulfate & $1.43+1.0 \times 10^{-8} i$ & Hess et al. (1998) & Toon et al. (1976) \\
Black carbon & $1.85+7.1 \times 10^{-1} i$ & Bond and Bergstrom (2006) & Bond and Bergstrom (2006), \\
& & & spectrally extrapolated with Hess et al. (1998) \\
POA & $1.53+5.5 \times 10^{-3} i$ & Koepke et al. (1997) & Hess et al. (1998) \\
SOA & $1.53+5.5 \times 10^{-3} i$ & Koepke et al. (1997) & Hess et al. (1998) \\
Sea Salt & $1.49+1.0 \times 10^{-3} i$ & Shettle and Fenn (1979) & Shettle and Fenn (1979) and Nilsson (1979) \\
Mineral dust & $1.52+1.1 \times 10^{-3} i$ & Kinne et al. (2003) & Irina Sokolik (pers. comm., 2006) \\
Aerosol water & $1.33+2.0 \times 10^{-7} i$ & Downing and Williams (1975) & Downing and Williams (1975) \\
\hline
\end{tabular}

radiative transfer calculation, assuming external mixing of the modes (Stier et al., 2005).

The refractive indices of various aerosol compositions at $\lambda=550 \mathrm{~nm}$ (shortwave) are listed in Table 3 , where $\lambda$ is the wavelength. Corresponding quantities for the longwave bands are shown in Fig. 1 of Stier et al. (2007) as functions of wavenumber. The refractive indices of black carbon used in HAM2 are the updated values evaluated by Stier et al. (2007). HAM2 considers both the longwave and shortwave effects of aerosols, while HAM1 considers only the shortwave effects. Radiative effects of the nucleation mode particles are ignored due to their small sizes.

\subsection{Aerosol indirect effects}

In the earlier model ECHAM5-HAM1 aerosols did not directly affect clouds because the one-moment cloud microphysics scheme therein (Lohmann and Roeckner, 1996) assumed fixed cloud droplet number concentration. In HAM2, the aerosol activation and ice nucleation parameterizations of the two-moment scheme of Lohmann et al. (2007) provide links between the simulated aerosol population and the number concentrations of cloud droplet and ice crystal. This version thus allows for the simulation of aerosol effects on cloud microphysics (droplet number and size) and macrophysics (liquid water path). More details are given in Sect. 4.1.6.

\section{Simulation setup}

We performed simulations of the year 2000 forced by sea surface temperature/sea ice prescriptions of the same year from the Second Atmospheric Model Intercomparison Project (http://www-pcmdi.llnl.gov/projects/amip/). Emis- sions of anthropogenic aerosols and their precursors, as well as biomass burning and volcanic aerosols are prescribed according to AeroCom Phase I emission data for the year 2000 (Dentener et al., 2006). Each integration starts from a meteorological state that is routinely used in climate simulations with ECHAM5. The initial concentrations of all aerosols and prognostic precursors are zero. Three months of integration are performed prior to January 2000 in each simulation. This is considered as the spin-up phase and not included in the analysis presented later in the paper.

Since the purpose of this study is to evaluate the aerosol module HAM rather than the host model ECHAM5, we carry out nudged simulations, which relax the meteorological fields towards the ERA-40 reanalysis (Uppala et al., 2005). This allows for detailed comparison between model results and observations, and also reduces the length of simulation that is required to draw sound conclusions.

To evaluate the aerosol properties in HAM2 and their differences compared to the earlier version HAM1, integrations are performed using the corresponding default model configurations. In addition, a number of sensitivity simulations are carried out and are discussed in Sect. 4. In each simulation, one component of the parameterized sub-grid processes in HAM2 is reverted to the old HAM1 setup, or replaced by an alternative that is implemented in the new version but not yet set as default. A list of simulations carried out in this study is given in Table 4.

\section{Model updates and their effects}

In this section we describe the model updates with respect to HAM1, and discuss their impact on the simulated aerosol 
Table 4. List of simulations presented in this paper.

\begin{tabular}{lll}
\hline Simulation & Description & Section number \\
\hline HAM1 & ECHAM-HAM version 1 as described by (Stier et al., 2005) & Sects. 4.1.1-4.1.6, Sects. 5.1-5.5 \\
HAM2 & Default configuration of ECHAM-HAM version 2 (this work) & Sects. 4.1.1-4.1.6, Sects. 5.1-5.5 \\
HAM2_H2SO4 & Same as HAM2 but with the old treatment for the sulfuric acid gas equation & Sect. 4.1.1 \\
HAM2_NUL & Same as HAM2 but with the old nucleation scheme and numerics for the sulfric acid equation. & Sect. 4.1.1 \\
HAM2_OA & Same as HAM2 but with the old treatment with organic aerosol & Sect. 4.1.2 \\
HAM2_WAT & Same as HAM2 but with the old water-uptake scheme & Sect. 4.1.3 \\
HAM2_SS & Same as HAM2 but with the old sea salt emission scheme & Sect. 4.1.5 \\
HAM2_DU & Same as HAM2 but with the old dust emission scheme & Sect. 4.1.6 \\
HAM2_CLD & Same as HAM2 but with the Lohmann and Roeckner (1996) cloud microphysics without aerosol-cloud interaction & \\
HAM2_INCLD & Same as HAM2 but with the modified in-cloud wet scavenging scheme for mixed-phase cloud & \\
HAM2_BLCLD & Same as HAM2 but with the below-cloud wet scavenging scheme proposed by Croft et al. (2009) & \\
HAM2_cluster & Same as HAM2 but with cluster activation nucleation in the forested boundary layer & Sect. 4.2.2 \\
HAM2_kinetic & Same as HAM2 but with kinetic nucleation in the forested boundary layer & Sect. 4.2.3, 5.3 \\
\hline
\end{tabular}

distributions and properties. Those detailed in Sect. 4.1 have become part of the standard configuration of HAM2, while Sect. 4.2 describes alternative configurations that are of importance for scientific process studies (e.g. Makkonen et al., 2009; Kazil et al., 2010). They are included in this paper to provide the model users with a clear idea about the basis for future research.

\subsection{Standard configuration of HAM2}

\subsubsection{Sulfuric acid gas and aerosol nucleation}

The conversion of sulfuric acid $\left(\mathrm{H}_{2} \mathrm{SO}_{4}\right)$ gas to aerosol particles is one of the major mechanisms of particle formation in the atmosphere. In the HAM model sulfuric acid gas is produced by the oxidation of $\mathrm{SO}_{2}$, and removed by nucleation as well as condensation onto pre-existing aerosol particles. The strength of nucleation in the model is not only determined by the nucleation mechanism, but also strongly affected by the abundance of $\mathrm{H}_{2} \mathrm{SO}_{4}$ gas and the balance between its source and sink terms.

Nucleation of $\mathrm{H}_{2} \mathrm{SO}_{4} / \mathrm{H}_{2} \mathrm{O}$ in the earlier model version was described with the scheme of Vehkamäki et al. (2002) or that of Kulmala et al. (1998). The former was the default choice because it is based on a thermodynamically consistent version of the classical binary homogeneous nucleation theory, and is valid for a broader range of thermodynamical conditions (cf. Table 5). Kazil et al. (2010) implemented the scheme of Kazil and Lovejoy (2007) for neutral and charged nucleation of $\mathrm{H}_{2} \mathrm{SO}_{4}$ and $\mathrm{H}_{2} \mathrm{O}$. This parameterization is based on laboratory measurements using a semianalytical approach to calculate aerosol formation rates. It is now the default nucleation scheme in HAM2.

Another major change between HAM1 and HAM2 is the treatment of sulfuric acid gas. In the model, production and condensation are linear processes from the point of view of the gas-phase $\mathrm{H}_{2} \mathrm{SO}_{4}$ equation (cf. Eq. (2) in Vignati et al., 2004), while nucleation is a nonlinear process. In the default HAM1 configuration the gas-phase $\mathrm{H}_{2} \mathrm{SO}_{4}$ equation was numerically solved in three consecutive steps, each taking care of one process and using explicit time integration to update the $\mathrm{H}_{2} \mathrm{SO}_{4}$ concentration for the next step. Kokkola et al. (2009) proposed a different operator-splitting algorithm in which the production-condensation equation is solved analytically in the first step to provide an intermediate estimate of sulfuric acid gas concentration, followed by a second step accounting for nucleation. This new algorithm has the advantage of converging towards the exact solution of the production-condensation equation when nucleation is weak. Kokkola et al. (2009) showed with a box model that this time stepping outperformed the original one. In addition to the revised numerics, Kazil et al. (2010) introduced the assumption that in the cloudy portion of a grid box, all $\mathrm{H}_{2} \mathrm{SO}_{4}$ gas condenses on the largest soluble particles if there is any, and on the largest insoluble particles otherwise. There is complete removal of sulfuric acid gas in clouds, where no aerosol nucleation takes place.

To demonstrate the impact of these changes at the global scale, we present vertical cross-sections of the number concentration of ultra-fine (nucleation mode) particles together with the mass concentration of $\mathrm{H}_{2} \mathrm{SO}_{4}$ gas in Fig. 2. The right column shows results from the standard HAM2 configuration; The middle column uses the Kazil et al. (2010) (HAM2 default) nucleation parameterization but the old time stepping method and without complete in-cloud removal (referred to as experiment HAM2_H2SO4 in Table 4). The left column, corresponding to experiment HAM2_NUL, uses the HAM1 set-up which includes the Vehkamäki et al. (2002) parameterization, three-step explicit numerics, and no distinction between condensation in clouds and in the cloud-free parts. All other aspects are identical in the three simulations.

Switching from Vehkamäki et al. (2002) to the Kazil and Lovejoy (2007) parameterization leads to an upward shift of the highest concentrations of fine particles (Fig. 2a-b), due to a strong reduction of nucleation at altitudes of $400-150 \mathrm{hPa}$ and a moderate increase at $150-50 \mathrm{hPa}$ (not shown). Accordingly, there is more sulfuric acid gas remaining in the air in the upper troposphere, and less near the tropical tropopause (Fig. 2d-e).

Changing the handling of the $\mathrm{H}_{2} \mathrm{SO}_{4}$ gas equation, on the other hand, results in higher concentrations for the nucleation 
Table 5. Binary aerosol nucleation schemes available in ECHAM-HAM2 and their valid range of thermodynamical conditions. Boundary values are used in case the actual atmospheric condition is out of range.

\begin{tabular}{lllll}
\hline & Temperature & Relative Humidity & $\mathrm{H}_{2} \mathrm{SO}_{4}$ Concentration & Note \\
\hline Kulmala et al. (1998) & $233-298 \mathrm{~K}$ & $10-100 \%$ & $($ No constraint) & \\
Vehkamäki et al. (2002) & $230.15-305.15 \mathrm{~K}$ & $0.01-100 \%$ & $10^{4} \mathrm{~cm}^{-3}-10^{11} \mathrm{~cm}^{-3}$ & HAM1 default \\
Kazil et al. (2010) & $180-320 \mathrm{~K}$ & $1-101 \%$ & $10^{5} \mathrm{~cm}^{-3}-5 \times 10^{9} \mathrm{~cm}^{-3}$ & HAM2 default \\
\hline
\end{tabular}
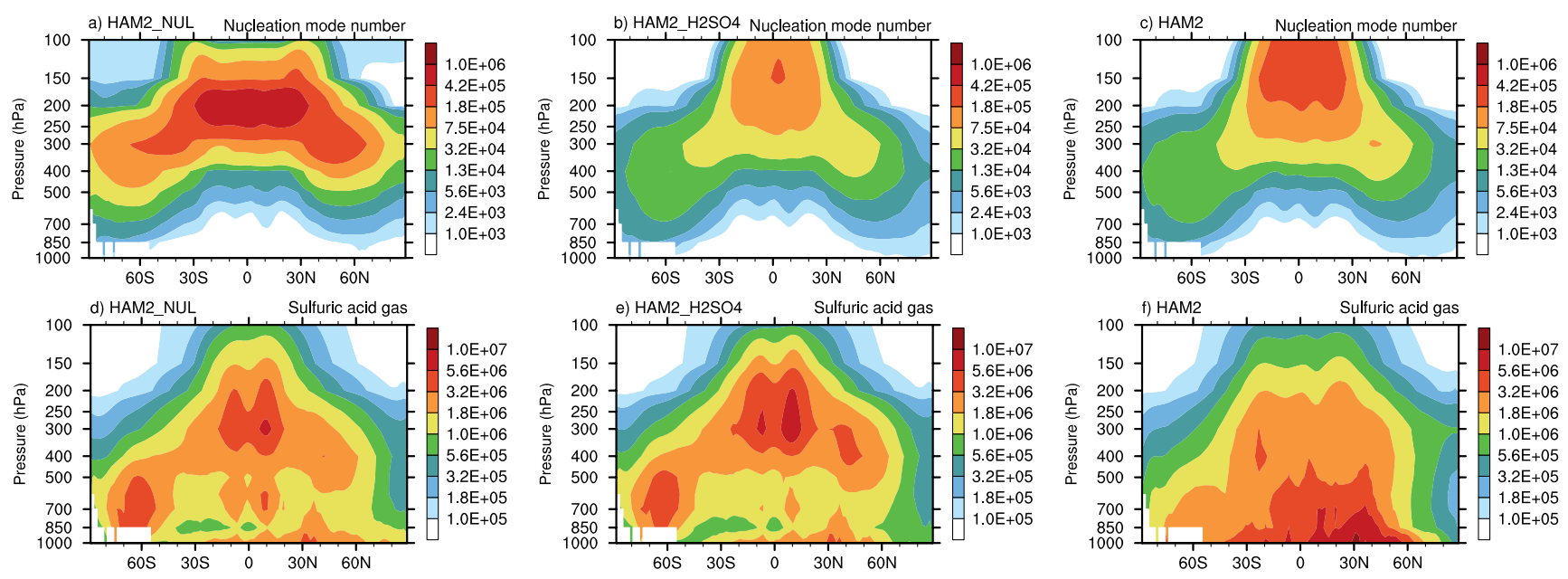

Fig. 2. Annual and zonal mean vertical cross-sections of the number concentration of nucleation mode particles (upper row, unit: particles $\mathrm{cm}^{-3}$ STP $(1013.25 \mathrm{hPa}, 273.15 \mathrm{~K})$ ) and mass concentration of $\mathrm{H}_{2} \mathrm{SO}_{4}$ gas (lower row, unit: molecules $\mathrm{cm}^{-3}$ ). The three columns correspond to different simulations, as indicated by the title of each panel: "HAM2" refers to the standard ECHAM-HAM2 configuration; "HAM2_H2SO4" uses the Kazil et al. (2010) aerosol nucleation scheme but the old handling of the $\mathrm{H}_{2} \mathrm{SO}_{4}$ equation (cf. Sect. 4.1.1); "HAM2_NUL" is similar to "HAM2_H2SO4" but uses the Vehkamäki et al. (2002) nucleation parameterization. All other aspects of model configuration are identical in the three simulations.

mode particle number (Fig. 2b-c), and a qualitative change in the vertical distribution of the sulfuric acid gas (Fig. 2e-f). An additional simulation reveals that the differences between panels e and $f$ in the tropical upper troposphere and above the Southern Hemisphere storm track are caused by the distinction between cloud-free and in-cloud condensation of the $\mathrm{H}_{2} \mathrm{SO}_{4}$ gas in HAM2 (not shown). The other differences seen in the middle and right columns in the figure are caused by the revised numerical method.

It is worth noting that in HAM1, due to the sequential operator splitting, the $\mathrm{H}_{2} \mathrm{SO}_{4}$ concentration seen by the condensation calculation is the value updated after taking into account only the chemical production. Because of the large time step used in the climate model, this intermediate concentration has a large positive bias when production is strong. The subsequently computed condensation rate is thus significantly overestimated. This explains the box model results in Fig. 1 of Kokkola et al. (2009) in which the "M7 original" scheme systematically underestimates the sulfuric acid gas concentrations in all three scenarios investigated therein. We have carried out a sensitivity experiment similar to HAM2_H2SO4, in which the first two steps (production and condensation) in the old time integration scheme are solved together using a simple Euler forward scheme. In other words, the sequential split between production and condensation is replaced by parallel split. The effect is a clear increase of the $\mathrm{H}_{2} \mathrm{SO}_{4}$ concentration in comparison to Fig. 2de. In particular, in the near-surface layers, the magnitudes and characteristic pattern become very similar to Fig. $2 \mathrm{f}$ (not shown).

In both HAM1 and HAM2, nucleation is computed after production and condensation, using sequential operator splitting. When the model time step is long and nucleation is strong, this can also lead to numerical errors in the simulated nucleation rate and $\mathrm{H}_{2} \mathrm{SO}_{4}$ gas concentration. We have performed numerical convergence test for the sulfuric acid gas equation using sub-stepping and various time integrations schemes, from which a reference solution is established. It is found that the simulated $\mathrm{H}_{2} \mathrm{SO}_{4}$ gas concentration and aerosol nucleation rate are more sensitive to the splitting technique applied between production and condensation than that for nucleation. With respect to the reference solution, the error in annual mean $\mathrm{H}_{2} \mathrm{SO}_{4}$ gas burden is reduced by a factor of more than 10 from the HAM1 numerics to HAM2. The error in total nucleation rate is reduced by a factor of about 5. Reduction of error can be seen at most of the model grid 
points though the factor is not homogeneously distributed. This indicates that from a numerical point of view, the solution procedure in HAM2 better represents the $\mathrm{H}_{2} \mathrm{SO}_{4}$ processes.

Currently there is research going on in the ECHAM-HAM community to implement and evaluate additional nucleation parameterization schemes in the planetary boundary layer. In this context, the numerical methods used for the $\mathrm{H}_{2} \mathrm{SO}_{4}$ processes will possibly be refined. Time integration schemes with adaptive step size and dynamical error control, such as those used by Herzog et al. (2004) and Zaveri et al. (2008) will be considered.

\subsubsection{Secondary organic aerosol (SOA)}

The first version of HAM had a very simple treatment of secondary organic aerosols following the AeroCom approach (Dentener et al., 2006). $15 \%$ of the prescribed natural terpene emission was oxidized in the surface layer and condensed immediately on existing aerosol particles (Stier et al., 2005; Kanakidou et al., 2005). The SOA therein was assumed to have identical properties to primary organic aerosols (POA).

O'Donnell et al. (2011) implemented an explicit SOA module in ECHAM-HAM, which considers aerosols originating from biogenic (isoprene and monoterpenes) and anthropogenic sources (xylene, toluene and benzene). The emissions of biogenic precursors are computed online using MEGAN (Guenther et al., 2006; Guenther, 2007) for isoprene, and following the work of Guenther et al. (1995) for monoterpenes. Emission of anthropogenic precursors is prescribed according to EDGAR (fast-track issue, Olivier et al., 2005b).

Oxidation processes of the precursors are explicitly described. An oxidation product is considered either as volatile or semi-volatile, depending on the precursor. Organic matter formed from anthropogenic sources is assumed as nonvolatile following $\mathrm{Ng}$ et al. (2007). Its mass is allocated to the aerosol phase immediately on formation. Products of xylene, toluene and benzene can be either lumped together or tracked separately in the model. The oxidation products of isoprene and terpene are considered to be semi-volatile. The mass is partitioned between the gas and aerosol phases based on an equilibrium scheme, namely the two-product model of Odum et al. (1996). The absorption-based theory of Pankow $(1994 a, b)$ is used to further partition the condensed mass to size-resolved modes. Different SOA products are assumed to be absorbed by POA and by each other, thus the modes in which SOA can occur are the same as those that contain POA, namely the Aitken insoluble, Aitken soluble, accumulation soluble, and coarse soluble modes (cf. Fig. 1).

The SOA module introduces 13 or 21 new tracers to the model that need to be transported, depending on whether the xylene-, toluene- and benzene-derived SOA is lumped together. This include 5 precursor gases (isoprene, monoterpenes, xylene, toluene and benzene), 4 condensable organics from the oxidation of isoprene and monoterpenes (i.e. 2 precursors $\times 2$ products each, before gas-aerosol partitioning), and 1 (lumped) or 3 (not lumped) anthropogenic SOA mass concentrations in each of the mode that contains organic matter (cf. previous paragraph and Fig. 1).

Refractive indices of SOA are assumed the same as those of POA (Table 3). Further details of the SOA scheme can be found in O'Donnell et al. (2011).

When the new SOA scheme is switched on, the interactively computed biogenic precursor emissions (441.6 $\mathrm{Tg} \mathrm{yr}^{-1}$ isoprene and $86.3 \mathrm{Tg} \mathrm{yr}^{-1}$ monoterpenes) produce about $119.1 \mathrm{Tg} \mathrm{yr}^{-1}$ semi-volatile condensable species (106.5 $\mathrm{Tg} \mathrm{yr}^{-1}$ from isoprene, $12.6 \mathrm{Tg} \mathrm{yr}^{-1}$ from monoterpenes). These oxidation products form $15.7 \mathrm{Tg}$ SOA per year, which, in terms of absolute value, is not far away from the old scheme (19.1 $\mathrm{Tg} \mathrm{yr}^{-1}$, Dentener et al., 2006). The SOA yield, however, is only $3 \%$ and much smaller than specified by AeroCom (15\%). The yield of $15 \%$ used in AeroCom is realistic at lab temperatures (typically $25^{\circ} \mathrm{C}$ ), while our model has a temperature-dependent SOA yield from monoterpenes (Saathoff et al., 2009) which predicts decreasing SOA formation with increasing temperature. Since the majority (over $75 \%$ ) of the monoterpene mass is emitted at high temperatures in the tropics, the SOA yield drops below the figure used for AeroCom. The fact that we get a SOA production similar to the AeroCom specification despite a considerably lower yield reflects the dominance of isoprene emissions, which were not included in the old scheme. The anthropogenic emissions result in $5.5 \mathrm{Tg} \mathrm{yr}^{-1}$ oxidation products, which are assumed non-volatile and convert totally to SOA.

The spatial distribution of aerosol concentrations also changes substantially. In Fig. 3 we present zonal mean mass concentration of total organic aerosols (also referred to as particulate organic matter, POM) simulated by HAM2 with different SOA schemes. The most evident effect of the new scheme is the higher loading in the upper troposphere, associated with enhanced SOA formation due to tropical convective transport of the condensable oxidation products, especially high-volatility products associated with isoprene oxidation, which condense only at very low temperatures. Results obtained with the original SOA scheme (Fig. 3a), in contrast, resembles closely the POA distribution of HAM1 (shown in Fig. 5 of O'Donnell et al., 2011) as one would expect. The differences in the lower troposphere in Fig. 3c mainly reflect the changes in precursor emissions. The increased concentrations between $20^{\circ} \mathrm{S}$ and $15^{\circ} \mathrm{N}$ are connected to the biogenic sources, while those at $15-40^{\circ} \mathrm{N}$ are primarily related to the anthropogenic sources.

Following Heald et al. (2011) we compared the vertical profiles of total POM (POA + SOA) mass concentration in HAM1 and HAM2 sampled in the month-of-year and regions of 17 field campaigns (not shown). Consistent with Fig. 3, increases in POM concentration are seen in HAM2 in the lower troposphere. Despite such increases, the model 

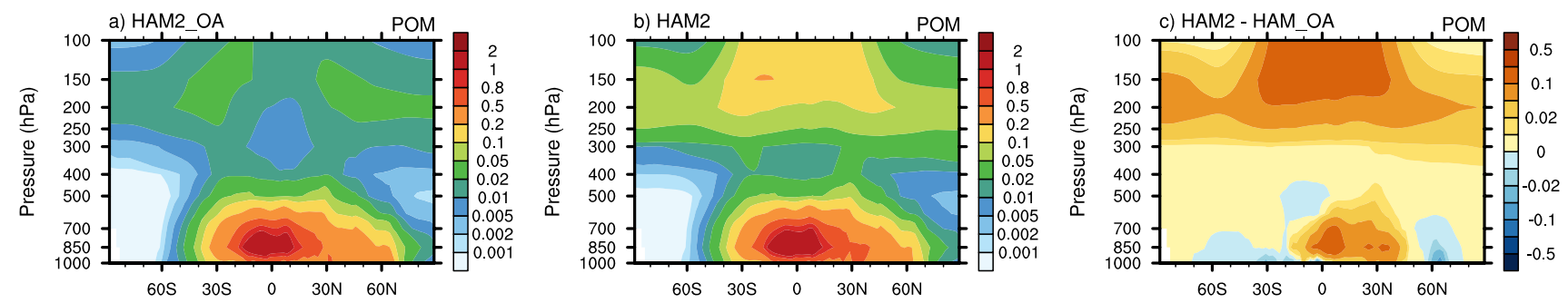

Fig. 3. Temporal and zonal mean vertical cross-sections of the mass concentration of particulate organic matter (POM) (unit: $\left.\mu \mathrm{g} \mathrm{m}^{-3}\right)$. The middle panel shows results from the standard ECHAM-HAM2 model (i.e. with the O'Donnell et al. (2011) SOA submodel switched on); The left panel corresponds to a sensitivity experiment HAM2_OA that uses the old (HAM1) simple SOA scheme described in Sect. 4.1.2 and in Stier et al. (2005); Differences between the two simulations are indicated in the rightmost panel.

Table 6. Values of the hygroscopicity parameter $\kappa$ used in ECHAMHAM2 for the $\kappa$-Köhler theory based water uptake scheme. The observed ranges of $\kappa$ listed in the rightmost column are quoted from Table 1 in Petters and Kreidenweis (2007), which were derived from the laboratory measured growth factor of particle radius. For primary organic aerosols, the observed range is obtained from mean $\kappa$ values of various organic compounds other than secondary organic aerosol.

\begin{tabular}{lll}
\hline Species & $\kappa$ & Observed Range of $\kappa$ \\
\hline Sulfate & 0.60 & $0.33-0.72$ \\
Sea salt & 1.12 & $0.91-1.33$ \\
Primary organic aerosol & 0.06 & $0.006-0.44$ \\
Secondary organic aerosol & 0.037 & $0.022-0.070$ \\
Black carbon & 0 & - \\
Mineral dust & 0 & - \\
\hline
\end{tabular}

still generally underestimates organic mass compared to the observations presented in Fig. 3 of Heald et al. (2011). Our results are similar to the GEOS-Chem model discussed in their paper, which also has an explicit treatment for the semivolatile SOA.

\subsubsection{Water uptake}

Water uptake is an important process that changes the size and optical properties of aerosol particles. In the real world non-organic aerosols that contain sulfate and/or sea salt, and some organic aerosols, are hygroscopic. In HAM1, however, water uptake was considered only for non-organic particles. For pure sulfate particles, water uptake was calculated using regression fits to solutions of the generalized Kelvin equation (Zeleznik, 1991); For mixed particles that contain sulfate but not sea salt, sulfate mass was regarded as the effective soluble mass and used in the calculation of the equilibrium particle density; For particles containing sea salt, complete ion dissociation was assumed, with the water uptake calculated according to the ZSR method (Zdanovskii, 1948; Stokes and Robinson, 1966), which regards an aerosol particle as a solution of mixed electrolytes. The scheme assumes a $95 \%$ ceil- ing of ambient relative humidity (RH) when calculating water content of the nucleation and Aitken mode particles, and a ceiling of $100 \%$ for the accumulation and coarse modes.

When introducing the new SOA scheme mentioned in the previous subsection, O'Donnell et al. (2011) implemented a semi-empirical water uptake scheme based on the $\kappa$-Köhler theory (Petters and Kreidenweis, 2007), now used for all hygroscopic aerosols in HAM2. This approach uses a prescribed hygroscopicity parameter $\kappa$ for each substance (Table 6). For an internally-mixed aerosol particle, the overall $\kappa$ value is calculated by taking the volume-weighted sum of the parameter of each soluble compound. Having computed the hygroscopicity parameter of a particle, and with its dry diameter, the air temperature and relative humidity known, the growth factor of particle radius can be determined using Eq. (11) of Petters and Kreidenweis (2007) and therefore the aerosol water content. In the model, a look-up table is used to enhance computational efficiency. The RH ceiling in this implementation is set to $95 \%$ for all aerosol modes, considering that the $\kappa$ values are typically taken from the humidified tandem differential mobility analyzer (HTDMA) below this RH value (Kreidenweis et al., 2005).

For clarification it is worth noting that results in the work of Kreidenweis et al. (2008), who applied simplifying assumptions to the theory developed by Petters and Kreidenweis (2007), have been widely interpreted as meaning that predictions using the $\kappa$-Köhler theory are inherently and severely low-biased at low $\mathrm{RH}$ at least for certain species, especially $\mathrm{NaCl}$. In our model the simplifications of Kreidenweis et al. (2008) are not used ${ }^{1}$. Our approach still underpredicts the water uptake of pure $\mathrm{NaCl}$ when compared to results from the Aerosol Inorganic Model (AIM, Wexler and Clegg (2002), the reference model used in Kreidenweis et al., 2008), but not as severely as indicated in their

\footnotetext{
${ }^{1}$ Our implementation uses the full $\kappa$-Köhler theory. Eq. (11) in Petters and Kreidenweis (2007) is solved numerically for the growth factor for each soluble mode, taking into account ambient temperature and relative humidity, the mode's number median particle radius, and the $\kappa$ value.
} 

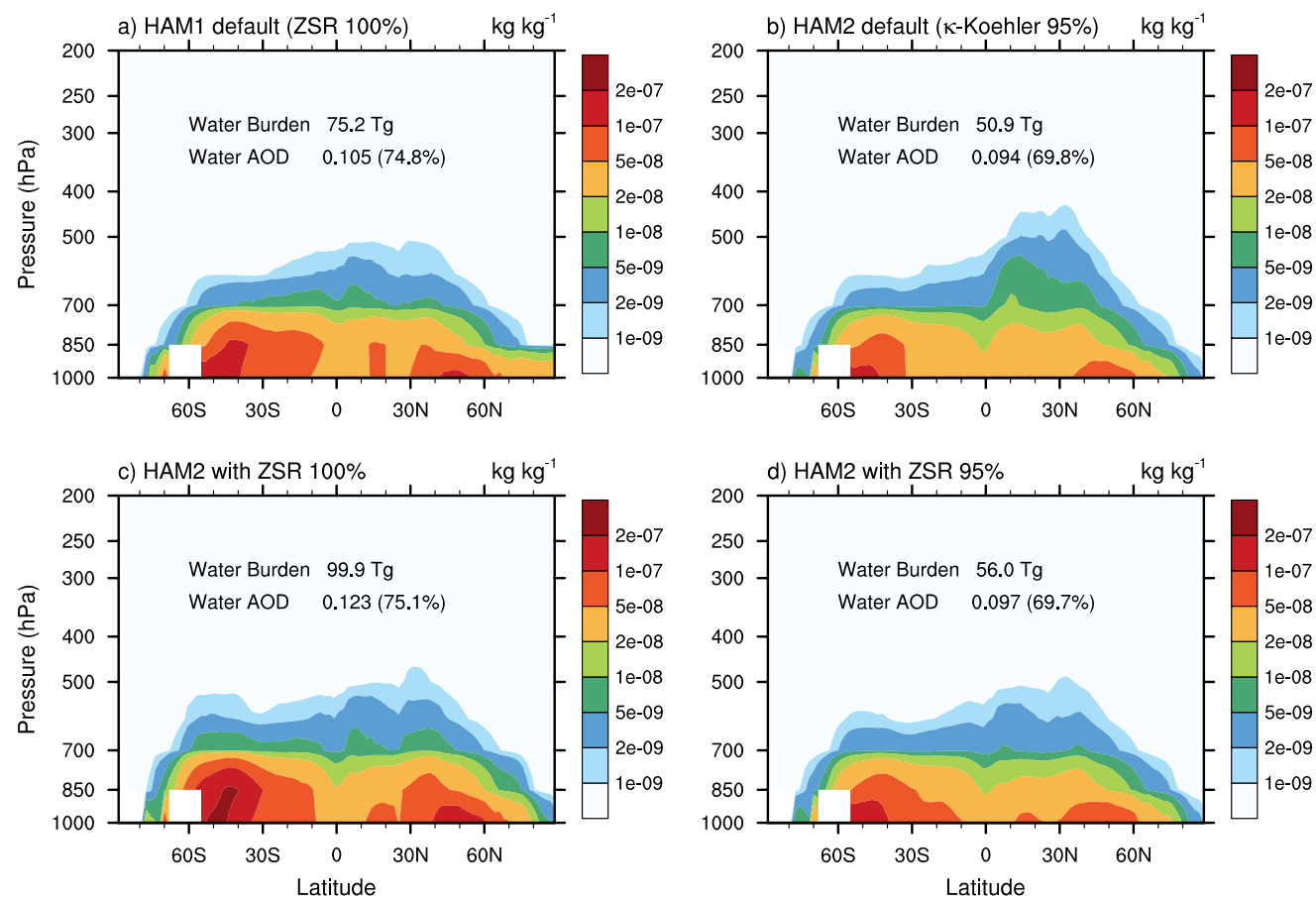

Fig. 4. Zonal and annual mean aerosol water content in (a) default HAM1, (b) default HAM2, and (c)-(d) two simulations performed with HAM2 but the old water uptake scheme. Different RH ceilings are used in (c) and (d) in the calculation of water uptake by the accumulation and coarse mode particles. Numbers noted in the figure are the annual mean global total aerosol water content as well as the absolute and relative contributions of aerosol water to the aerosol optical depth (AOD). Further details can be found in Sect. 4.1.3.

paper. Furthermore, relative humidity in the near-surface layers over the ocean (where most sea salt is found) is generally in the higher range where the $\kappa$-Köhler theory and AIM are in good agreement. For these reasons, we believe that underestimation of the water uptake of certain species by the $\kappa$-Köhler theory at low relative humidity has very limited effects on our model results.

As already mentioned, the purpose of updating the water uptake parameterization in HAM2 was to implement a single scheme that can be used also for SOA. The new scheme results in a significant decrease in water uptake in the lower troposphere and a slight increase aloft (Fig. 4a-b), reducing the total aerosol water from $75 \mathrm{Tg}$ (HAM1) to $51 \mathrm{Tg}$ (HAM2), the latter being closer to the multi-model average of the AeroCom Project (35 Tg, Textor et al., 2006). The absolute and relative contributions of aerosol water to the aerosol optical depth (AOD) decrease from 0.105 and $74.8 \%$ (HAM1) to 0.094 and $69.8 \%$ (HAM2), respectively. Our investigation reveals that this substantial decrease is largely caused by the different RH ceilings used for the accumulation and coarse mode particles (100\% in ZSR and $95 \%$ for $\kappa$-Köhler). This can be seen in Fig. 4c-d which shows two sensitivity experiments performed using HAM2 but with the water uptake scheme reverted to ZSR. Despite an increase in dry aerosol burden compared to HAM1 which is accompanied by an increase in aerosol water content (Fig. $4 \mathrm{a}, \mathrm{c}$ ), the change of
RH ceiling (Fig. 4c, d) results in a considerable reduction in aerosol water that more than compensates the dry burden effect. Replacement of the ZSR method by the $\kappa$-Köhler theory, in contrast, has only marginal effect on the results (Fig. 4d and 4a). These results are consistent with the work of Adams et al. (2001) who found the use of higher maximum RH cut-off resulted in stronger water uptake and higher estimated direct forcing in the general circulation model of the Goddard Institute for Space Studies, especially when relative humidity is higher than $95 \%$.

\subsubsection{Sea salt emission}

Sea salt emission is a primary source of soluble accumulation mode and coarse mode aerosol over the oceans in the model. The emission fluxes are parameterized as functions of 10$\mathrm{m}$ wind speed following the work of Monahan et al. (1986) and Smith and Harrison (1998). In HAM1, look-up tables of emission flux against 10-m wind were established using the Monahan formula for small particles (dry radius $r<2 \mu \mathrm{m}$ ), the Smith-Harrison formula for large particles $(r>4 \mu \mathrm{m})$, and a smoothly merged function for the size range in between (Stier et al., 2005). Zhang et al. (2010) noticed that the partitioning of sea salt emission between accumulation and coarse modes in ECHAM-HAM1 was evidently different from two 


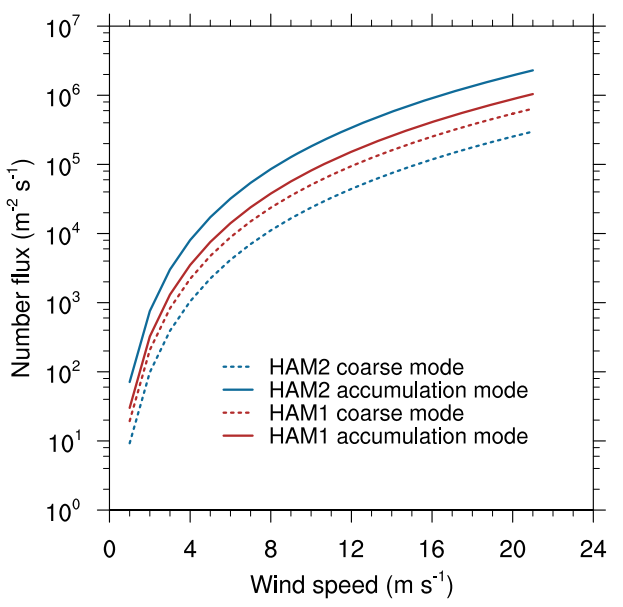

Fig. 5. Accumulation mode and coarse mode sea salt aerosol number fluxes (unit: $\mathrm{m}^{-2} \mathrm{~s}^{-1}$ ) as functions of $10-\mathrm{m}$ wind speed (unit: $\mathrm{m} \mathrm{s}^{-1}$ ), given by different implementations of the Monahan et al. (1986) and Smith and Harrison (1998) sea salt emission schemes. The red curves correspond to the the old (HAM1) version, and blue the new (HAM2) version.

other models using the same microphysics package, and attributed the differences to the emission scheme.

In HAM2 we still use the source functions of Monahan et al. (1986) and Smith and Harrison (1998), but directly apply the Monahan et al. (1986) formula for the radius range of 2-4 $\mu \mathrm{m}$ without merging, and replace the look-up tables by online integration of the source functions. As shown in Fig. 5, the new implementation produces stronger emissions in the accumulation mode and weaker in the coarse mode in terms of number flux. The ratio of the accumulation mode number flux to that of the coarse mode is now 7.7 in contrast to 1.6 in HAM1, and is closer to the value 6.7 that can be derived from the Dentener et al. (2006) emission dataset recommended for AeroCom. In terms of mass flux, there is an increase of emission in both modes (not shown), implying that the emitted coarse mode particles are larger than in HAM1. Further discussions of these changes are presented in Sect. 5.

\subsubsection{Dust emission}

Dust emissions in HAM1 were calculated interactively using the scheme of Tegen et al. (2002) which was based on observations from Africa but resulted in considerable biases in East Asia. Cheng et al. (2008) made attempts to improve dust emission by modifying the surface conditions used in the model. They employed a new global dataset of aerodynamic roughness length derived by Prigent et al. (2005) from satellite retrievals, and the East-Asian soil properties from Laurent et al. (2006). In addition, impact of soil moisture was taken into account when computing the threshold frictional wind velocity of dust mobilization. Because the satellite-
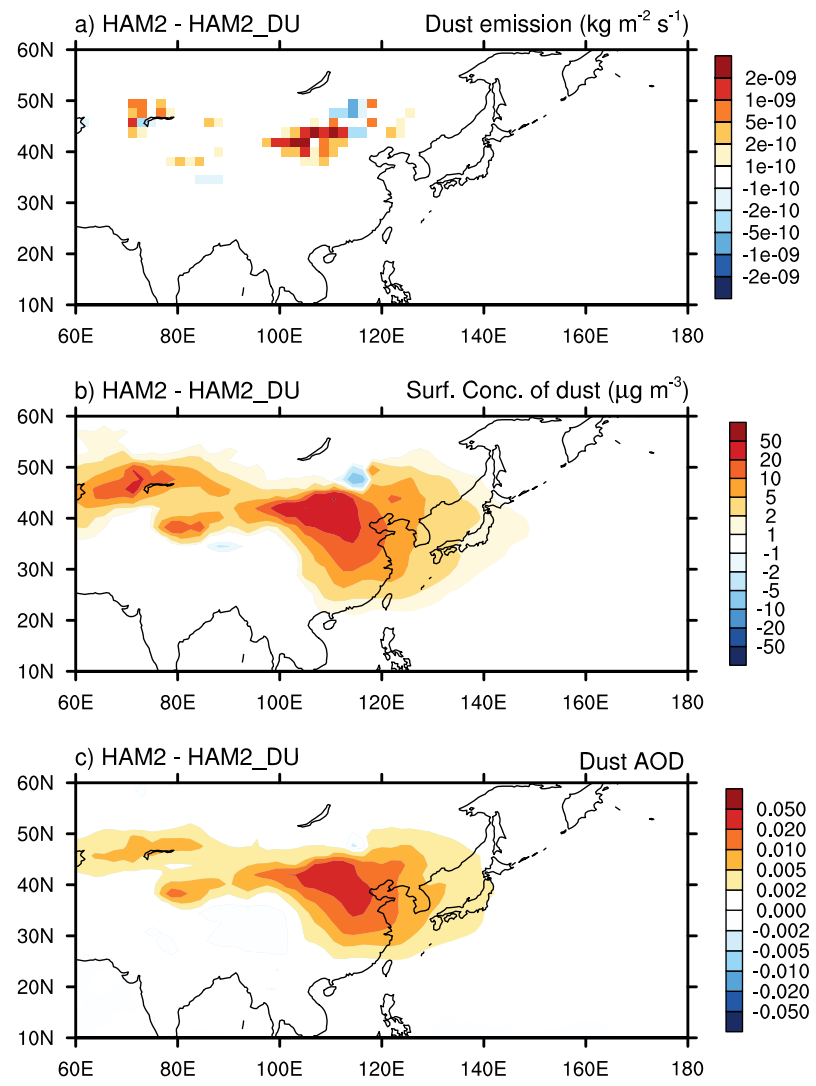

Fig. 6. (a) Changes in the annual mean dust emission mass flux due to modified soil properties in East Asia; (b) corresponding changes in the mass concentration of dust aerosols in the lowest model layer; (c) the resulting changes in aerosol optical depth (AOD).

derived roughness lengths were much larger than those used in the original model, a scaling factor had to be applied to the frictional velocity and fine-tuned in order to give a reasonable global total emission. Recent model evaluation has revealed that this modification leads to an overestimate of AOD over North Africa, while the inclusion of soil moisture in frictional velocity calculation does not lead to significant improvement (not shown). Therefore in HAM2 only the modification of East Asia soil properties is adopted from the work of Cheng et al. (2008).

To demonstrate the effect of this update, the standard HAM2 results are compared with a sensitivity simulation HAM2_DU performed using the old soil property data. The characteristic spatial pattern of dust emission is largely unchanged, but the strength increases significantly over Mongolia, in the western part of Inner Mongolia, and near the Balquash lake (Fig. 6a). The simulated near surface dust concentration (Fig. 6b) and AOD (Fig. 6c) in the vicinity of the source regions as well as in the downstream areas also increase, which leads to better agreements between model and observation (not shown). 
Table 7. Impact of cloud microphysics parameterization on aerosol lifetime (unit: day). The sensitivity experiment HAM2_CLD uses the scheme of Lohmann and Roeckner (1996), while the standard ECHAM-HAM2 model uses the two-moment scheme of Lohmann et al. (2007). Further details can be found in Sect. 4.1.6.

\begin{tabular}{lrrr}
\hline & \multicolumn{2}{c}{ Aerosol lifetime } & \\
\cline { 2 - 3 } & HAM2_CLD & HAM2 & Relative diff. \\
\hline Sulfate & 3.6 & 4.4 & $+22 \%$ \\
SOA & 5.5 & 11.4 & $+107 \%$ \\
Sea salt & 0.59 & 0.69 & $+17 \%$ \\
Black carbon & 5.2 & 5.9 & $+13 \%$ \\
POA & 5.9 & 6.4 & $+8.5 \%$ \\
Dust & 5.0 & 5.2 & $+4.0 \%$ \\
\hline
\end{tabular}

\subsubsection{Cloud microphysics and aerosol activation}

In the earlier model ECHAM-HAM1 the stratiform cloud microphysics scheme (Lohmann and Roeckner, 1996) predicted mass concentrations of water vapor, cloud water and cloud ice by taking into account phase transitions, precipitation processes (autoconversion, accretion, aggregation), evaporation of rain and melting of snow, as well as sedimentation of cloud ice. Regarding stratiform cloud formation, the cloud droplet number concentrations (CDNC) were prescribed as functions of pressure and surface type (land or ocean). The conversion of aerosol particles into cloud droplets - often referred to as aerosol activation or cloud droplet nucleation was not considered. While clouds could directly affect the aerosol population via wet scavenging (cf. Sects. 2.5, 4.2.1, and 4.2.2), aerosols could only affect clouds via the direct and semi-direct aerosol effects on model meteorology.

In order to explicitly simulate the effects of aerosols on stratiform cloud microphysics, Lohmann et al. (2007) introduced a two-moment scheme, with further improvements proposed by Lohmann and Hoose (2009). The new scheme includes prognostic equations for number concentrations of cloud droplets and ice crystals, and is used as the default stratiform cloud microphysics scheme for HAM2. Many details of the parameterized phase change and precipitation processes (e.g. autoconversion and accretion) are different from the the earlier scheme.

The impact of aerosols on cloud microphysics is implemented as follows: Aerosol activation in warm clouds is described by the semi-empirical scheme of Lin and Leaitch (1997). Autoconversion of cloud droplets to rain is parameterized as in Khairoutdinov and Kogan (2000). Homogeneous ice nucleation in cirrus clouds is assumed to happen at air temperatures below $-38^{\circ} \mathrm{C}$ when supercooled solution droplets freeze. The production rate of ice crystals is computed following Kärcher and Lohmann (2003). Heterogeneous nucleation happens in the model when dust exists and the air temperature lies between $-38^{\circ} \mathrm{C}$ and $0^{\circ} \mathrm{C}$. Internally mixed dust and black carbon aerosols are assumed to act as immersion nuclei while only externally mixed dust particles act as contact nuclei. Contact freezing by black carbon is not considered as it is quite uncertain (Lohmann and Hoose, 2009).

The replacement of cloud microphysics parameterization has complex impacts on the hydrological cycle and aerosol lifecycle in the model, a comprehensive analysis of which falls out of the scope of this paper. For the aerosols, we present in Table 7 differences in the lifetime of various compositions between the standard ECHAM-HAM2 and a sensitivity experiment HAM2_CLD that uses the old stratiform cloud microphysics scheme. Here we see a general increase in aerosol lifetime when the two-moment cloud scheme is used. Analysis shows that although there is only a marginal change $(<2 \%)$ in global mean precipitation rate, the liquid water path increases from about $50 \mathrm{~g} \mathrm{~m}^{-2}$ (HAM2_CLD) to $85 \mathrm{~g} \mathrm{~m}^{-2}$ (HAM2). It follows that the conversion efficiency of cloud water to precipitation, defined as the net precipitation production rate divided by liquid water path, decreases when the two-moment cloud scheme is used, because the precipitation formation depends inversely on the cloud droplet number concentration which in turn depends on the number of aerosols (Lohmann and Feichter, 1997). Because in-cloud scavenging is directly related to this conversion efficiency in the model (cf. Sect. 2.5), lower conversion efficiency results in weaker in-cloud scavenging, which partly explains the longer aerosol lifetimes in Table 7.

\subsection{Alternative configurations of HAM2}

In addition to the updates described in the previous subsection which have become the default in HAM2, a few modified or new parameterizations have been introduced to the model to provide a more realistic representation of certain processes, to incorporate additional processes that are of scientific importance, and/or to reduce certain biases in the model. These alternative schemes are available in the official release of the ECHAM-HAM2 code, and all produce reasonable results. They are not yet used as default because further evaluations are planned by the model developers. These alternatives are briefly described in this subsection.

\subsubsection{Aerosol wet removal from mix-phase clouds}

As already mentioned in Sect. 2.5, in-cloud scavenging of aerosols in the HAM model is calculated using a scavenging parameter (denoted by $R$ following Stier et al., 2005). A constant value is prescribed for each aerosol mode and cloud type. The values are listed in Table 3 of Stier et al. (2005). For mixed-phase clouds, the same value is used for the liquid and ice portions of the cloud condensate. In reality, the partitioning of aerosols between cloud droplets and ice crystals depends on details of the particle characteristics (e.g. chemical composition) and environmental conditions (e.g. temperature and updraft velocity). This can lead to different removal rates associated to cloud water and ice. For mixed-phase clouds, 

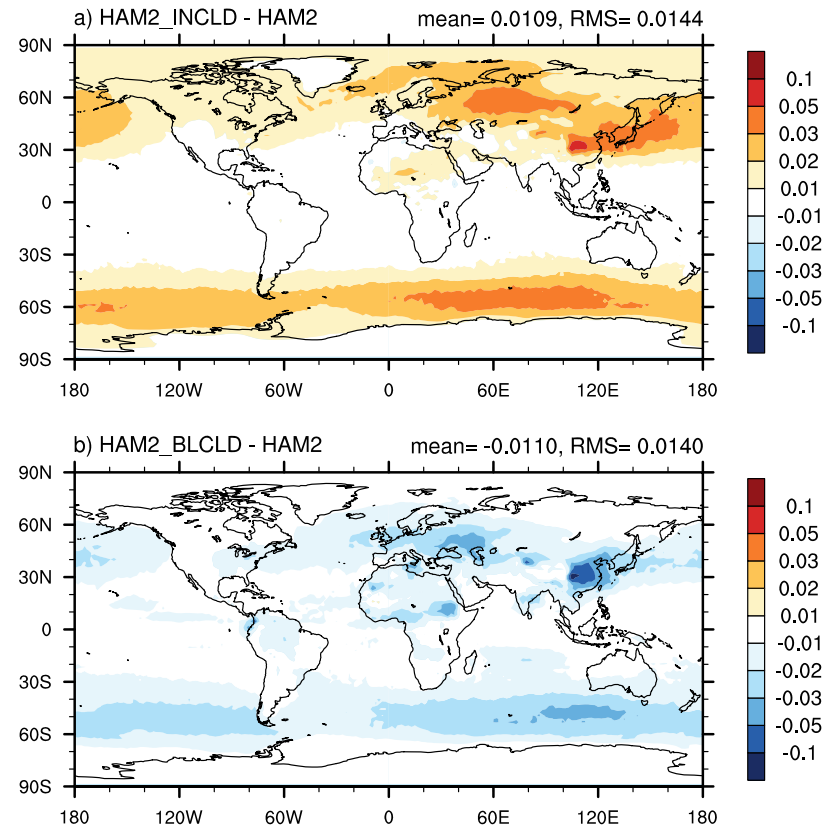

Fig. 7. Changes in annual mean AOD caused by (a) modification in the in-cloud scavenging of mixed-phase stratiform clouds; (b) modifications in the below-cloud (rain and snow) scavenging parameterization (Croft et al., 2009); the global mean and root mean square differences are noted above each panel. The standard configuration of HAM2 has a global and annual mean AOD of 0.135. The three experiments (HAM2, HAM2_INCLD and HAM2_BLCLD, cf. Table 4) are identical in all other aspects of model configuration. Further details can be found in Sects. 4.2.1 and 4.2.2.

Verheggen et al. (2007) analyzed measurements obtained at the high alpine research station Jungfraujoch (Switzerland), and derived the following relationship between air temperature $\left(T\right.$, in Kelvin) and the fraction of aerosols $\left(F_{N}\right)$ contained in the cloud droplets or ice crystals:

$F_{N}(T)=0.031+0.93\left[1+\exp \left(-\frac{T-269.51}{3.42}\right)\right]^{-1}$

Using this formula, we have added in HAM2 a new option for the scavenging parameter of mixed-phase stratiform clouds:

$R_{\text {mix }, i}(T)=\frac{F_{N}(T)}{F_{N}\left(T_{0}\right)} R_{0, i}$,

where $T_{0}=273.15 \mathrm{~K} ; R_{0, i}$ is the scavenging parameter for aerosol mode $i$ in mixed-phase clouds as prescribed by Stier et al. (2005). The scaled scavenging parameters $R_{\text {mix }, i}$ decrease with temperature, and are generally smaller than the original values. Consequently wet deposition becomes weaker and aerosol loading higher, especially in middle and high latitude regions, as can been seen from the annual mean AOD shown by Fig 7a. In terms of global mean, the AOD change is 0.0109 , meaning a $8 \%$ increase relative to the standard HAM2. The relative changes are much larger in the regions from $45^{\circ} \mathrm{N} / 45^{\circ} \mathrm{S}$ poleward (not shown) because the total aerosol loading is considerably smaller in the high latitudes than in the tropics (cf. Fig. A1b).

\subsubsection{Below-cloud scavenging}

Below-cloud scavenging by rain and snow are considered separately in HAM. Mode-dependent impaction scavenging coefficients were prescribed in HAM1 for rain. For the scavenging by snow, a fixed coefficient of $0.005 \mathrm{~m}^{2} \mathrm{~kg}^{-1}$ was used for all modes (Stier et al., 2005). This simple treatment has been updated by Croft et al. (2009) to take into account aerosol and collector size distributions in the rain case, and aerosol size in the snow case. These changes yield a reduction of AOD at most geographical locations (Fig. 7b, corresponding to a $8 \%$ decrease in global mean), especially over the storm tracks, and in mid-latitude continental areas that are associated with high aerosol concentrations.

In the first and second rows of Fig. 8, annual and regional mean aerosol mass concentration profiles are shown for the Southern Hemisphere storm track and for East Asia, where the largest changes are seen in the AOD maps. Only sea salt (sulfate) is shown in the storm track (East Asia) because it is the dominating aerosol species in the region. In terms of the magnitude of absolute change in aerosol concentration, modifications in the below-cloud removal parameterizations have the greatest impact in the lowest model layers (Fig. $8 \mathrm{~b}$ and e, dashed blue curves), while the changes due to in-cloud scavenging do not peak at surface (same figure, dashed orange curves). In the lowest layers $(0-2 \mathrm{~km})$ where the aerosol concentration is considerably higher than above, the two modifications lead to similar magnitudes of change in aerosol mass although the signs are opposite (Fig. $8 \mathrm{~b}$ and e). In relative terms, changes in aerosol mass in the HAM2_BLCLD simulation do not exceed $-30 \%$ in these regions, but those due to the revised in-cloud parameterization can be as large as $200 \%$ in the middle troposphere (Fig. 8c, f).

In the bottom row of Fig. 8 the response of $\mathrm{BC}$ mass loading is shown for the Arctic region. Although $\mathrm{BC}$ in this area has a minor contribution to the total AOD, its deposition at the surface can affect the surface albedo thus the polar climate. Earlier studies (e.g. Koch et al., 2009) have revealed a severe underestimation of Arctic BC concentration in HAM1. The weaker in-cloud scavenging and considerably higher BC loading in HAM2_INCLD could potentially be helpful. More efforts are still needed to further improve the simulated vertical profiles of black carbon mass concentrations in the Arctic.

\subsubsection{Boundary layer nucleation}

In the planetary boundary layer, the nucleation of $\mathrm{H}_{2} \mathrm{SO}_{4}$ and an organic compound can be considered using either the cluster activation scheme of Kulmala et al. (2006) and Riipinen et al. (2007), or the kinetic nucleation scheme of Laakso et al. (2004) and Kuang et al. (2008). In the currently 
SH storm track $\left(45-70^{\circ} \mathrm{S}\right)$, sea salt
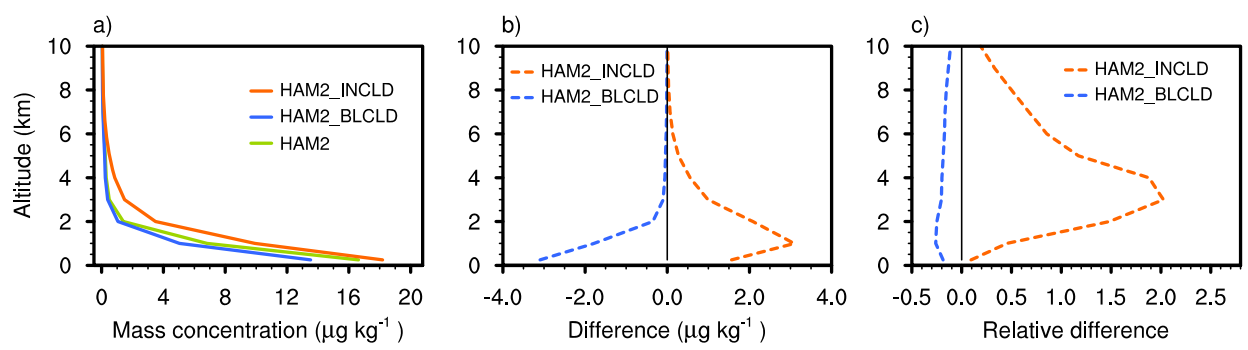

East Asia $\left(15-45^{\circ} \mathrm{N}, 100-150^{\circ} \mathrm{E}\right)$, sulfate
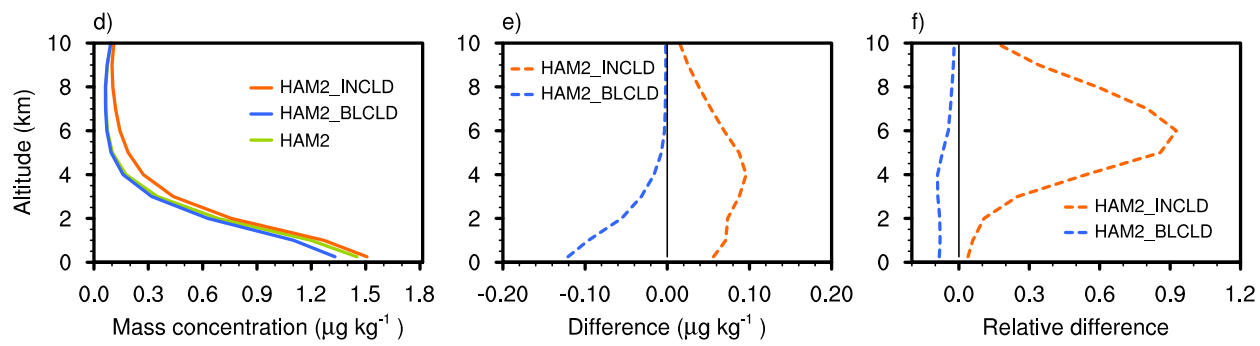

Arctic $\left(70-90^{\circ} \mathrm{N}\right)$, black carbon
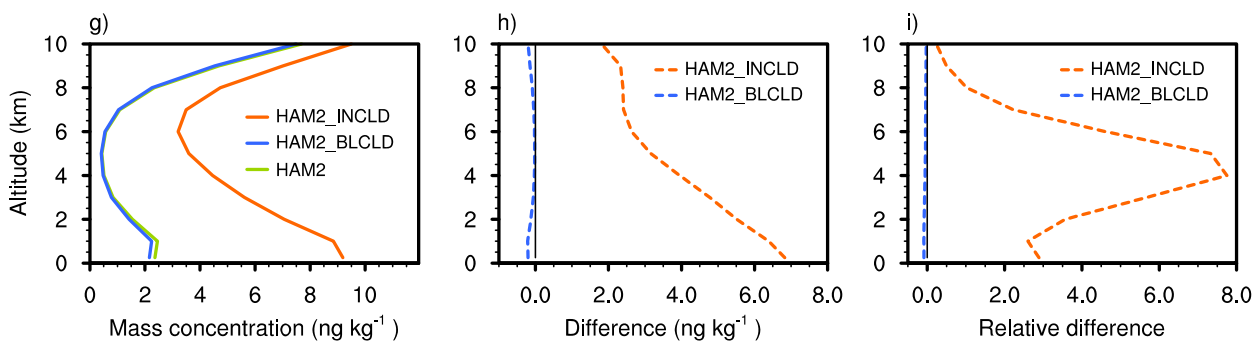

Fig. 8. Annual mean vertical profiles of aerosol mass concentrations in various regions in the sensitivity simulations HAM2_INCLD and HAM2_BLCLD (left panels), the differences (middle column) and relative differences with respect to standard HAM2 (right panels). Further details can be found in Sects. 4.2.1 and 4.2.2.

implementation these processes (when switched on) are limited to forested areas. Sensitivity experiments are performed with both schemes (HAM2_cluster and HAM2_kinetic in Table 4). The simulated aerosol concentration and size distribution are discussed in Sects. 5.2 and 5.3 in the context of comparison with observations. These nucleation pathways may be important for studies of aerosol-cloud interactions because they may affect the number concentration of cloud condensation nuclei, although the topic is not the focus of the present paper.

\section{Evaluation of HAM2 against HAM1 and observations}

Having documented in the previous section the new features in model formulation and their individual impacts on simulation results, we now move on to their combined effects. This section compares the overall behavior of HAM2 with that of the earlier version HAM1, and, when possible, against observations.

\subsection{Global mean aerosol mass budgets and concentrations}

We start the intercomparison with the annual mean global mass budget of different aerosol types shown in Table 8. Results from the AeroCom intercomparison project (Dentener et al., 2006) are also included in the table so as to place our results in perspective.

To the first order, HAM1 and HAM2 have very similar mass budgets. The relative differences are, in most cases, considerably smaller than the discrepancies among the AeroCom models. On the other hand, differences can still be clearly seen between the two HAM versions. For instance the nucleation source of sulfate aerosol increases considerably in the new version (Table 8, first block), which is in agreement 
Table 8. Annual mean global mass budget of SU, BC, POM, SS and DU simulated by two version of the HAM model, and their relative differences. To put the numbers in perspective, the multi-model mean and standard deviation of the AeroCom intercomparison project (from Textor et al., 2006) are also listed. The standard deviations are given as percentages of the corresponding mean values. The AeroCom dry deposition listed here is the sum of dry deposition and sedimentation. For sea salt there was an outlier model that featured very high emissions. We therefore cite the multi-model median (indicated by asterisks) instead of mean for the sea salt budget.

\begin{tabular}{|c|c|c|c|c|c|}
\hline & \multirow{2}{*}{ HAM1 } & \multirow{2}{*}{ HAM2 } & \multirow{2}{*}{$\begin{array}{l}\text { HAM2 vs HAM1 } \\
\text { Relative Diff. }\end{array}$} & \multicolumn{2}{|c|}{ AeroCom (Textor et al., 2006) } \\
\hline & & & & Mean & Std. Dev. \\
\hline \multicolumn{6}{|l|}{$\mathrm{SO}_{4}^{2-}$ particle } \\
\hline Burden (Tg S) & 0.78 & 0.85 & $+9 \%$ & 0.67 & $25 \%$ \\
\hline \multicolumn{6}{|l|}{ Sources $\left(\mathrm{Tg} \mathrm{S} \mathrm{yr}^{-1}\right)$} \\
\hline Total & 77.6 & 70.9 & $-8.6 \%$ & 59.7 & $22 \%$ \\
\hline Primary emissions & 2.3 & 2.3 & $0.0 \%$ & & \\
\hline Nucleation & 0.11 & 0.21 & $+91 \%$ & & \\
\hline $\mathrm{H}_{2} \mathrm{SO}_{4}$ condensation & 27.1 & 25.8 & $-4.8 \%$ & & \\
\hline Aqueous oxidation & 48.0 & 42.5 & $-11 \%$ & & \\
\hline \multicolumn{6}{|l|}{ Sinks $\left(\operatorname{Tg~S~yr}{ }^{-1}\right)$} \\
\hline Total & 77.3 & 70.5 & $-8.8 \%$ & & \\
\hline Dry deposition & 2.16 & 2.33 & $+7.9 \%$ & & \\
\hline Sedimentation & 1.62 & 1.56 & $-3.7 \%$ & 6.9 & $55 \%$ \\
\hline Wet deposition & 73.5 & 66.6 & $-9.4 \%$ & 52.8 & $22 \%$ \\
\hline Lifetime (days) & 3.7 & 4.4 & $+16 \%$ & 4.12 & $18 \%$ \\
\hline \multicolumn{6}{|l|}{ Black carbon } \\
\hline Burden $(\mathrm{Tg})$ & 0.11 & 0.13 & $+18 \%$ & 0.24 & $42 \%$ \\
\hline \multicolumn{6}{|l|}{ Sources $\left(\mathrm{Tg} \mathrm{yr}^{-1}\right)$} \\
\hline Emissions & 7.7 & 7.7 & $0.0 \%$ & 11.9 & $23 \%$ \\
\hline \multicolumn{6}{|l|}{ Sinks $\left(\mathrm{Tg} \mathrm{yr}^{-1}\right)$} \\
\hline Dry deposition & 0.59 & 0.64 & $+8.5 \%$ & & \\
\hline Sedimentation & 0.02 & 0.02 & $0.0 \%$ & 32.55 & $55 \%$ \\
\hline Wet deposition & 7.19 & 7.14 & $-7.0 \%$ & 9.35 & $31 \%$ \\
\hline Lifetime (days) & 5.3 & 5.9 & $+11 \%$ & 7.12 & $33 \%$ \\
\hline Aging time (days) & 0.72 & 0.86 & $+19 \%$ & & \\
\hline POM & $\mathrm{POA}+\mathrm{SOA}$ & POA, SOA & & & \\
\hline Burden (Tg) & 0.99 & $0.83,0.65$ & $+49 \%(\mathrm{POA}+\mathrm{SOA})$ & 1.70 & $27 \%$ \\
\hline \multicolumn{6}{|l|}{ Sources $\left(\mathrm{Tg} \mathrm{yr}^{-1}\right)$} \\
\hline Total & 66.1 & 68.4 & $+3.5 \%(\mathrm{POA}+\mathrm{SOA})$ & 96.6 & $26 \%$ \\
\hline POA emissions & 47.0 & $47.1,-$ & $+0.2 \%(\mathrm{POA})$ & & \\
\hline SOA from monoterpenes & 19.1 &,- 3.7 & & & \\
\hline SOA from isoprene & - &,- 12.0 & & & \\
\hline Anthropogenic SOA emissions & - &,- 5.6 & & & \\
\hline \multicolumn{6}{|l|}{ Sinks $\left(\operatorname{Tg~yr}^{-1}\right)$} \\
\hline Dry deposition & 4.9 & $3.3,1.2$ & $-8.2 \%(\mathrm{POA}+\mathrm{SOA})$ & 192 & $40 \%$ \\
\hline Sedimentation & 0.19 & $0.13,0.06$ & $0.0 \%(\mathrm{POA}+\mathrm{SOA})$ & \} 19.2 & $49 \%$ \\
\hline Wet deposition & 61.4 & $43.9,19.4$ & $+3.1 \%(\mathrm{POA}+\mathrm{SOA})$ & 76.7 & $32 \%$ \\
\hline Lifetime (days) & 5.5 & $6.4,11.4$ & $+16 \%(\mathrm{POA}),+107 \%(\mathrm{SOA})$ & 6.54 & $27 \%$ \\
\hline Aging time (days) & 0.96 & $1.00,-$ & $+4.2 \%(\mathrm{POA})$ & & \\
\hline \multicolumn{6}{|l|}{ Sea salt } \\
\hline Burden (Tg) & 10.3 & 11.6 & $+13 \%$ & $6.37^{*}$ & $54 \%$ \\
\hline \multicolumn{6}{|l|}{ Sources $\left(\operatorname{Tg~yr}^{-1}\right)$} \\
\hline Emissions & 5019 & 6110 & $+22 \%$ & $6280^{*}$ & $199 \%$ \\
\hline \multicolumn{6}{|l|}{ Sinks $\left(\operatorname{Tg~yr}^{-1}\right)$} \\
\hline Dry deposition & 948 & 1484 & $+57 \%$ & (3277* & \\
\hline Sedimentation & 1376 & 2038 & $+48 \%$ & \} $4377^{*}$ & $219 \%$ \\
\hline Wet deposition & 2721 & 2591 & $-4.8 \%$ & $1902^{*}$ & $77 \%$ \\
\hline Lifetime (days) & 0.75 & 0.69 & $-8.0 \%$ & $0.41^{*}$ & $58 \%$ \\
\hline \multicolumn{6}{|l|}{ Dust } \\
\hline Burden (Tg) & 10.3 & 11.6 & $+13 \%$ & 19.20 & $40 \%$ \\
\hline \multicolumn{6}{|l|}{ Sources $\left(\mathrm{Tg} \mathrm{yr}^{-1}\right)$} \\
\hline Emissions & 751 & 805 & $+7.2 \%$ & 1840 & $49 \%$ \\
\hline Sinks $\left(\mathrm{Tg} \mathrm{yr}^{-1}\right)$ & & & & & \\
\hline Dry deposition & 44.8 & 56.1 & $+25 \%$ & & \\
\hline Sedimentation & 289 & 341 & $+18 \%$ & \} 1235 & $84 \%$ \\
\hline Wet deposition & 423 & 410 & $-3.1 \%$ & 607 & $54 \%$ \\
\hline Lifetime (days) & 5.0 & 5.2 & $+4 \%$ & 4.1 & $43 \%$ \\
\hline Aging time (days) & 4.8 & 5.4 & $+12 \%$ & & \\
\hline
\end{tabular}



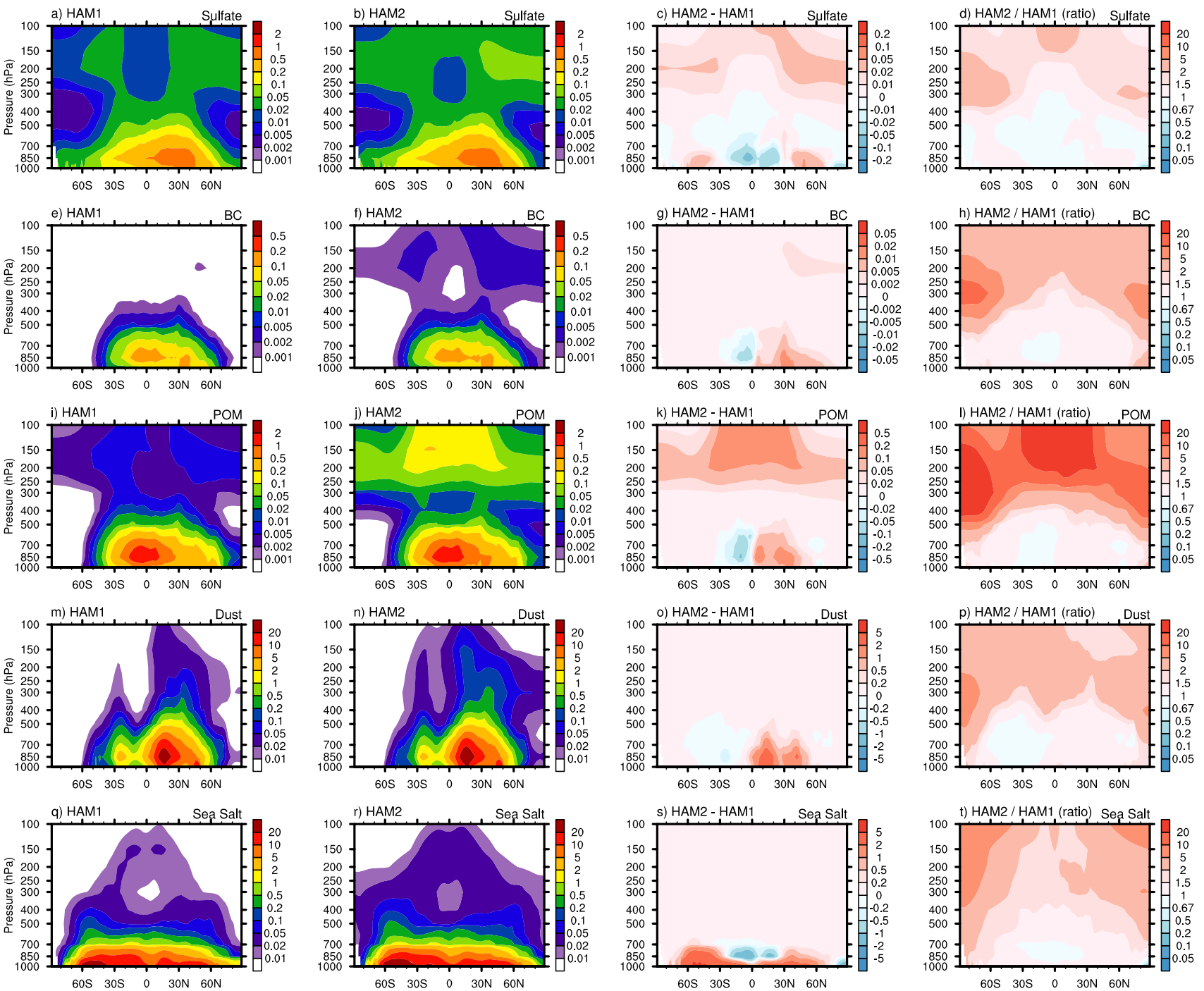

Fig. 9. Annual and zonal mean cross-sections of aerosol mass concentrations simulated by HAM1 (left column, unit: $\mu \mathrm{g} \mathrm{m}^{-3}$ ) and $\mathrm{HAM}_{2}$ (column 2, unit: $\mu \mathrm{g} \mathrm{m}^{-3}$ ), their differences (column 3, unit: $\mu \mathrm{g} \mathrm{m}^{-3}$ ), and the ratio (right column).

with earlier discussions in Sect. 4.1.1. HAM2 also shows a marked increase $(+49 \%)$ in POM burden, which is not surprising considering the inclusion of the explicit SOA module.

Another point worth noting is the shorter lifetime of sea salt in HAM2 (Table 8, fourth block). In Sect. 4.1.4 we mentioned that the modified emission scheme produces stronger number fluxes in the accumulation mode and weaker in the coarse mode, as well as an increase of mass flux in both modes compared to HAM1. Consequently, the coarse mode particles become much larger than in HAM1, and are more efficiently removed from the atmosphere through dry deposition and sedimentation. Because coarse mode particles constitute more than $95 \%$ of the total sea salt mass, they play a determining role in the changes in sea salt sinks we see in Table 8.
The four aerosol species other than sea salt have longer lifetimes in HAM2 compared to HAM1 (Table 8). This is mainly related to cloud microphysics and wet deposition as discussed in Sect. 4.1.6 and Table 7.

In Fig. 9 we present the annual and zonal mean mass concentration of the five aerosol types. Consistent with Table 8 , an overall increase in aerosol burden can be seen in HAM2. In terms of the absolute amount, changes in dust and sea salt concentrations are largely confined to the near surface levels and in the source regions (Fig. 9o and s), while sulfate and POM feature increased concentrations also near the tropopause. This is particularly true for POM which, as pointed out in the previous section, results from the vertical transport of condensable gases by convection and SOA formation in the upper troposphere. In relative 
terms, the increase of concentration is more evident in the free troposphere. The near-surface layers feature marginal changes within a factor of 1.5 except in the Polar Regions (Fig. 9, rightmost row). A comparison of the simulated monthly mean surface mass concentrations against the EMEP (European Monitoring and Evaluation Programme), IMPROVE (Interagency Monitoring of Protected Visual Environments) and the University of Miami networks further confirms that the surface concentrations are similar to those in HAM1 (not shown).

\subsection{Condensation nuclei}

This subsection evaluates the simulated number concentrations of condensation nuclei (CN, i.e. aerosol particles of dry diameter larger than $0.01 \mu \mathrm{m}$ ), using a collection of aircraft measurements between the years 1991 and 2008, provided by NASA LaRC ${ }^{2}$, NCAR EOL $^{3}$ and BADC ${ }^{4}$. The geographical coverage is mainly the Pacific Ocean, with a few additional flights over the North Atlantic and the Indian Ocean, and near the North Pole. The flight trajectories are illustrated in Fig. 10. Further details of the measurement campaigns are given in the Appendix (Table A1). For the model evaluation, we present in Fig. 11 zonal cross-sections of CN concentration in different latitude bands, and in Fig. 12 the vertical profiles averaged over the six regions denoted by hatched boxes on the trajectory map. In order to prepare these plots, each measured concentration is assigned to a model grid point according to its location. Arithmetic averages are then computed for all samples available in a $30^{\circ}$ (latitude) by $1.875^{\circ}$ (longitude) box, or in the hatched regions in Fig. 10. As for model simulations, we first vertically interpolate the daily output to height levels, pick out the $\mathrm{CN}$ concentration occurring at the same location and in the same month as a measurement, then compute the arithmetic average for the longitudelatitude bands and boxes. The $\mathrm{CN}$ concentration in the model is calculated by integrating the simulated number size distribution above the lower cut-off dry diameter $(0.01 \mu \mathrm{m})$.

Figure 11 reveals that both model versions can correctly capture the basic features of $\mathrm{CN}$ distribution at different locations. In the low-latitude areas (Fig. 11a-f, regions A, B, and $\mathrm{C}$ in Fig. 12) the concentrations are highest in the upper troposphere $\left(>4000 \mathrm{~cm}^{-3} \mathrm{STP}^{5}\right)$ due to strong nucleation. The concentrations decrease quickly towards the surface by about an order of magnitude. In the Northern Hemisphere midlatitudes (Fig. 11g-i), the maxima at $120-170^{\circ} \mathrm{E}$ (region D) and $120-60^{\circ} \mathrm{W}$ (region E) are caused by strong $\mathrm{SO}_{2}$ sources in

\footnotetext{
${ }^{2}$ Langley Research Center of the National Aeronautics and Space Administration (http://www-air.larc.nasa.gov/data.htm)

${ }^{3}$ National Center for Atmospheric Research Earth Observing Laboratory (http://data.eol.ucar.edu/)

${ }^{4}$ British Atmospheric Data Centre (http://badc.nerc.ac.uk)

${ }^{5} \mathrm{STP}$ stands for standard temperature and pressure, i.e. (1013.25 hPa, 273.15 K).
}

Asia and the USA. The air over Canada, Greenland and the Northern Polar Region is much cleaner (Figs. 10 and $11 \mathrm{j}-1$ ).

Comparing the two HAM versions, we see that the new model produces better results in the northern high-latitude clean regions (last row of Fig. 11, region F in Fig. 12). The east-west gradient in the upper troposphere over the Northwest Pacific (region D in Fig. 11h) is better represented. The high concentrations in the upper tropical troposphere are slightly closer to the observation in HAM2 (first row in Fig. 11, region A), although positive biases are still evident in the middle and lower troposphere over the tropical oceans (Fig. 12, regions A and B).

Note that the observations suggest very high $\mathrm{CN}$ concentrations $\left(>4000 \mathrm{~cm}^{-3} \mathrm{STP}\right)$ in the surface layers near the $\mathrm{SO}_{2}$ source regions (Fig. 11i and regions C, D, E in Fig. 12). This feature is missing in the standard HAM1 and HAM2 simulations, but can be better represented in HAM2 using the kinetic nucleation scheme of Kuang et al. (2008), as can be seen from the solid green profiles in Fig. 12. Inclusion of the cluster activation scheme (Kulmala et al., 2006; Riipinen et al., 2007; Kazil et al., 2010) can also improve the results (dashed green lines), but not as satisfactorily.

\subsection{Aerosol size distribution in the boundary layer}

In observational studies it is a common practice to fit the measured aerosol number concentrations into log-normal probability density functions and summarize their characteristics by a few parameters. Such records are relatively straightforward to use in our model evaluation since HAM uses the same modal method to describe aerosol size distribution.

Figures 13-15 present aerosol number concentrations and size distributions at six European surface sites in different seasons. The measurements are from Putaud (2003) and Tunved et al. (2003), which contain data at Harwell, Hohenpeissenberg, Aspvretren and Ispra from 1997 to 2001, and at Pallas and Hyytiälä in 2000 and 2001. In addition to the standard HAM1 and HAM2 simulations, the two sensitivity experiments discussed in the previous subsection (cf. Fig. 12) are also shown.

The model is able to reproduce the correct magnitude of aerosol number concentration at these locations except for Ispra. At Ispra the geographic conditions that favor the stagnation of pollutants (from, e.g. Milan) can not be resolved by the relatively coarse model grid, resulting in a considerable underestimate of the number concentration in both winter and summer. At most of the other sites, results given by the standard HAM2 agree with the observation within a factor of two.

The three-mode size distribution functions derived by Putaud (2003) and Tunved et al. (2003) are compared with HAM simulations in Figs. 14 and 15. In terms of the characteristic shapes, differences between HAM1 and HAM2 are smaller than those between simulations and observations. 


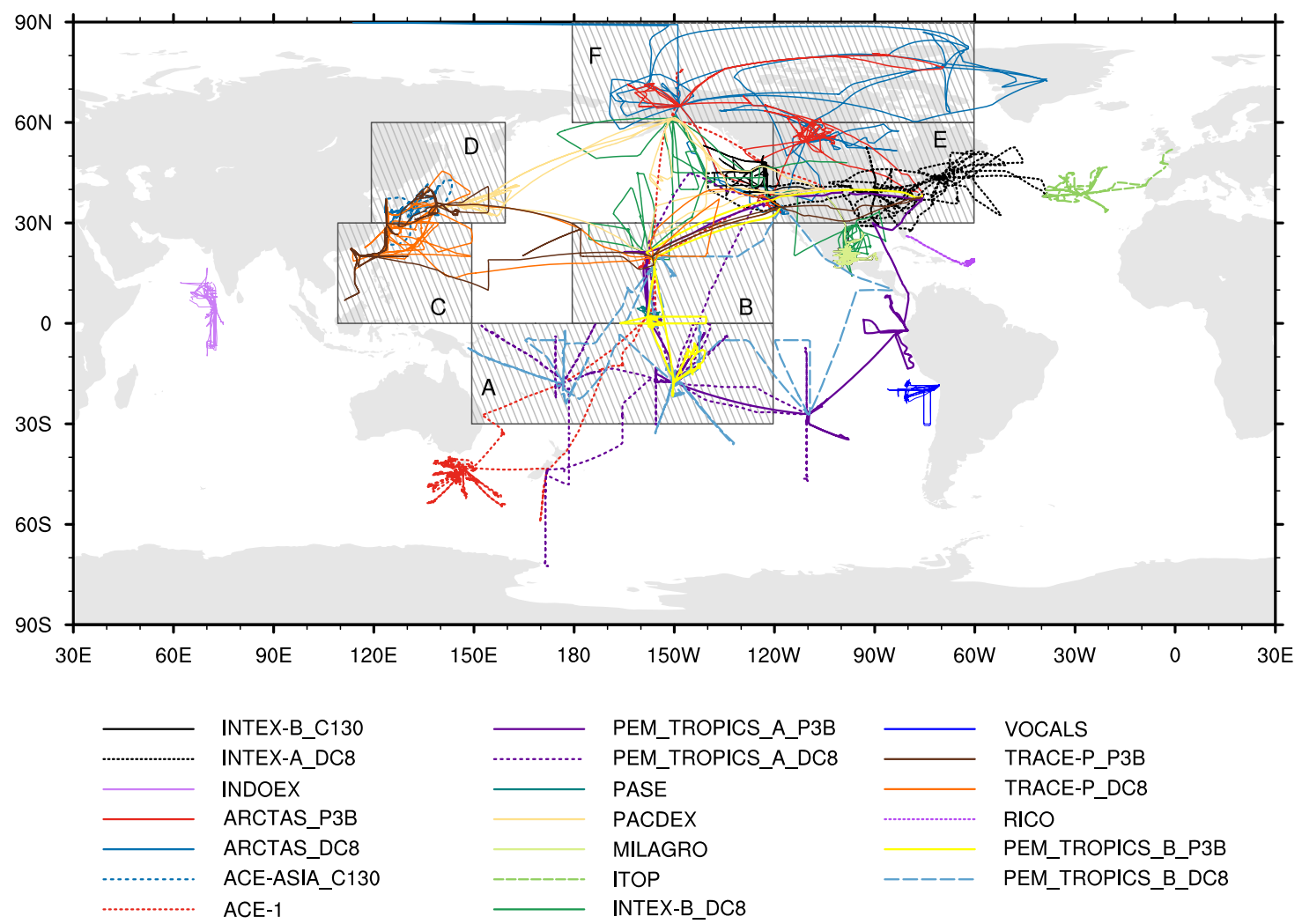

Fig. 10. Aircraft trajectories of the condensation nuclei measurements used for model evaluation in Sect. 5.2 and Figs. 11-12. Hatched boxes indicate regions in which the vertical profiles are compared in Fig. 12. Further details of the campaigns can be found in the Appendix (Table A1).

In winter, all HAM2 simulations are very similar. Compared to HAM1 there is a slight shift of the distribution functions towards larger sizes, possibly related to enhanced particle growth due to changes in the surface condensation of $\mathrm{H}_{2} \mathrm{SO}_{4}$ gas (cf. Fig. 2, bottom row). In summer, stronger solar radiation enhances the oxidation of $\mathrm{SO}_{2}$, resulting in high concentrations of sulfuric acid gas in the near surface layers. Under such conditions, the model results become sensitive to the nucleation scheme. Consistent with the earlier discussion on $\mathrm{CN}$ concentration, Fig. 15 reveals a clear increase in the number concentration of small particles when kinetic nucleation is included (solid green lines in the figure), and a moderate increase when the cluster activation scheme is used (dotted green lines). Such increases lead to positive biases at the sites shown in this figure, which (except for Ispra) are background stations representing relatively clean situations. In contrast, in the previous subsection we noted that in the polluted regions in the Northern Hemisphere, even with boundary nucleation switched on, the model still severely underestimate the particle number concentration in the nearsurface layers (Fig. 12, regions D and E). This seems to suggest the regional gradient in aerosol concentrations is underestimated, which is likely related to the fact that with the rel- atively coarse (although typical for climate simulations) resolution used here, the model can not resolve the horizontal scales of aerosol plumes. Other possible explanations include inaccuracies in the emission of aerosols and their precursors, and/or the model representation of aerosol microphysics processes or meteorological conditions. So far we have not yet been able to collect sufficiently detailed, consistent and accurate observational data to help pinpoint the cause of these biases. Further studies are needed to address this issue.

For the marine boundary layer there exists a 30-yr climatology compiled by Heintzenberg et al. (2000) with relatively large geographical coverage. Using measurements obtained in a number of $15^{\circ} \times 15^{\circ}$ (latitude $\times$ logitude) regions, they derived number concentration, geometric mean diameter and standard deviation of the Aitken and accumulation modes for 10 latitude bands. These parameters are provided in Table 3 of their paper. In Fig. 16 we compare this data set (black curves) with the standard HAM1 and HAM2 simulations (red and blue curves). In contrast to continental areas, the remote oceans are characterized by well-defined and clearly separated Aitken and accumulation modes. This feature is correctly captured in both model versions. In HAM1 the number concentration of the Aitken mode is considerably higher than 
a) HAM1, $0-30^{\circ} \mathrm{S}$
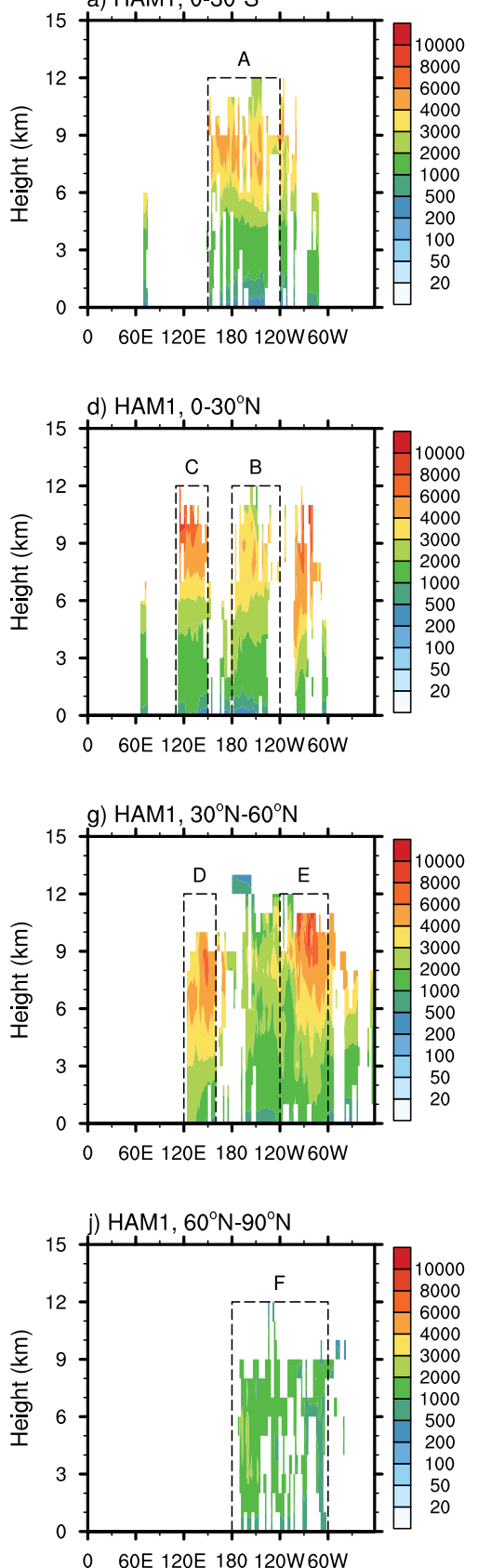

b) $\mathrm{HAM} 2,0-30^{\circ} \mathrm{S}$
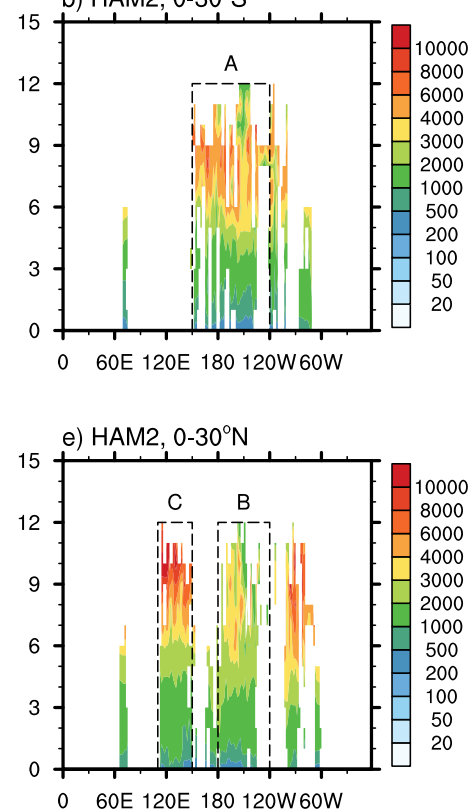

h) $\mathrm{HAM} 2,30^{\circ} \mathrm{N}-60^{\circ} \mathrm{N}$
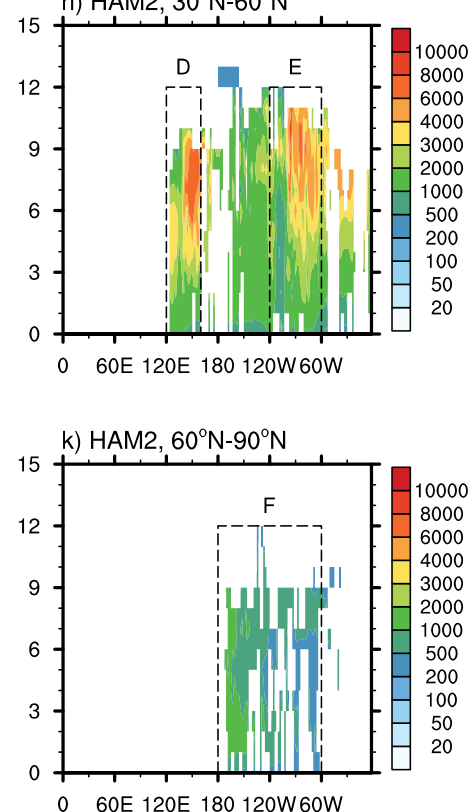

c) OBS, $0-30^{\circ} \mathrm{S}$
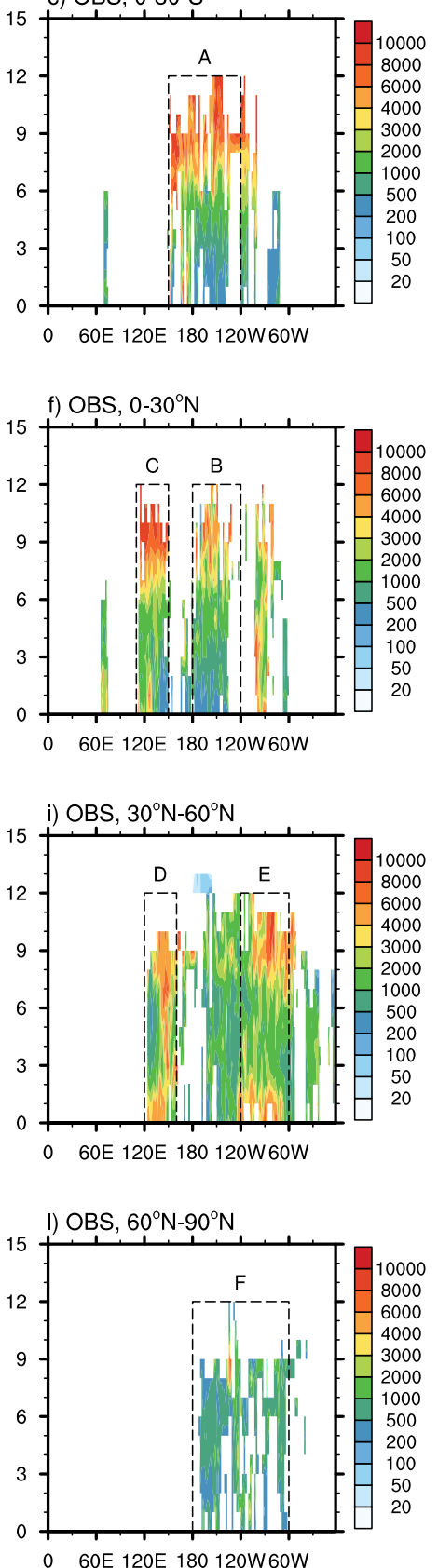

Fig. 11. Vertical distribution of simulated and observed condensation nuclei concentrations (unit: $\mathrm{cm}^{-3} \mathrm{STP}$ ) in different regions. The observational data are compiled from campaign measurements shown in Fig. 10 and Table A1. Model results are derived from daily mean output of the months in which the measurements were obtained. The simulated $\mathrm{CN}$ concentrations are derived by integrating over the aerosol size distributions. The lower cut-off value of particle dry diameter is $0.01 \mu \mathrm{m}$. Dashed boxes indicate regions in which the vertical profiles are compared in Fig. 12.

accumulation mode in all latitude bands. The contrast is less pronounced in HAM2 because the modified sea salt emission scheme increases the emission flux of the accumulation mode (cf. Sect. 4.1.4), bringing the HAM2 results closer to observation, especially in the middle and low latitudes. The simulated distribution functions are generally broader than the Heintzenberg et al. (2000) dataset, due to the fact that the prescribed standard deviation (1.59 for both modes) is often larger than the observed values (typically 1.4-1.5). 

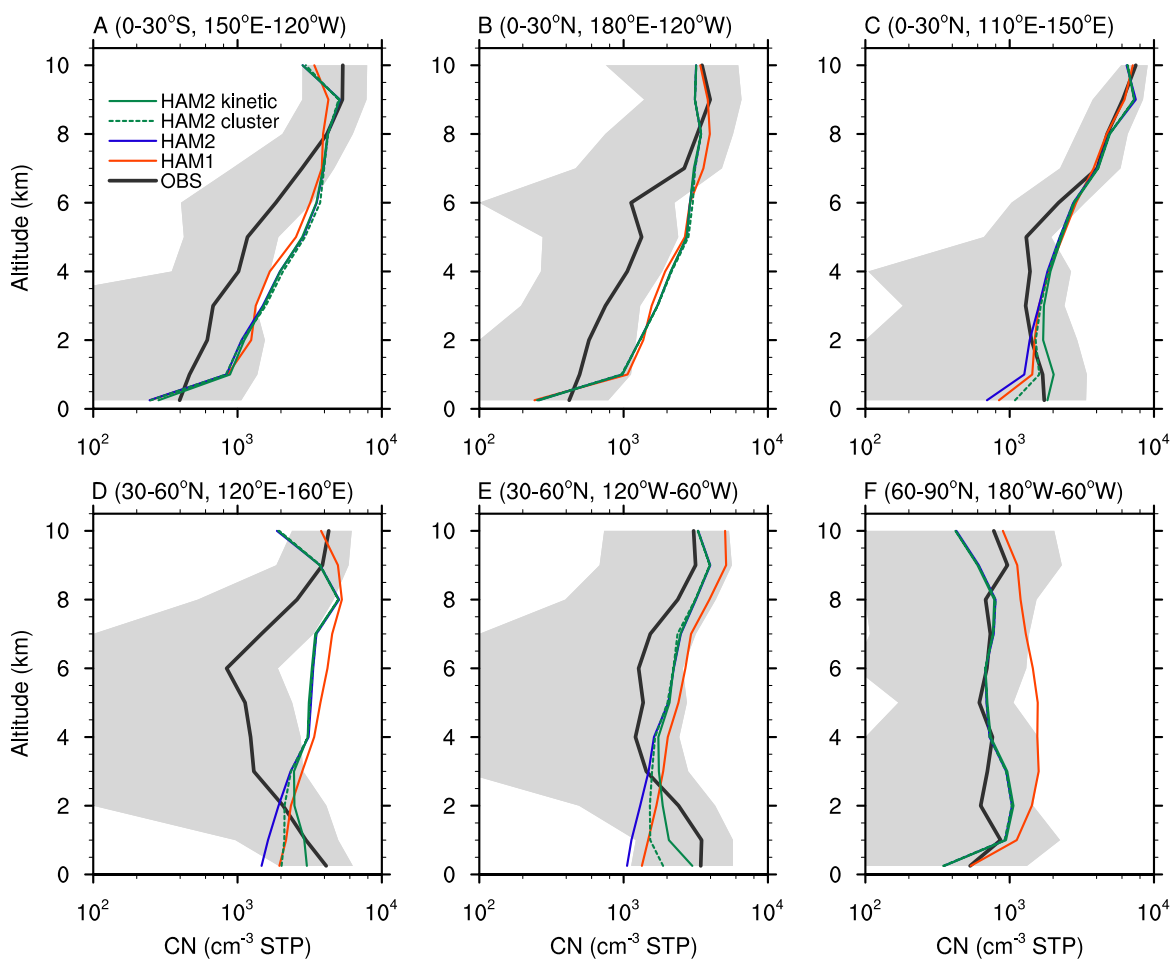

Fig. 12. Observed (black) and simulated (colored) $\mathrm{CN}$ concentration profiles (unit: $\mathrm{cm}^{-3} \mathrm{STP}$ ) over the regions indicated in Figs. $10-11$. Gray shading shows standard deviation of the measurements. Further details are given in Sect. 5.2.

\subsection{Radiative properties of aerosols}

The ultimate goal of simulating aerosols in a climate model is to understand their impact on climate. In this subsection we look at aerosol radiative properties that determine the direct and semi-direct aerosol effects in the model. In Fig. 17 the simulated global and zonal mean AOD and Ångström parameter are compared with the MODIS satellite retrievals, while the aerosol absorption optical depth (AAOD) is compared with a climatology compiled by Kinne et al. (2012). The Taylor diagrams in Fig. 18 present a concise evaluation of the simulated geographical distribution of these three parameters. The corresponding contour plots can be found in the Appendix (Figs. A1 and A2). Here the AOD and AAOD are presented at the mid-visible wavelength $0.55 \mu \mathrm{m}$. The simulated Ångström parameter is calculated using the two wavelengths $0.55 \mu \mathrm{m}$ and $0.825 \mu \mathrm{m}$.

The observed meridional variation of AOD in Fig. 17a features a primary peak around $20^{\circ} \mathrm{N}$ mainly related to dust, and a secondary peak over the Southern Hemisphere storm tracks associated with sea salt. This is reproduced by both HAM1 and HAM2, although with significant positive biases over the Southern Oceans. From HAM1 to HAM2, the decrease of AOD over the tropical oceans (cf. global distributions displayed in Fig. A1c-d) can be attributed to the new water uptake scheme. The correlation between simulated and observed global distributions is improved over both land and ocean (Fig. 18a). For the Ångström parameter there is a systematic increase in the new version in most latitudes (Fig. 17b, with global maps shown in Fig. A1g-h), resulting from the shift of size distribution of the sea salt emission and reduced aerosol water uptake. The Taylor diagram in Fig. 18b suggests the particle size distributions over land need to be improved.

In Fig. 19 the global mean AOD in HAM1 and HAM2 are further decomposed into contributions from aerosol water and dry mass. The contributions of different chemical species are presented in the Appendix (Table A2). Note that because our model assumes internal mixing between different chemical species within a log-normal mode, the component AOD is diagnosed by calculating the volume-weighted attribution of AOD per mode followed by summation over all modes. Unlike in models that assume pure external mixing, the component AOD in HAM is a proxy diagnosed for illustrative purposes.

In both model versions, water makes up more than two thirds of the total AOD. From HAM1 to the standard version of HAM2 there is a moderate increase in the dry AOD which is overcompensated by the decrease in aerosol water. For HAM2 the whiskers in the figure indicate the spread among sensitivity experiments discussed in Sect. 4, giving a sense of uncertainties in this quantity. The lowest values (of total, water and dry AOD) are all associated with the Lohmann and Roeckner (1996) cloud microphysics parameterization 

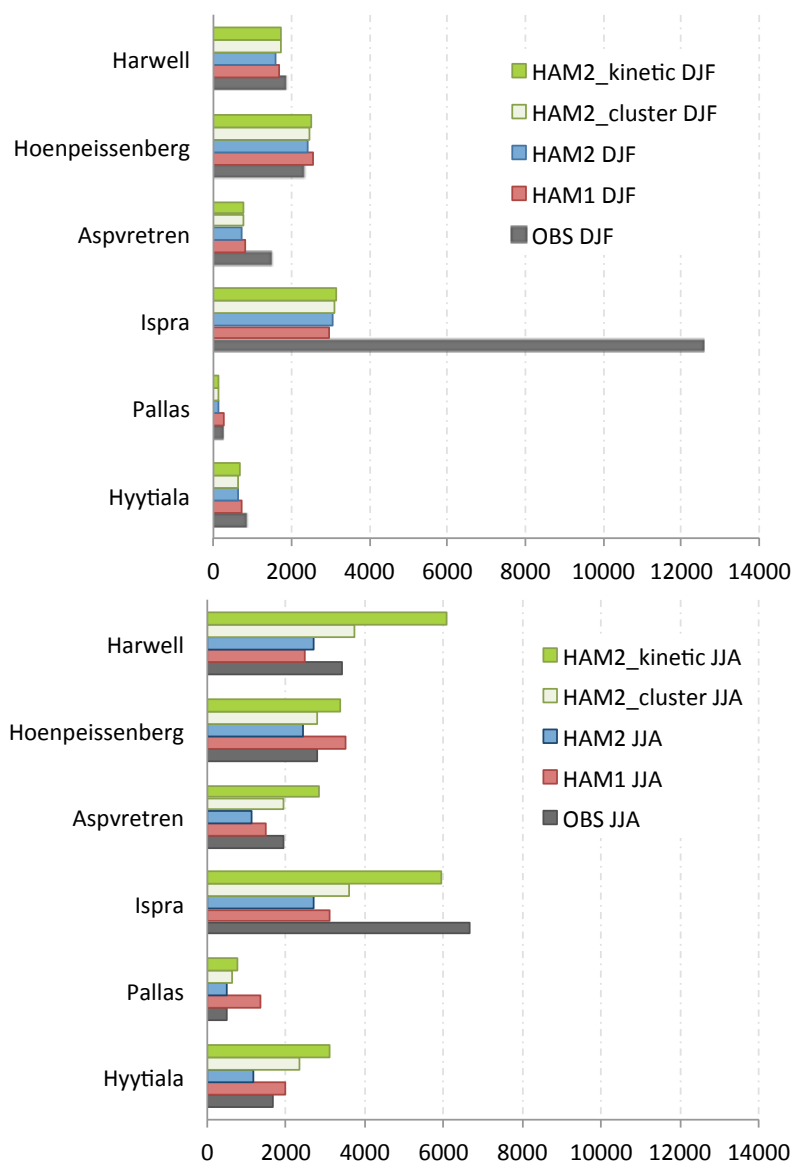

Fig. 13. Simulated and measured aerosol number concentration $\left(\mathrm{cm}^{-3}\right)$ in the planetary boundary layer at various continental sites. The observational data are from Putaud (2003) and Tunved et al. (2003). The corresponding particle size distributions are shown in Figs. 14 and 15.

(stronger wet deposition), while the highest values of the total and water AOD are from the simulation using the old water uptake scheme (using 100\% RH ceiling). Global mean values of AOD in the sensitivity simulations are listed in Table A3.

The magnitude and distribution of AAOD are key for atmospheric absorption, direct and semi-direct aerosol radiative effects. The reference AAOD climatology used in this study is compiled by Kinne et al. (2012) using the multimodel median from AeroCom combined with measurements from the NASA AERONET program (http://aeronet.gsfc. nasa.gov). The main contributors of AAOD are black carbon and dust, rendering high values over the middle- and low-latitude continents (Figs. 17c and A2). The Taylor diagram in Fig. 18c suggests that the spatial distribution is well reproduced by both HAM1 and HAM2 (correlation coefficient ca. 0.9), but with significant systematic underestimation of the magnitude. The negative bias has been reduced in HAM2 partly because the refractive index of black carbon
(BC) was updated according to the medium-absorbing values from Bond and Bergstrom (2006). The other major contributor is the weaker wet scavenging in the two-moment cloud microphysics scheme which increases the lifetime of $\mathrm{BC}$, and consequently the overall BC burden.

To have a closer look at the model results beyond annual mean, we use daily mean data of the year 2000 from AERONET. A map of the site locations is presented in Fig. 20. Daily mean model output is interpolated to the sites and sampled on the same days to derive the probability density functions (PDFs) shown in Fig. 21. For AOD, the joint PDF of HAM2 vs HAM1 (panel c) features an elongated shape located near the diagonal of the diagram, indicating that results from the two versions are by and large similar. On the other hand, there is a clear increase of AOD in HAM2 in the clean regions as indicated by the upward bending of the "cloud" near the bottom left corner of the diagram in Fig. 21c. Although AERONET rarely observed AOD below $2 \times 10^{-2}$, HAM1 tends to produce very small values (Fig. 21a) in the high latitudes. Such underestimates have been reduced in HAM2, making the joint PDF in Fig. 21b better centered along the diagonal. As for the Angström parameter, the modified sea salt emission has reduced the number of cases of too large particles (small values of the Ångström parameter, Fig. 21d-e), while there is still a substantial number of cases of overestimated Ångström parameter that need to be improved in the future. The different symbols in Fig. 20 provide a summary of the model performance at individual sites.

\subsection{Direct radiative effect of aerosols}

For the simulations listed in Table 4 performed with HAM2 and its variants, various components of the aerosol radiative effect are diagnosed. Figure 22 illustrates the direct radiative effect of all (i.e. natural and anthropogenic) aerosols in the model atmosphere. On the global scale the scattering of shortwave radiation (cooling) overwhelms the absorption of longwave radiation (warming), rendering a net direct effect of $-1.76 \mathrm{~W} \mathrm{~m}^{-2}$ at the top of the atmosphere (TOA) in the standard HAM2. The various parameterization schemes discussed in this study exhibit considerable variation in the radiative effects, as can be seen from the whiskers. The numbers behind the bar chart are given in the Appendix (Table A3). Again we see a strong sensitivity of the model result to the water uptake scheme (experiment HAM2_WAT) and cloud microphysics (experiment HAM2_CLD), both at TOA and at the Earth's surface.

To estimate the radiative forcing of anthropogenic aerosols, we performed simulations with present-day (PD) and pre-industrial (PI) emissions of aerosols and their precursors. The PD emissions are the same as described in Sect. 3 (year 2000). The PI emissions are that of year 1750 as in Schulz et al. (2006). According to Schulz et al. (2006) and Myhre et al. (2012), the anthropogenic forcing is defined as 

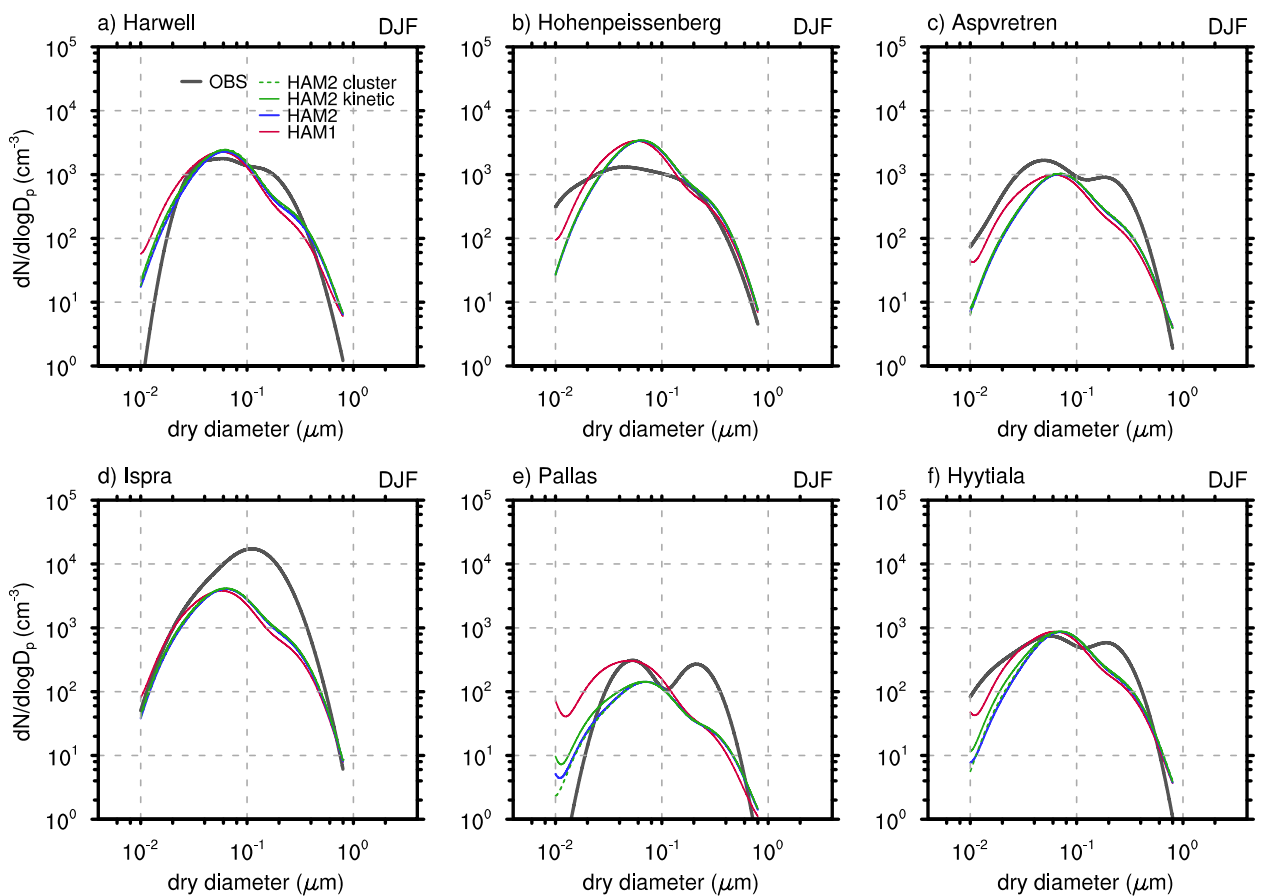

Fig. 14. Comparison of the simulated and measured aerosol size distributions in the planetary boundary layer over land in boreal winter (December-January-February). The thick black curves are the observed median size distributions from Putaud (2003) and Tunved et al. (2003). Model results (the colored curves) are plotted only for the diameter range between 0.01 and $0.8 \mu \mathrm{m}$ because this is the range measured in the references. Note that most parts of the dotted lines underlie solid color lines.
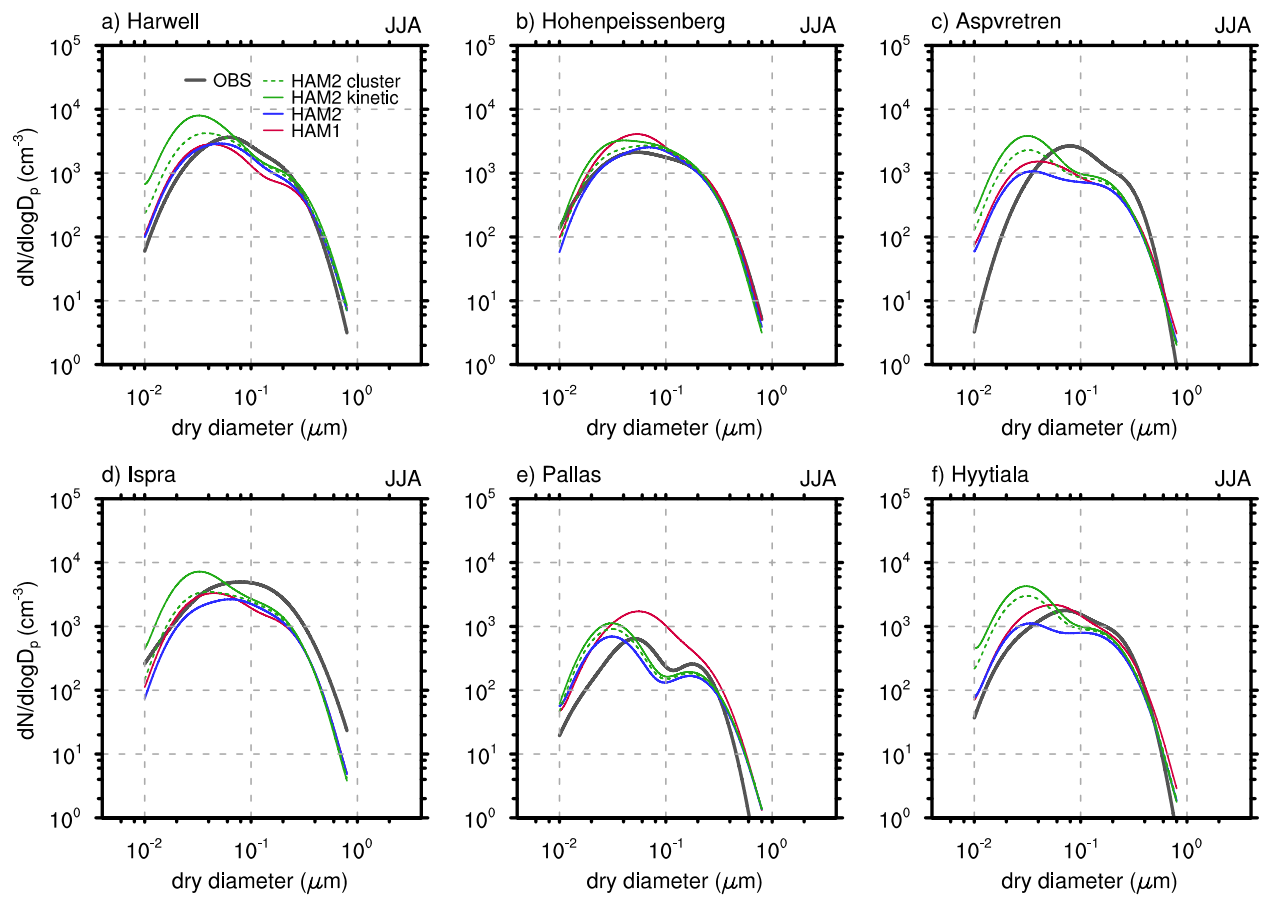

Fig. 15. As in Fig. 14 but for boreal summer (June-July-August). 

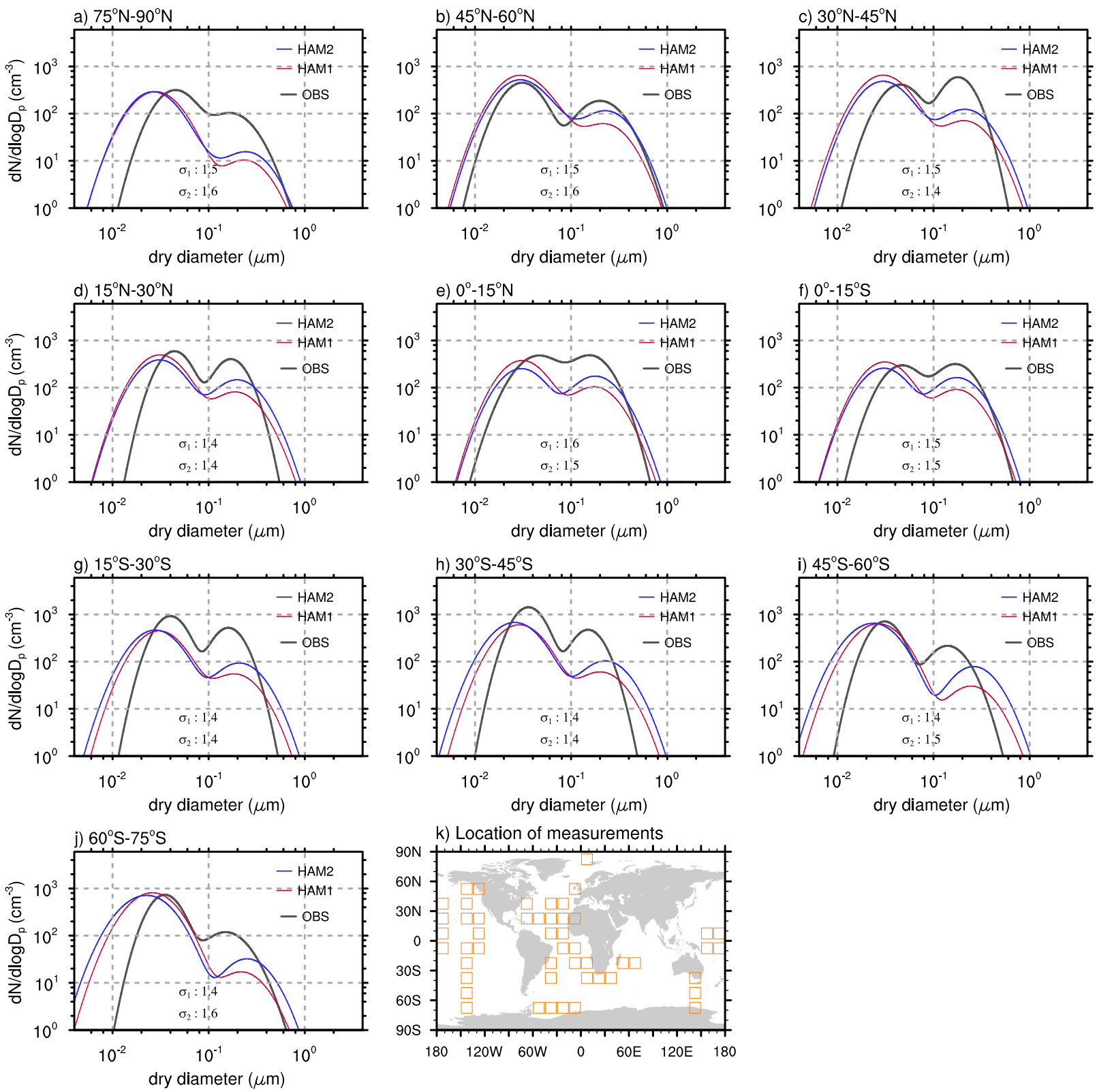

Fig. 16. Comparison of the measured (black curves) and simulated (colored curves) size distribution functions of the Aitken and accumulation modes (soluble and insoluble) in the marine boundary layer. The observations are a 30-yr climatology covering the brown boxes shown in (k), compiled by Heintzenberg et al. (2000). The simulations shown in red and blue correspond to the HAM1 and HAM2 simulations, respectively. $\sigma_{1}$ and $\sigma_{2}$ in each panel are the observed standard deviation of the Aitken and accumulation mode. In the HAM model a fixed value of 1.59 is prescribed for both modes.

the difference in TOA (top-of-atmosphere) shortwave flux between the PD and PI simulations under the same cloud distribution and properties. To strictly follow this definition, we use the HAM2_CLD configuration to exclude the aerosol indirect effects. Within a pair of PD and PI simulations, the model meteorology is kept exactly the same by using the Tanre et al. (1984) aerosol climatology when calculating the radiative heating/cooling that affects the atmospheric circu- lation. In each simulation, two additional radiative transfer calculations are performed, one with no aerosols, the other with the interactively predicted aerosol concentrations. The differences in radiative fluxes from these two diagnostic calculations are referred to as the direct radiative effect. The PD and PI simulations are then compared to derive the effect of anthropogenic aerosols, referred to as the anthropogenic aerosol direct forcing. 

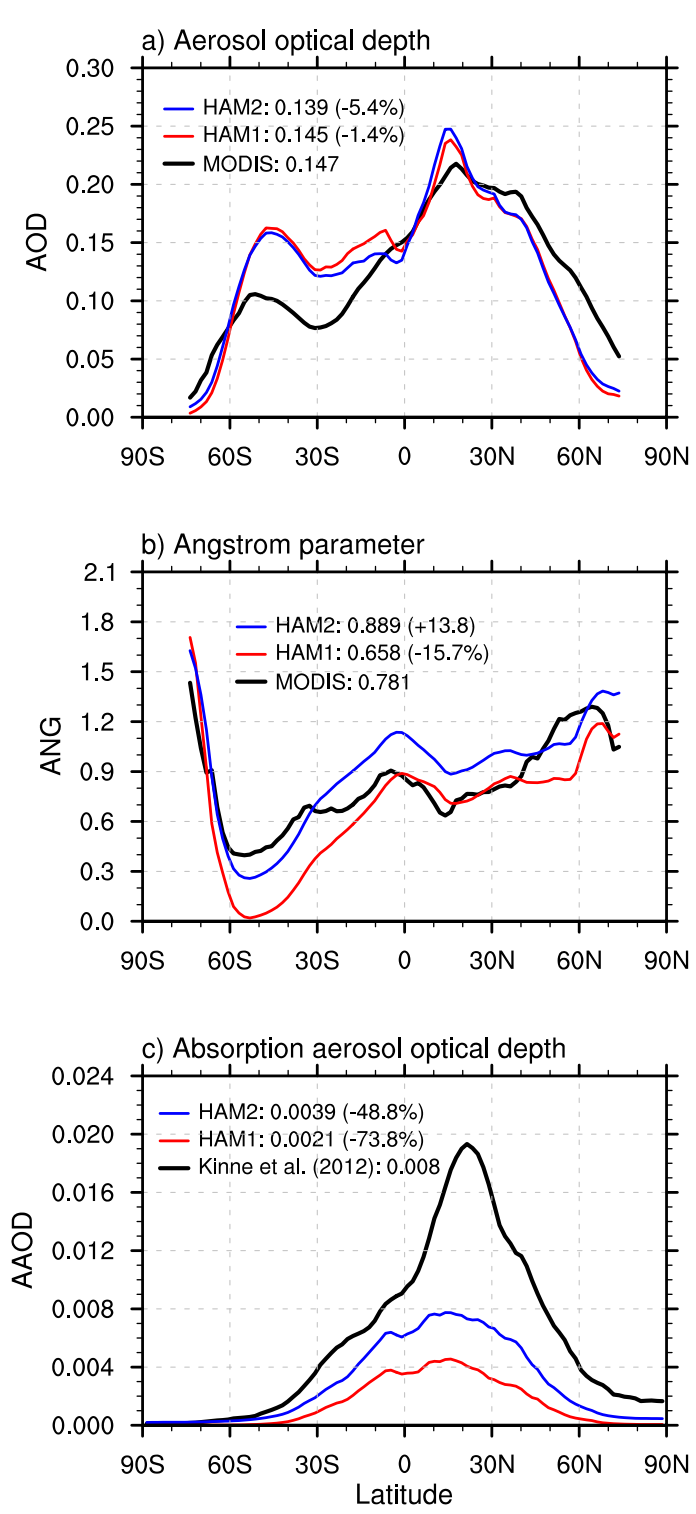

Fig. 17. Comparison of the simulated annual and zonal mean aerosol radiative properties with (a) MODIS aerosol optical depth (AOD), (b) MODIS Ångström parameter (ANG), and (c) aerosol absorption optical depth (AAOD) from Kinne et al. (2012). Numbers given in legends are the global mean values and relative differences. Polar Regions $\left(75^{\circ} \mathrm{N} / \mathrm{S}\right.$ poleward $)$ are excluded for AOD and ANG because of the limited number of satellite retrievals.

Table 9 presents the results in the style of Table 5 in Schulz et al. (2006). The simulated anthropogenic AOD (0.028) and its contribution to the present day total AOD (25.2\%) are close to the AeroCom Phase I multi-model averages. The clear-sky and all-sky TOA forcings are smaller than the AeroCom average. The radiative properties and forcing of different anthropogenic aerosol species are shown in Table 10. The results are obtained by perturbing emissions of individual species separately. A sensitivity experiment using the old
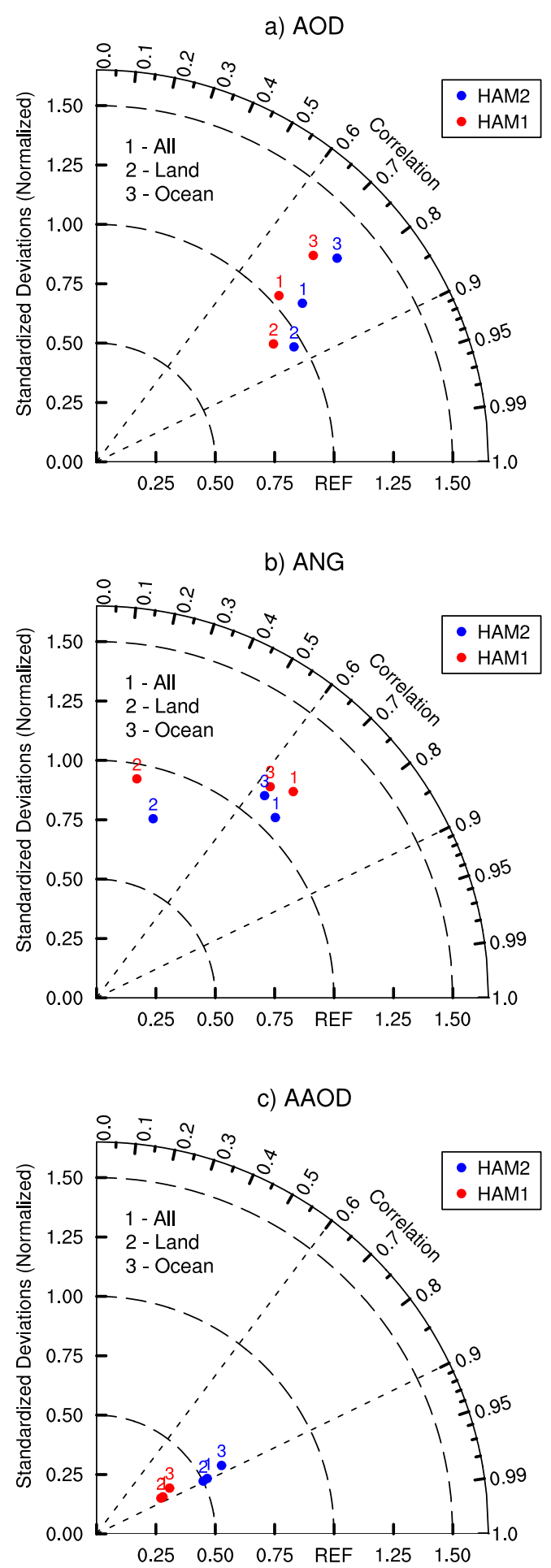

Fig. 18. Taylor diagrams comparing the simulated annual mean aerosol radiative properties with (a) MODIS aerosol optical depth (AOD), (b) MODIS Ångström parameter (ANG), and (c) aerosol absorption optical depth (AAOD) from Kinne et al. (2012). The corresponding zonal mean plots and global mean values are shown in Fig. 17. 


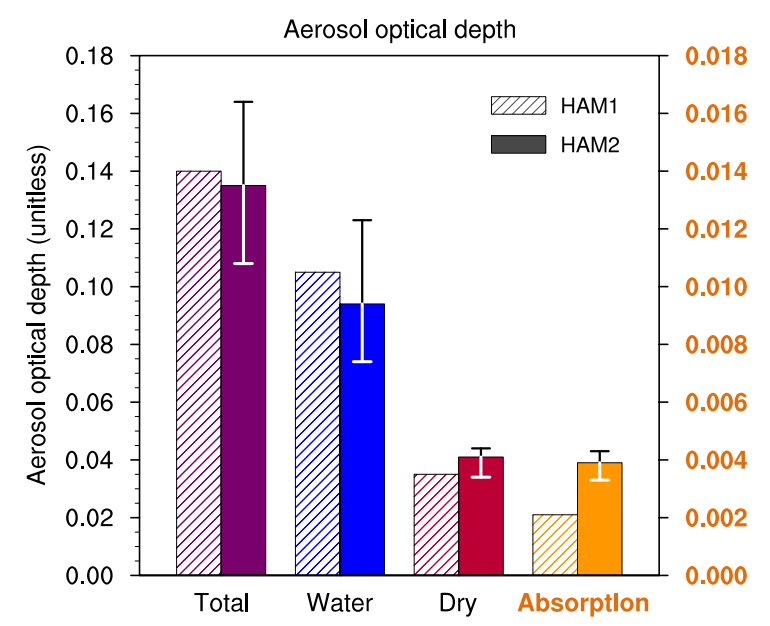

Fig. 19. Global and annual mean aerosol optical depth simulated by HAM1 and HAM2, the corresponding contributions from aerosol water and dry mass, as well as the absorption AOD. Whiskers associated with the HAM2 results indicate the ranges given by the sensitivity experiments listed in Table 4 . Note that the absorption AOD is displayed with a different scale.

water uptake scheme (HAM2_CLD_WAT) reveals a close relation between the aerosol water content and radiative forcing (the RF and NRFM values).

Tables 9 and 10 only provide a first view of the PD-PI simulations described here. Further analyses are planned. Within the framework of the AeroCom Phase II intercomparison (Myhre et al., 2012), it will be interesting to investigate issues like the regional responses to anthropogenic aerosol forcing, and modeling uncertainties in the distribution and absorption properties of black carbon (Zarzycki and Bond, 2011; Samset and Myhre, 2011; Stier et al., 2007).

\section{Conclusions}

This paper introduces improved aerosol representations in the second version of the ECHAM-HAM model and quantifies their impact on the simulated aerosol properties, global distribution, and direct radiative effects. Some of the model updates, for example in the sea salt and dust emissions, were directly motivated by previously noticed model biases. The others aimed at having a physically more realistic representation of the aerosol lifecycle, and extending the model's capability in consistently simulating the interactions between various aerosol-related micro- and macro-scale processes. The new $\mathrm{H}_{2} \mathrm{SO}_{4} / \mathrm{H}_{2} \mathrm{O}$ aerosol nucleation scheme considers both neutral and charged nucleation, which can be used to investigate the impact of nucleation from ions caused by cosmic rays (Kazil et al., 2010) and by radioactive species effusing from the Earth's surface (Zhang et al., 2011). The explicit treatment of SOA introduced by O'Donnell et al. (2011) can be used to investigate, for instance, the impact of vegetation change on aerosol formation and the consequent changes in cloud radiative forcing. The incorporation of a two-moment stratiform cloud microphysics scheme (Lohmann et al., 2007) allows aerosols to directly affect cloud microphysics through cloud droplet activation and ice nucleation.

The impacts of these updates on the simulation of aerosol distribution and property are analysed in Sects. 4 and 5. The new parameterizations that have largest impact on the global mean AOD and aerosol radiative effects are the water uptake scheme and the new stratiform cloud microphysics. The water uptake scheme implemented by O'Donnell et al. (2011) considerably reduces the aerosol water content in the lower troposphere due to the use of a lower $\mathrm{RH}$ ceiling. The resulting (global) total mass of aerosol water is in closer agreement with the AeroCom multi-model average. In comparison to the cloud microphysics scheme of Lohmann and Roeckner (1996), the new two-moment scheme features weaker conversion efficiency of cloud condensate to precipitation, which contributes to changes to aerosol lifetime and wet deposition. Compared to HAM1, aerosol lifetimes are increased in HAM2 for all aerosol species except sea salt. The percentages are between $10 \%$ and $20 \%$ for sulfate, black carbon, and POA, $107 \%$ for SOA, and $4 \%$ for dust. Wet deposition decreased for all aerosol species except particulate organic matter.

The modified sea salt emission calculation significantly changes the partitioning of particle number fluxes between accumulation mode and coarse mode, resulting in a shift of the size distribution to smaller particles.

The nucleation parameterization of Kazil et al. (2010) leads to an upward shift of the strongest nucleation to the tropical tropopause. Resulting changes in the direct aerosol effect are relatively small because of the small sizes of the nucleation mode particles.

By including all these updates in the model, we are able to obtain improved results compared to HAM1. As shown in Sects. 5.2-5.4, the aerosol size distribution and spatialtemporal variability simulated by HAM2 show better agreement with the observations. The systematic negative bias in AAOD has been reduced. The remaining major model deficiencies include (i) positive bias of AOD over the ocean, (ii) negative bias of AOD and aerosol mass concentration in high-latitude regions, and (iii) negative bias of particle number concentration, especially that of the Aitken mode, in the lower troposphere over the heavily polluted regions.

There are a few other modifications that have already been implemented in the model but not switched on in the standard HAM2. Taking into account the aerosol formation by cluster activation (Kulmala et al., 2006; Riipinen et al., 2007) or by kinetic nucleation (Laakso et al., 2004; Kuang et al., 2008) can help improve near-surface aerosol number concentrations in polluted regions, but meanwhile lead to overestimation in cleaner continental regions. The temperaturedependent in-cloud scavenging coefficient for mixed-phase 


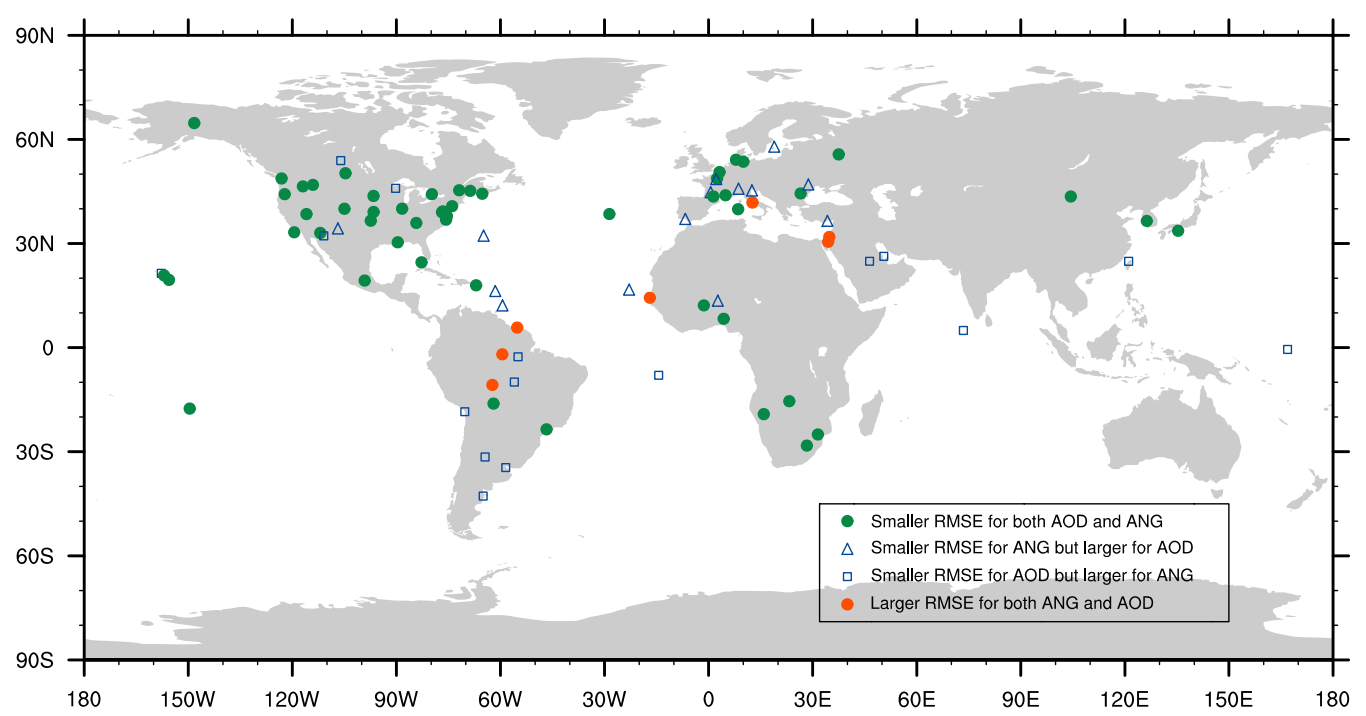

Fig. 20. Map showing the AERONET sites at which the daily mean aerosol optical depth (AOD) and Ångström parameter (ANG) of the year 2000 are used for the comparison in Fig. 21. At each site the root mean square error (RMSE, of daily mean AOD or ANG) against measurements is computed for both the HAM1 and HAM2 simulations. Green dots indicate improved results in HAM2 (reduced RMSE) for both AOD and ANG; Orange dots indicate degraded results for both parameters; empty triangles and rectangles mark the locations where mixed results are obtained. AOD is calculated/retrieved at the mid-visible wavelength $0.55 \mu \mathrm{m}$. The AERONET Ångström parameter is retrieved using the wavelengths $0.44 \mu \mathrm{m}$ and $0.87 \mu \mathrm{m}$. The model-simulated ANG is calculated using the wavelengths $0.55 \mu \mathrm{m}$ and $0.825 \mu \mathrm{m}$.
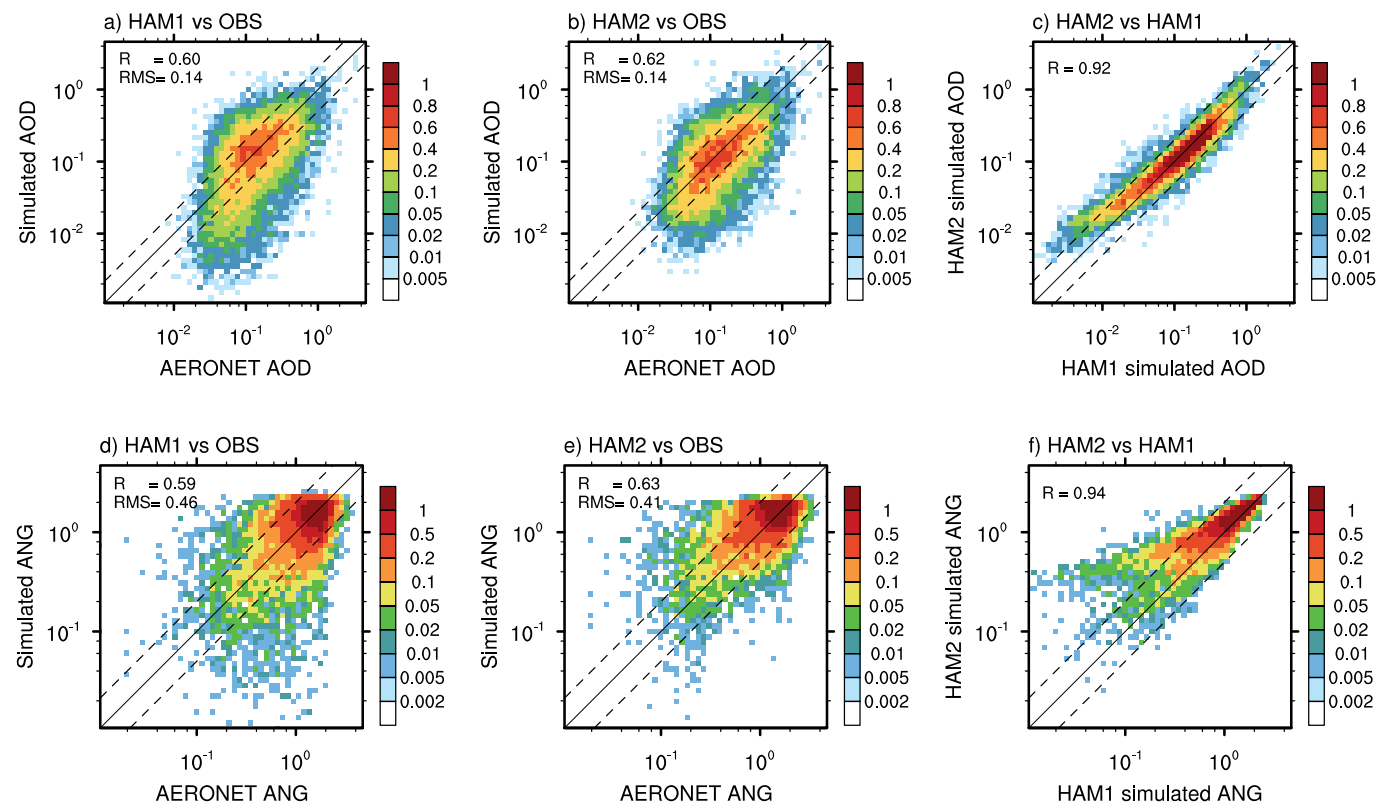

Fig. 21. Comparison of the AERONET-retrieved and model-simulated aerosol optical depth (upper row) and Ångström parameter (lower row). The color shading shows the joint probability density distribution (unit: \%) as a function of, for example in (a), the AERONETretrieved and HAM1 simulated AOD, computed from the daily mean measurement retrieved from AERONET for the year 2000 at all locations indicated in Fig. 20 and model output (also daily means) sampled at the same time instances and locations. The R- and RMS-values noted in each panel are the correlation coefficient and root mean square difference of the two data series. Further details can be found in Sect. 5.4. 
Table 9. Radiative properties and direct shortwave forcing of anthropogenic aerosols in HAM2, following Schulz et al. (2006). AOD ant and $\mathrm{AOD}_{\mathrm{ant}} / \mathrm{AOD} \mathrm{PD}$ are the anthropogenic AOD and its contribution to the present-day total AOD. RF stands for radiative forcing. NRF is the normalized radiative forcing per unit AOD. TOA stands for top-of-atmosphere. The AeroCom I multi-model mean and standard deviation are from Schulz et al. (2006). Further details can be found in Sect. 5.5.

\begin{tabular}{lrrrrrrrrr}
\hline Model & $\mathrm{AOD}_{\text {ant }}$ & $\begin{array}{r}\mathrm{AOD}_{\text {ant }} / \\
\mathrm{AOD}\end{array}$ & $\begin{array}{r}\text { Cloud } \\
\text { Cover }\end{array}$ & $\begin{array}{r}\mathrm{NRF} \\
\text { clear-sky } \\
\left(\mathrm{W} \mathrm{m}^{-2}\right)\end{array}$ & $\begin{array}{r}\text { RF TOA } \\
\text { all-sky/ } \\
\text { clear-sky }\end{array}$ & $\begin{array}{r}\text { RF TOA } \\
\text { clear-sky } \\
\left(\mathrm{W} \mathrm{m}^{-2}\right)\end{array}$ & $\begin{array}{r}\text { RF TOA } \\
\text { all-sky } \\
\left(\mathrm{W} \mathrm{m}^{-2}\right)\end{array}$ & $\begin{array}{r}\text { Surface } \\
\text { forcing } \\
\text { all-sky }\left(\mathrm{W} \mathrm{m}^{-2}\right)\end{array}$ \\
$\begin{array}{l}\text { HAM2_CLD } \\
\text { AeroCom I }\end{array}$ & $0.029 \pm 0.010$ & $25 \pm 11 \%$ & $63 \pm 5 \%$ & $-23 \pm 7$ & $0.33 \pm 0.21$ & $-0.68 \pm 0.24$ & $-0.22 \pm 0.16$ & $-1.02 \pm 0.23$ & $\begin{array}{r}\text { Atmos. } \\
\text { forcing }\end{array}$ \\
\hline
\end{tabular}

Table 10. Radiative properties and anthropogenic (direct) shortwave forcing of individual aerosol species. AOD ant, $A A O D_{\text {ant }}$ and $\omega_{\text {ant }}$ are the optical depth, absorption optical depth and single scattering albedo of anthropogenic aerosols. MEC stands for dry mass extinction coefficient, RF for radiative forcing. NRF is the normalized RF per unit AOD. NRFM is the raditive forcing efficiency per unit aerosol load. The AeroCom I multi-model mean and standard deviation are from Schulz et al. (2006). Further details can be found in Sect. 5.5.

\begin{tabular}{llrrrrrrrr}
\hline Model & $\begin{array}{r}\text { Load } \\
\left(\mathrm{mg} \mathrm{m}^{-2}\right)\end{array}$ & AOD ant & $\begin{array}{r}\text { AAOD ant } \\
* 1000\end{array}$ & $\begin{array}{c}\omega_{\text {ant }} \\
\left(\mathrm{m}^{2} \mathrm{~g}^{-1}\right)\end{array}$ & $\begin{array}{r}\text { RF } \\
\left(\mathrm{W} \mathrm{m}^{-2}\right)\end{array}$ & $\begin{array}{r}\text { NRF } \\
\left(\mathrm{W} \mathrm{m}^{-2}\right)\end{array}$ & $\begin{array}{r}\text { NRFM } \\
\left(\mathrm{W} \mathrm{g}^{-1}\right)\end{array}$ \\
\hline \multirow{2}{*}{ Sulfate } & HAM2_CLD & 2.12 & 0.019 & 0.202 & 1.00 & 9.1 & -0.26 & -13.2 \\
& HAM2_CLD_WAT & 2.11 & 0.026 & 0.252 & 1.00 & $\begin{array}{r}8.1 \\
-0.32\end{array}$ & $\begin{array}{r}-119 \\
-150\end{array}$ \\
& AeroCom I & $2.12 \pm 0.82$ & $0.019 \pm 0.009$ & - & - & $9.1 \pm 2.7$ & $-0.35 \pm 0.15$ & $-19.0 \pm 7.0$ & $-161 \pm 41$ \\
\hline BC & HAM2_CLD & 0.093 & 0.0011 & 1.001 & 0.92 & 11.6 & 0.13 & 123 & 1421 \\
& AeroCom I & - & - & - & - & & $0.12 \pm 0.04$ & - \\
\hline POA & HAM2_CLD & 0.24 & 0.0008 & 0.046 & 0.96 & 3.4 & -0.015 & -18.1 & -61.1 \\
\hline SOA & HAM2_CLD & 0.15 & 0.0016 & 0.035 & 0.98 & 10.9 & -0.02 & -12.9 & -141 \\
\hline
\end{tabular}

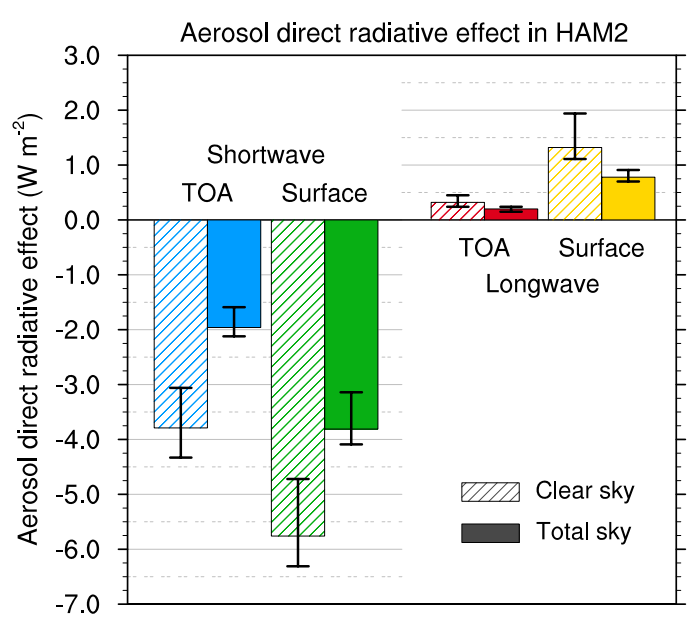

Fig. 22. Global and annual mean aerosol direct radiative effect simulated by HAM2 at top of the atmosphere (TOA) and at the Earth's surface. Whiskers indicate the spread among the HAM2 sensitivity experiments listed in Table 4. clouds and the below-cloud scavenging scheme of Croft et al. (2009) that takes into account aerosol and collector sizes appear to have some positive impacts on model results, but more extensive evaluations are still needed.

In this study the evaluation was concentrated on the global distribution and radiative properties of aerosols. With the new two-moment cloud microphysics, it is possible to investigate the aerosol effect on cloud via the first indirect effect and/or the second indirect effect. It will be useful to study the indirect effects of anthropogenic aerosols on climate in our model and their sensitivity to model configuration and resolution, not only in nudged integrations, but in "free" climate simulations. These will be presented in separate papers. Furthermore, the aerosol activation scheme of Lin and Leaitch (1997), currently used in HAM2, is highly simplified in terms of particle size and composition effects. Recently Stier et al. have implemented the Köhler theory based scheme of Abdul-Razzak and Ghan (2000). The evaluation will be presented in a separate paper. Croft et al. (2010) developed a new in-cloud aerosol scavenging scheme which may help achieve consistency with the cloud microphysics parameterization and reduce model biases. 


\section{Appendix A}

Table A1. List of observational data used in Sect. 5.2 for evaluating the simulated concentration of condensation nuclei. The measurement campaigns include: ACE-1 (Southern Hemisphere Marine Aerosol Characterization Experiment), ACE-ASIA (Asian Pacific Regional Aerosol Characterization Experiment), ARCTAS (Research of the Composition of the Troposphere from Aircraft and Satellites), INDOEX (Indian Ocean Experiment), INTEX-A (Intercontinental Chemical Transport Experiment - Phase A), INTEX-B (Intercontinental Chemical Transport Experiment - Phase B), ITOP (International Transport of Ozone and Precursors), PACDEX (PACific Dust EXperiment), RICO (Rain in Cumulus Over the Ocean), VOCALS (VAMOS Ocean Cloud Atmosphere Land Study), PASE (Pacific Atmospheric Sulfur Experiment), PEM-Tropics A (Pacific Exploratory Missions Tropics A), PEM-Tropics B (Pacific Exploratory Missions Tropics B), TRACE-P (TRAnsport and Chemical Evolution over the Pacific). The data are provided by the NASA LaRC Airborne Science Data for Atmospheric Composition program (NASA LaRC), National Center for Atmospheric Research Earth Observing Laboratory (NCAR EOL), and the British Atmospheric Data Centre (BADC). The aircraft trajectories are shown in Fig. 10.

\begin{tabular}{|c|c|c|c|c|c|}
\hline $\begin{array}{l}\text { Field } \\
\text { Campaign } 1\end{array}$ & Platform & $\begin{array}{l}\text { Latitude } \\
\text { Range }\end{array}$ & $\begin{array}{l}\text { Lontitude } \\
\text { Range }\end{array}$ & $\begin{array}{l}\text { Temporal } \\
\text { coverage }\end{array}$ & Source \\
\hline ACE-1 & C-130 & $70-30^{\circ} \mathrm{S}$ & $100-180^{\circ} \mathrm{E}$ & 31 Oct-23 Dec 1991 & NCAR EOL \\
\hline ACE-ASIA & C-130 & $10-50^{\circ} \mathrm{N}$ & $100-170^{\circ} \mathrm{E}$ & 31 Mar-5 May 2001 & NCAR EOL \\
\hline ARCTAS & DC-8 & $32-90^{\circ} \mathrm{N}$ & $169-37^{\circ} \mathrm{W}$ & $\begin{array}{l}3 \text { Apr-22 Apr } 2008 \\
20 \text { Jun-15 Jul } 2008\end{array}$ & NASA LaRC \\
\hline ARCTAS & P3-B & $32-81^{\circ} \mathrm{N}$ & $164-69^{\circ} \mathrm{W}$ & $\begin{array}{l}1 \text { Apr-21 Apr } 2008 \\
23 \text { Jun-13 Jul } 2008\end{array}$ & NASA LaRC \\
\hline INDOEX & C-130 & $10^{\circ} \mathrm{S}-17.5^{\circ} \mathrm{N}$ & $65-85^{\circ} \mathrm{E}$ & 16 Feb-24 Mar 1999 & NCAR EOL \\
\hline INTEX-A & DC-8 & $27-53^{\circ} \mathrm{N}$ & $140-36^{\circ} \mathrm{W}$ & 5 Aug-7 Sept 2007 & NASA LaRC \\
\hline INTEX-B & $\begin{array}{l}\text { C-130 } \\
\text { DC-8 }\end{array}$ & $\begin{array}{l}16-53^{\circ} \mathrm{N} \\
16-53^{\circ} \mathrm{N}\end{array}$ & $\begin{array}{l}141^{\circ} \mathrm{W}-89^{\circ} \mathrm{W} \\
175^{\circ} \mathrm{E}-86^{\circ} \mathrm{W}\end{array}$ & $\begin{array}{l}4 \text { Mar-15 May } 2006 \\
5 \text { Mar-16 May } 2006\end{array}$ & NASA LaRC \\
\hline ITOP & BAE-146 & $33-52^{\circ} \mathrm{N}$ & $40^{\circ} \mathrm{W}-0^{\circ} \mathrm{E}$ & 13 Jul-14 Aug 2004 & BADC \\
\hline MILAGRO & C-130 & $16-40^{\circ} \mathrm{N}$ & $106-88^{\circ} \mathrm{W}$ & 28 Feb-29 Mar 2006 & NCAR EOL \\
\hline PACDEX & HIAPER & $20-60^{\circ} \mathrm{N}$ & $136^{\circ} \mathrm{E}-105^{\circ} \mathrm{W}$ & 29 Apr-25 May 2007 & NCAR EOL \\
\hline PASE & C-130 & $1-3^{\circ} \mathrm{N}$ & $160-153^{\circ} \mathrm{W}$ & 8 Aug-7 Sep 2007 & NCAR EOL \\
\hline PEM-Tropics A & $\begin{array}{l}\text { DC-8 } \\
\text { P3-B }\end{array}$ & $\begin{array}{l}72^{\circ} \mathrm{S}-45^{\circ} \mathrm{N} \\
35^{\circ} \mathrm{S}-39^{\circ} \mathrm{N}\end{array}$ & $\begin{array}{l}152^{\circ} \mathrm{E}-109^{\circ} \mathrm{W} \\
165-77^{\circ} \mathrm{W}\end{array}$ & $\begin{array}{l}31 \text { Aug-7 Oct } 1996 \\
16 \text { Aug-27 Sep } 1996\end{array}$ & NASA LaRC \\
\hline PEM-Tropics B & $\begin{array}{l}\text { DC-8 } \\
\text { P3-B }\end{array}$ & $\begin{array}{l}36^{\circ} \mathrm{S}-35^{\circ} \mathrm{N} \\
21^{\circ} \mathrm{S}-40^{\circ} \mathrm{N}\end{array}$ & $\begin{array}{l}148^{\circ} \mathrm{E}-85^{\circ} \mathrm{W} \\
166-76^{\circ} \mathrm{W}\end{array}$ & $\begin{array}{l}7 \text { Mar-19 Apr } 1999 \\
12 \text { Mar-12 Apr } 1999\end{array}$ & NASA LaRC \\
\hline RICO & C-130 & $15-21^{\circ} \mathrm{N}$ & $72-57^{\circ} \mathrm{W}$ & 24 Dec 2004-24 Jan 2005 & NCAR EOL \\
\hline TRACE-P & $\begin{array}{l}\text { DC-8 } \\
\text { P3-B }\end{array}$ & $\begin{array}{l}13-46^{\circ} \mathrm{N} \\
6-41^{\circ} \mathrm{N}\end{array}$ & $\begin{array}{l}113^{\circ} \mathrm{E}-118^{\circ} \mathrm{W} \\
111^{\circ} \mathrm{E}-75^{\circ} \mathrm{W}\end{array}$ & $\begin{array}{l}27 \text { Feb-10 Apr } 2001 \\
25 \text { Feb-11 Apr } 2001\end{array}$ & NASA LaRC \\
\hline VOCALS & C-130 & $30-15^{\circ} \mathrm{S}$ & $90-70^{\circ} \mathrm{W}$ & 15 Oct-15 Nov 2008 & NCAR EOL \\
\hline
\end{tabular}

Table A2. Globally $\left(90^{\circ} \mathrm{S}-90^{\circ} \mathrm{N}\right)$ and regionally (land, ocean) averaged annual mean single scattering albedo ( $\omega$ ), absorption aerosol optical depth (AAOD) and total aerosol optical depth (AOD) in HAM1 and HAM2, and the contribution to AOD from different chemical compositions.

\begin{tabular}{lllllll}
\hline & & HAM1 & & & HAM2 \\
& Global & Land & Ocean & Global & Land & Ocean \\
\hline$\omega$ & 0.987 & 0.972 & 0.993 & 0.974 & 0.951 & 0.983 \\
AAOD & 0.0021 & 0.0042 & 0.0012 & 0.0039 & 0.0073 & 0.0026 \\
AOD & 0.140 & 0.130 & 0.144 & 0.135 & 0.135 & 0.134 \\
AOD $_{\text {water }}$ & 0.105 & 0.073 & 0.118 & 0.094 & 0.073 & 0.102 \\
AOD $_{\text {SU }}$ & 0.0107 & 0.0165 & 0.0083 & 0.0136 & 0.0205 & 0.0109 \\
AOD $_{\text {BC }}$ & 0.0006 & 0.0012 & 0.0003 & 0.0007 & 0.0015 & 0.0004 \\
AOD $_{\text {OA }}$ & 0.0051 & 0.0105 & 0.0029 & 0.0049 & 0.0096 & 0.0030 \\
AOD $_{\text {SS }}$ & 0.0066 & 0.0024 & 0.0083 & 0.0084 & 0.0030 & 0.0105 \\
AOD $_{\text {DU }}$ & 0.0124 & 0.0267 & 0.0067 & 0.0129 & 0.0273 & 0.0072 \\
\hline
\end{tabular}


a) MODIS Aerosol optical depth (AOD)
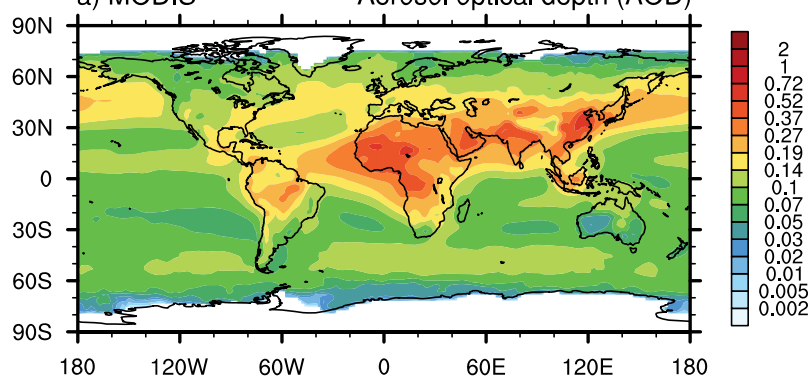

b) HAM2
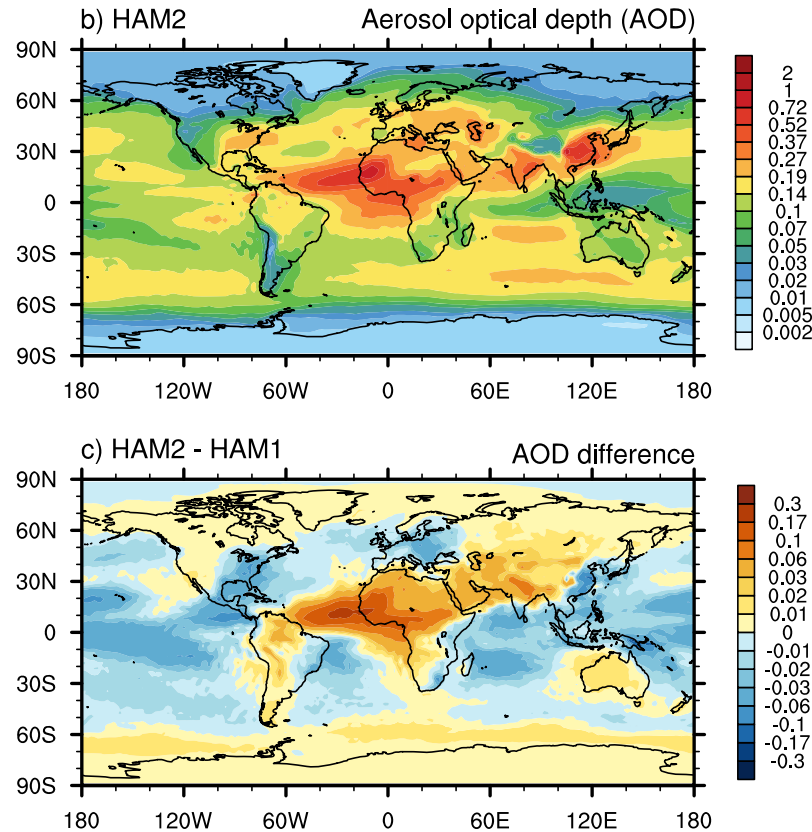

d) (HAM2-HAM1) / HAM1 AOD relative difference

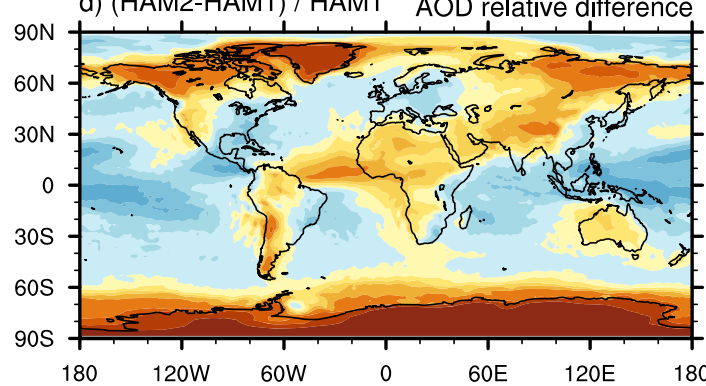

e) MODIS

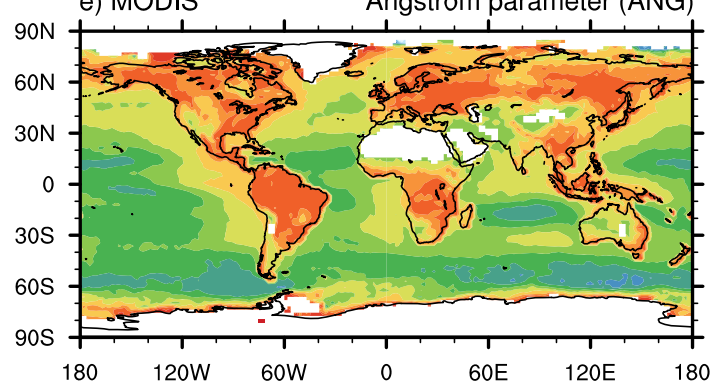

f) HAM2
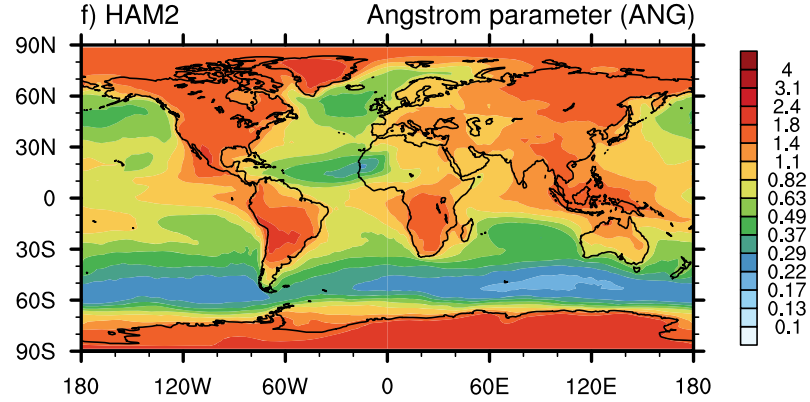

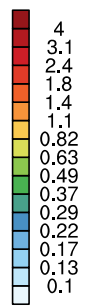

g) HAM2 - HAM1

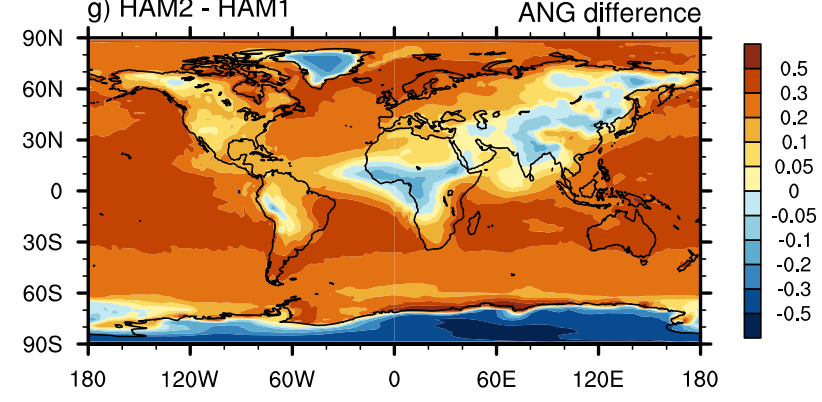

h) (HAM2-HAM1) / HAM1 ANG relative difference

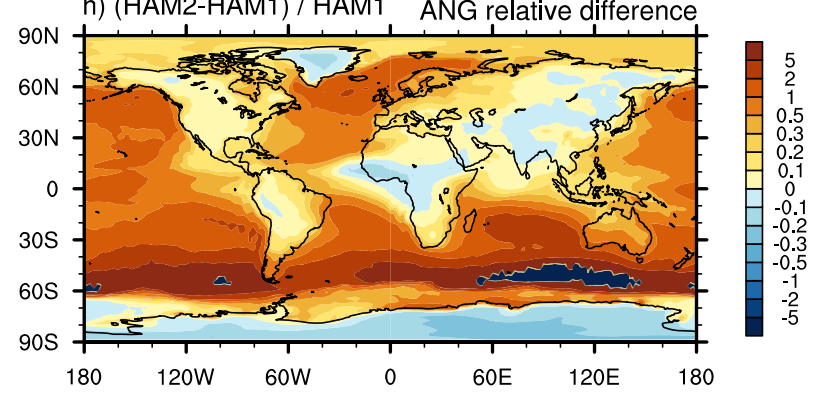

Fig. A1. Geographical distribution of the annual mean aerosol optical depth (AOD, left column) and Ångström parameter (ANG, right column) from the MODIS retrieval (top row), simulated by HAM2 (second row), and the differences between HAM2 and HAM1 results (third and bottom rows). The displayed satellite retrievals are multi-year mean fields. The AOD fields are calculated/retrieved at the midvisible wavelength $0.55 \mu \mathrm{m}$. The MODIS Ångström parameter is retrieved using the wavelengths $0.55 \mu \mathrm{m}$ and $0.865 \mu \mathrm{m}$ over the ocean, and $0.47 \mu \mathrm{m}$ and $0.66 \mu \mathrm{m}$ over land. The model-simulated ANG is calculated using the wavelengths $0.55 \mu \mathrm{m}$ and $0.825 \mu \mathrm{m}$ at all grid points. 
a) HAM1

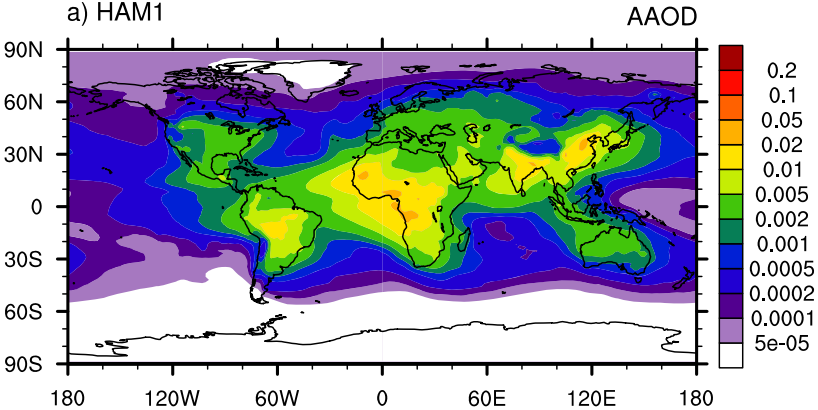

c) HAM2 - HAM1

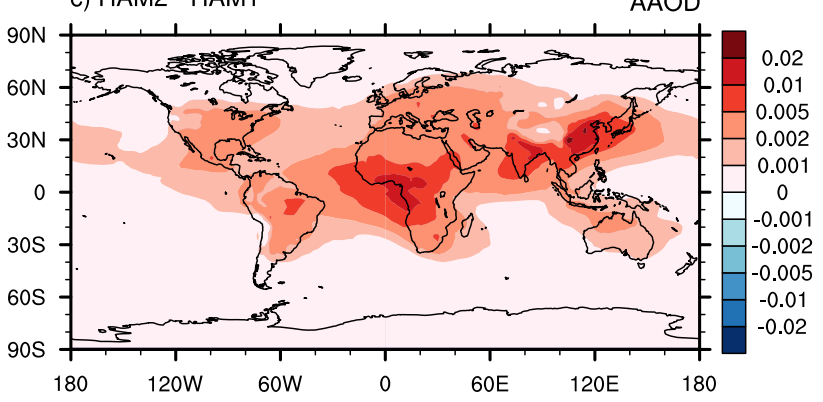

b) HAM2

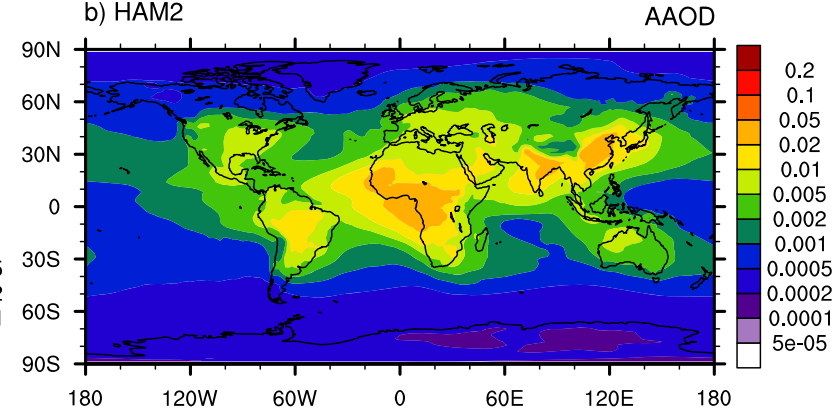

d) AeroCom median adjusted using AERONET AAOD

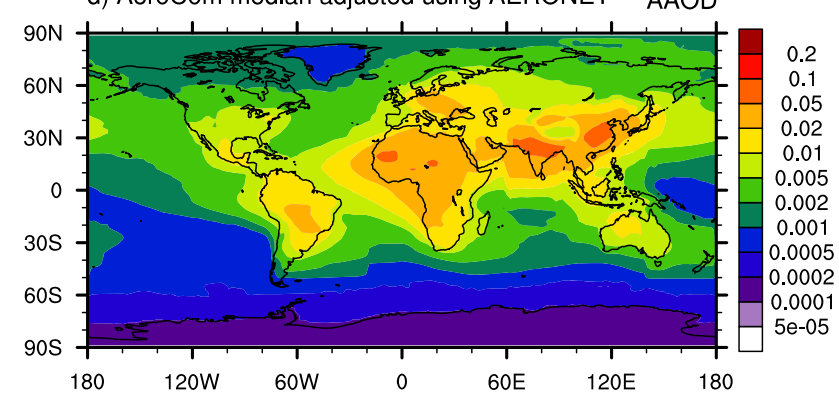

Fig. A2. Geographical distribution of the annual mean aerosol absorption optical depth (AAOD) simulated by HAM1 and HAM2 (top row), their differences (bottom left panel), and the reference result (bottom right panel) compiled by Kinne et al. (2012) using the AeroCom multi-model median adjusted with AERONET measurements.

Table A3. Aerosol optical depth (AOD, unitless) and direct radiative effect (unit: $\mathrm{W} \mathrm{m}^{-2}$ ) in simulations discussed in this paper. AOD and $\mathrm{AOD}_{\mathrm{d}}$ stand for the optical depth associated with aerosol water and dry mass, respectively. The radiative effect is presented in the

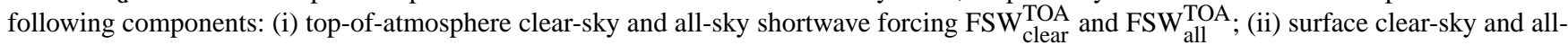
sky shortwave forcing $\mathrm{FSW}_{\text {clear }}^{\mathrm{SFC}}$ and $\mathrm{FSW}_{\text {all }}^{\mathrm{SFC}}$; (iii) top-of-atmosphere clear-sky and all-sky longwave forcing FLW clear $^{\mathrm{TOA}}$ and FLW all ; $^{\mathrm{TOA}}$ (iv) surface clear-sky and all-sky longwave forcing $\mathrm{FLW}_{\text {clear }}^{\mathrm{SFC}}$ and $\mathrm{FLW}_{\text {all }}^{\mathrm{SFC}}$. Numbers given in bold are the largest and smallest values among the sensitivity experiments carried out with HAM2.

\begin{tabular}{llllllllllll}
\hline & $\mathrm{AOD}$ & $\mathrm{AOD}_{w}$ & $\mathrm{AOD}_{d}$ & $\mathrm{FSW}_{\text {clear }}^{\mathrm{TOA}}$ & $\mathrm{FSW}_{\text {all }}^{\mathrm{TOA}}$ & $\mathrm{FSW}_{\text {clear }}^{\mathrm{SFC}}$ & $\mathrm{FSW}_{\text {all }}^{\mathrm{SFC}}$ & $\mathrm{FLW}_{\text {clear }}^{\mathrm{TOA}}$ & $\mathrm{FLW}_{\text {all }}^{\mathrm{TOA}}$ & $\mathrm{FLW}_{\text {clear }}^{\mathrm{SFC}}$ & $\mathrm{FLW}_{\text {all }}^{\mathrm{SFC}}$ \\
\hline HAM2 & 0.135 & 0.094 & 0.041 & -3.79 & -1.96 & -5.76 & -3.81 & 0.32 & 0.20 & 1.32 & 0.78 \\
HAM2_H2SO4 & 0.130 & 0.089 & 0.041 & -3.69 & -1.94 & -5.71 & -3.86 & 0.31 & 0.20 & 1.21 & 0.76 \\
HAM2_NUL & 0.137 & 0.096 & 0.041 & -3.86 & -1.98 & -5.83 & -3.83 & 0.33 & 0.20 & 1.32 & 0.78 \\
HAM2_cluster & 0.135 & 0.094 & 0.041 & -3.80 & -1.95 & -5.76 & -3.80 & 0.32 & 0.20 & 1.32 & 0.78 \\
HAM2_kinetic & 0.135 & 0.095 & 0.040 & -3.81 & -1.94 & -5.77 & -3.79 & 0.32 & 0.20 & 1.32 & 0.78 \\
HAM2_WAT & $\mathbf{0 . 1 6 3}$ & $\mathbf{0 . 1 2 3}$ & 0.041 & $-\mathbf{4 . 3 3}$ & -2.03 & $-\mathbf{6 . 3 1}$ & -3.89 & $\mathbf{0 . 4 5}$ & $\mathbf{0 . 2 4}$ & $\mathbf{1 . 9 4}$ & $\mathbf{0 . 9 1}$ \\
HAM2_OA & 0.131 & 0.089 & 0.042 & -3.54 & -1.85 & -5.40 & -3.59 & 0.30 & 0.19 & 1.31 & 0.78 \\
HAM2_DU & 0.134 & 0.094 & 0.040 & -3.78 & -1.95 & -5.74 & -3.80 & 0.32 & 0.20 & 1.31 & 0.78 \\
HAM2_SS & 0.139 & 0.098 & 0.041 & -4.06 & $-\mathbf{2 . 1 2}$ & -6.03 & -3.97 & 0.34 & 0.21 & 1.45 & 0.85 \\
HAM2_BLCLD & 0.124 & 0.085 & 0.039 & -3.52 & -1.86 & -5.42 & -3.66 & 0.29 & 0.19 & 1.17 & 0.74 \\
HAM2_INCLD & 0.145 & 0.101 & $\mathbf{0 . 0 4 4}$ & -4.08 & -2.07 & -6.20 & $-\mathbf{4 . 0 9}$ & 0.37 & 0.23 & 1.40 & 0.83 \\
HAM2_CLD & $\mathbf{0 . 1 0 9}$ & $\mathbf{0 . 0 7 4}$ & $\mathbf{0 . 0 3 4}$ & $\mathbf{- 3 . 0 6}$ & $\mathbf{- 1 . 5 9}$ & $-\mathbf{4 . 7 2}$ & $\mathbf{- 3 . 1 4}$ & $\mathbf{0 . 2 4}$ & $\mathbf{0 . 1 5}$ & $\mathbf{1 . 1 1}$ & $\mathbf{0 . 7 0}$ \\
\hline
\end{tabular}


Acknowledgements. The authors thank U. Niemeier (MPI-M) for her comments on an earlier version of the manuscript, and M. Esch for her support in coupling HAM with the ECHAM model. KZ appreciates very helpful discussions with X. Liu and S. Burrows (PNNL). Comments and suggestions from the two anonymous reviewers significantly helped to improve the manuscript. We acknowledge the NASA Langley Research Center, the NCAR Earth Observing Laboratory, and the British Atmospheric Data Centre for providing the aircraft measurements used in this study. The principal investigators of these measurement campaigns provided very helpful suggestions on how to compare the data with model results. We also thank the AERONET Principal Investigators and the AeroCom project for compiling and providing the aerosol optical depth, Angström parameter, and the surface aerosol mass concentration data used in the model evaluation. Simulations were performed at the German Climate Computing Center (Deutsches Klimarechenzentrum GmbH, DKRZ) in Hamburg, Germany. J. Kazil, D. O'Donnell, and K. Zhang gratefully acknowledge the support by the FP6 project EUCAARI (Contract 34684). Work done by KZ at PNNL also benefited from the SciDAC Project "Applying Computationally Efficient Schemes for BioGeochemical Cycles" of US Dept. of Energy. HW is grateful for the support of the Linus Pauling Distinguished Postdoctoral Fellowship. Her contribution to this paper was made under the Laboratory Directed Research and Development Program at PNNL.

The service charges for this open access publication have been covered by the Max Planck Society.

Edited by: F. Yu

\section{References}

Abdul-Razzak, H. and Ghan, S. J.: A parameterization of aerosol activation - 2. multiple aerosol types, J. Geophys. Res., 105, 68376844, doi:10.1029/1999JD901161, 2000.

Adams, P. J., Seinfeld, J. H., Koch, D., Mickley, L., and Jacob, D.: General circulation model assessment of direct radiative forcing by the sulfate-nitrate-ammonium-water inorganic aerosol system, J. Geophys. Res., 106, 1097-1111, doi:10.1029/2000JD900512, 2001.

Andres, R. J. and Kasgnoc, A. D.: A time-averaged inventory of subaerial volcanic sulfur emissions., J. Geophys. Res., 103, 25251-25261, 1998.

Barth, M., Rasch, P. J., Kiehl, J. T., Benkovitz, C. M., and Schwartz, S. E.: Sulfur chemistry in the NCAR CCM: Description, evaluation, features and sensitivity to aqueous chemistry., J. Geophys. Res., 105, 1387-1415, 2000.

Bauer, S. E., Wright, D. L., Koch, D., Lewis, E. R., McGraw, R., Chang, L.-S., Schwartz, S. E., and Ruedy, R.: MATRIX (Multiconfiguration Aerosol TRacker of mIXing state): an aerosol microphysical module for global atmospheric models, Atmos. Chem. Phys., 8, 6003-6035, doi:10.5194/acp-8-60032008, 2008.

Bergman, T., Kerminen, V.-M., Korhonen, H., Lehtinen, K. J., Makkonen, R., Arola, A., Mielonen, T., Romakkaniemi, S., Kulmala, M., and Kokkola, H.: Evaluation of the sectional aerosol microphysics module SALSA implementation in ECHAM5-
HAM aerosol-climate model, Geosci. Model Dev., 5, 845-868, doi:10.5194/gmd-5-845-2012, 2012.

Bond, T. C. and Bergstrom, R. W.: Light Absorption by Carbonaceous Particles: An Investigative Review, Aerosol Sci. Technol., 40, 27-67, doi:10.1080/02786820500421521, 2006.

Bond, T. C., Streets, D. G., Yarber, K. F., Nelson, S. M., Woo, J.-H., and Klimont, Z.: A technology-based global inventory of black and organic carbon emissions from combustion, J. Geophys. Res., 109, D14203, doi:10.1029/2003JD003697, 2004.

Bourgeois, Q. and Bey, I.: Pollution transport efficiency toward the Arctic: Sensitivity to aerosol scavenging and source regions, J. Geophys. Res., 116, D08213, doi:10.1029/2010JD015096, 2011.

Brinkop, S. and Roeckner, E.: Sensitivity of a general circulationmodel to parameterizations of cloud-turbulence interactions inthe atmospheric boundary layer, Tellus, 47A, 197-220, 1995.

Cagnazzo, C., Manzini, E., Giorgetta, M. A., Forster, P. M. De F., and Morcrette, J. J.: Impact of an improved shortwave radiation scheme in the MAECHAM5 General Circulation Model, Atmos. Chem. Phys., 7, 2503-2515, doi:10.5194/acp-7-2503-2007, 2007.

Cheng, T., Peng, Y., Feichter, J., and Tegen, I.: An improvement on the dust emission scheme in the global aerosol-climate model ECHAM5-HAM, Atmos. Chem. Phys., 8, 1105-1117, doi:10.5194/acp-8-1105-2008, 2008.

Chin, M., Rood, R. B., Lin, S.-J., Müller, J. F., and Thompson, A. M. : Atmospheric sulfur cycle simulation in the global model GOCART: Model description and global properies, J. Geophys. Res., 105, 24671-24687, 2000.

Cofala, J., Amann, M., Klimont, Z., and Schopp, W.: Scenarios of World Anthropogenic Emissions of $\mathrm{SO}_{2}, \mathrm{NO}_{\mathrm{x}}$, and $\mathrm{CO}$ up to 2030, Austria 17 pp., Internal report of the Transboundary Air Pollution Programme, International Institute for Applied Systems Analysis, Laxenburg, 2005.

Croft, B., Lohmann, U., Martin, R. V., Stier, P., Wurzler, S., Feichter, J., Posselt, R., and Ferrachat, S.: Aerosol size-dependent below-cloud scavenging by rain and snow in the ECHAM5HAM, Atmos. Chem. Phys., 9, 4653-4675, doi:10.5194/acp-94653-2009, 2009.

Croft, B., Lohmann, U., Martin, R. V., Stier, P., Wurzler, S., Feichter, J., Hoose, C., Heikkilä, U., van Donkelaar, A., and Ferrachat, S.: Influences of in-cloud aerosol scavenging parameterizations on aerosol concentrations and wet deposition in ECHAM5-HAM, Atmos. Chem. Phys., 10, 1511-1543, doi:10.5194/acp-10-1511-2010, 2010.

Dentener, F., Kinne, S., Bond, T., Boucher, O., Cofala, J., Generoso, S., Ginoux, P., Gong, S., Hoelzemann, J. J., Ito, A., Marelli, L., Penner, J. E., Putaud, J.-P., Textor, C., Schulz, M., van der Werf, G. R., and Wilson, J.: Emissions of primary aerosol and precursor gases in the years 2000 and 1750 prescribed data-sets for AeroCom, Atmos. Chem. Phys., 6, 4321-4344, doi:10.5194/acp-64321-2006, 2006.

Downing, H. D. and Williams, D.: Optical constants of water in the infrared, J. Geophys. Res., 80, 1656-1661, doi:10.1029/JC080i012p01656, 1975.

Easter, R. C., Ghan, S. J., Zhang, Y., Saylor, R. D., Chapman, E. G., Laulainen, N. S., Abdul-Razzak, H., Leung, L. R., Bian, X., and Zaveri, R. A.: MIRAGE: Model description and evaluation of aerosols and trace gases, J. Geophys. Res., 109, D20210, doi:10.1029/2004JD004571, 2004. 
Feichter, J., Kjellström, E., Rodhe, H., Dentener, F., Lelieveld, J., and Roelofs, G. J.: Simulation of the tropospheric sulfur cycle in a global climate model, Atmos. Environ., 30, 1693-1707, doi:10.1016/1352-2310(95)00394-0, 1996.

Fischer-Bruns, I., Feichter, J., Kloster, S., and Schneidereit, A.: How present aerosol pollution from North America impacts North Atlantic climate, Tellus A, 62, 579-589, doi:10.1111/j.1600-0870.2010.00446.x, 2010.

Folini, D. and Wild, M.: Aerosol emissions and dimming/brightening in Europe: Sensitivity studies with ECHAM5-HAM, J. Geophys. Res., 116, D21104, doi:10.1029/2011JD016227, 2011.

Fouquart, Y. and Bonnel, B.: Computations of solar heating of the earth's atmosphere: A new parameterization, Beitr. Phys. Atmos., 53, 35-62, 1980.

Fuchs, N. A.: Evaporation and droplet growth in gaseous media, Pergamon, Tarrytown, New York, 1959.

Fuchs, N. A.: The mechanics of aerosols, Pergamon Press, Oxford, 1964.

Ganzeveld, L. and Lelieveld, J.: Dry Deposition parameterization in a chemical general circulation model and its influence on the distribution of reactive trace gases., J. Geophys. Res., 100, 20999 21012, 1995.

Ganzeveld, L., Lelieveld, J., and Roelofs, G.-J.: A dry deposition parameterization for sulfur oxides in a chemistry and general circulation model., Atmos. Environ., 103, 5679-5694, doi:10.1029/97JD03077, 1998.

Guenther, A.: Corrigendum to "Estimates of global terrestrial isoprene emissions using MEGAN (Model of Emissions of Gases and Aerosols from Nature)", Atmos. Chem. Phys., 7, 4327-4327, doi:10.5194/acp-7-4327-2007, 2007.

Guenther, A., Hewitt, C. N., Erickson, D., Fall, R., Geron, C., Graedel, T., Harley, P., Klinger, L., Lerdau, M., Mckay, W. A., Pierce, T., Scholes, B., Steinbrecher, R., Tallamraju, R., Taylor, J., and Zimmerman, P.: A global model of natural volatile organic compound emissions, J. Geophys. Res., 100, 8873-8892, doi:10.1029/94JD02950, 1995.

Guenther, A., Karl, T., Harley, P., Wiedinmyer, C., Palmer, P. I., and Geron, C.: Estimates of global terrestrial isoprene emissions using MEGAN (Model of Emissions of Gases and Aerosols from Nature), Atmos. Chem. Phys., 6, 3181-3210, doi:10.5194/acp-63181-2006, 2006.

Halmer, M. M., Schmincke, H.-U., and Graf, H.-F.: The annual volcanic gas input into the atmosphere, in particular into the stratosphere: a global data set for the past 100 years, Journal of Volcanology and Geothermal Research, 115, 511-528, 2002.

Heald, C. L., Coe, H., Jimenez, J. L., Weber, R. J., Bahreini, R., Middlebrook, A. M., Russell, L. M., Jolleys, M., Fu, T.-M., Allan, J. D., Bower, K. N., Capes, G., Crosier, J., Morgan, W. T., Robinson, N. H., Williams, P. I., Cubison, M. J., DeCarlo, P. F., and Dunlea, E. J.: Exploring the vertical profile of atmospheric organic aerosol: comparing 17 aircraft field campaigns with a global model, Atmos. Chem. Phys., 11, 12673-12696, doi:10.5194/acp-11-12673-2011, 2011.

Heintzenberg, J., Covert, D. C., and van Dingenen, R.: Size distribution and chemical composition of marine aerosols: a compilation and review, Tellus, 52B, 1104-1122, doi:10.1034/j.16000889.2000.00136.x, 2000.
Herzog, M., Weisenstein, D. K., and Penner, J. E.: A Dynamic Aerosol Module for Global Chemical Transport Models: Model Description, J. Geophys. Res., 109, D18202, doi:10.1029/2003JD004405, 2004.

Hess, M., Koepke, P., and Schult, I.: Optical Properties of Aerosols and clouds: The software package OPAC, B. Am. Met. Soc., 79, 831-844, 1998.

Hoose, C., Lohmann, U., Bennartz, R., Croft, B., and Lesins, G.: Global simulations of aerosol processing in clouds, Atmos. Chem. Phys., 8, 6939-6963, doi:10.5194/acp-8-6939-2008, 2008.

Horowitz, L. W., Walters, S., Mauzerall, D. L., Emmons, L. K., Rasch, P. J., Granier, C., Tie, X., Lamarque, J.-F., Schultz, M. G., Tyndall, G. S., Orlando, J. J., and Brasseur, G. P.: A global simulation of tropospheric ozone and related tracers: Description and evaluation of MOZART, version 2, J. Geophys. Res., 108, 4784, doi:10.1029/2002JD002853, 2003.

Jacobson, M. Z.: Global direct radiative forcing due to molticomponent anthropogenic and natural aerosols, J. Geophys. Res., 106, 1551-1568, 2001.

Kanakidou, M., Seinfeld, J. H., Pandis, S. N., Barnes, I., Dentener, F. J., Facchini, M. C., Van Dingenen, R., Ervens, B., Nenes, A., Nielsen, C. J., Swietlicki, E., Putaud, J. P., Balkanski, Y., Fuzzi, S., Horth, J., Moortgat, G. K., Winterhalter, R., Myhre, C. E. L., Tsigaridis, K., Vignati, E., Stephanou, E. G., and Wilson, J.: Organic aerosol and global climate modelling: a review, Atmos. Chem. Phys., 5, 1053-1123, doi:10.5194/acp-5-1053-2005, 2005.

Kärcher, B. and Lohmann, U.: A parameterization of cirrus cloud formation: Heterogeneous freezing, J. Geophys. Res.-Atmos., 108, 4402, doi:10.1029/2002JD003220, 2003.

Kazil, J. and Lovejoy, E. R.: A semi-analytical method for calculating rates of new sulfate aerosol formation from the gas phase, Atmos. Chem. Phys., 7, 3447-3459, doi:10.5194/acp-7-3447-2007, 2007.

Kazil, J., Stier, P., Zhang, K., Quaas, J., Kinne, S., O’Donnell, D., Rast, S., Esch, M., Ferrachat, S., Lohmann, U., and Feichter, J.: Aerosol nucleation and its role for clouds and Earth's radiative forcing in the aerosol-climate model ECHAM5-HAM, Atmos. Chem. Phys., 10, 10733-10752, doi:10.5194/acp-1010733-2010, 2010.

Kazil, J., Zhang, K., Stier, P., Feichter, J., Lohmann, U., and O'Brien, K.: The present-day decadal solar cycle modulation of Earth's radiative forcing via charged $\mathrm{H} 2 \mathrm{SO} 4 / \mathrm{H} 2 \mathrm{O}$ aerosol nucleation, Geophys. Res. Lett., 39, L02805, doi:10.1029/2011GL050058, 2012.

Kettle, A. J. and Andreae, M. O.: Flux of dimethylsulfide from the oceans: A comparison of updated data sets and flux models, J. Geophys. Res., 105, 26793-26808, doi:10.1029/2000JD900252, 2000.

Khairoutdinov, M. and Kogan, Y.: A New Cloud Physics Parameterization in a Large-Eddy Simulation Model of Marine Stratocumulus, Mon. Weather Rev., 128, 229, doi:10.1175/15200493(2000)128;0229:ANCPPI ¿2.0.CO;2, 2000.

Kinne, S., Lohmann, U., Feichter, J., Schulz, M., Timmreck, C., Ghan, S., Easter, R., Chin, M., Ginoux, P., Takemura, T., Tegen, I., Koch, D., Herzog, M., Penner, J., Pitari, G., Holben, B., Eck, T., Smirnov, A., Dubovik, O., Slutsker, I., Tanre, D., Torres, O., Mishchenko, M., Geogdzhayev, I., Chu, D. A., and Kaufman, 
Y.: Monthly averages of aerosol properties: A global comparison among models, satellite data, and AERONET ground data, J. Geophys. Res.-Atmos., 108, 4634, doi:10.1029/2001JD001253, 2003.

Kinne, S., Schulz, M., Textor, C., Guibert, S., Balkanski, Y., Bauer, S. E., Berntsen, T., Berglen, T. F., Boucher, O., Chin, M., Collins, W., Dentener, F., Diehl, T., Easter, R., Feichter, J., Fillmore, D., Ghan, S., Ginoux, P., Gong, S., Grini, A., Hendricks, J., Herzog, M., Horowitz, L., Isaksen, I., Iversen, T., Kirkevåg, A., Kloster, S., Koch, D., Kristjansson, J. E., Krol, M., Lauer, A., Lamarque, J. F., Lesins, G., Liu, X., Lohmann, U., Montanaro, V., Myhre, G., Penner, J., Pitari, G., Reddy, S., Seland, O., Stier, P., Takemura, T., and Tie, X.: An AeroCom initial assessment - optical properties in aerosol component modules of global models, Atmos. Chem. Phys., 6, 1815-1834, doi:10.5194/acp-6-1815-2006, 2006.

Kinne, S., O’Donnell, D., Stier, P., Kloster, S., Zhang, K., Schmidt, H., Rast, S., Giorgetta, M., Eck, T., and Stevens, B.: A new global aerosol climatology for climate studies, Journal of Advances in Modeling Earth Systems, submitted, 2012.

Kloster, S., Dentener, F., Feichter, J., Raes, F., van Aardenne, J., Roeckner, E., Lohmann, U., Stier, P., and Swart, R.: Influence of future air pollution mitigation strategies on total aerosol radiative forcing, Atmos. Chem. Phys., 8, 6405-6437, doi:10.5194/acp-86405-2008, 2008.

Koch, D., Schulz, M., Kinne, S., McNaughton, C., Spackman, J. R., Balkanski, Y., Bauer, S., Berntsen, T., Bond, T. C., Boucher, O., Chin, M., Clarke, A., De Luca, N., Dentener, F., Diehl, T., Dubovik, O., Easter, R., Fahey, D. W., Feichter, J., Fillmore, D., Freitag, S., Ghan, S., Ginoux, P., Gong, S., Horowitz, L., Iversen, T., Kirkevåg, A., Klimont, Z., Kondo, Y., Krol, M., Liu, X., Miller, R., Montanaro, V., Moteki, N., Myhre, G., Penner, J. E., Perlwitz, J., Pitari, G., Reddy, S., Sahu, L., Sakamoto, H., Schuster, G., Schwarz, J. P., Seland, Ø., Stier, P., Takegawa, N., Takemura, T., Textor, C., van Aardenne, J. A., and Zhao, Y.: Evaluation of black carbon estimations in global aerosol models, Atmos. Chem. Phys., 9, 9001-9026, doi:10.5194/acp-9-9001-2009, 2009.

Koepke, P., Hess, M., Schult, I., and Shettle, E.: Global Aerosol Data Set, Report 243 ISSN 0937-1060, Max Planck Institute for Meteorology, Hamburg, 1997.

Kokkola, H., Hommel, R., Kazil, J., Niemeier, U., Partanen, A.-I., Feichter, J., and Timmreck, C.: Aerosol microphysics modules in the framework of the ECHAM5 climate model - intercomparison under stratospheric conditions, Geosci. Model Dev., 2, 97-112, doi:10.5194/gmd-2-97-2009, 2009.

Kreidenweis, S. M., Koehler, K., DeMott, P. J., Prenni, A. J., Carrico, C., and Ervens, B.: Water activity and activation diameters from hygroscopicity data - Part I: Theory and application to inorganic salts, Atmos. Chem. Phys., 5, 1357-1370, doi:10.5194/acp-5-1357-2005, 2005.

Kreidenweis, S. M., Petters, M. D., and DeMott, P. J.: Single-parameter estimates of aerosol water content, Environ. Res. Lett., 3, 035002, http://stacks.iop.org/1748-9326/3/i=3/a= 035002, 2008.

Kuang, C., McMurry, P. H., McCormick, A. V., and Eisele, F. L.: Dependence of nucleation rates on sulfuric acid vapor concentration in diverse atmospheric locations, J. Geophys. Res., 113, D10209, doi:10.1029/2007JD009253, 2008.
Kulmala, M., Laaksonen, A., and Pirjola, L.: Parameterizations for sulfuric acid/water nucleation rates, J. Geophys. Res., 103, 83018307, doi:10.1029/97JD03718, 1998.

Kulmala, M., Lehtinen, K. E. J., and Laaksonen, A.: Cluster activation theory as an explanation of the linear dependence between formation rate of $3 \mathrm{~nm}$ particles and sulphuric acid concentration, Atmos. Chem. Phys., 6, 787-793, doi:10.5194/acp-6-787-2006, 2006.

Kulmala, M., Asmi, A., Lappalainen, H. K., Baltensperger, U., Brenguier, J.-L., Facchini, M. C., Hansson, H.-C., Hov, Ø., O'Dowd, C. D., Pöschl, U., Wiedensohler, A., Boers, R., Boucher, O., de Leeuw, G., Denier van der Gon, H. A. C., Feichter, J., Krejci, R., Laj, P., Lihavainen, H., Lohmann, U., McFiggans, G., Mentel, T., Pilinis, C., Riipinen, I., Schulz, M., Stohl, A., Swietlicki, E., Vignati, E., Alves, C., Amann, M., Ammann, M., Arabas, S., Artaxo, P., Baars, H., Beddows, D. C. S., Bergström, R., Beukes, J. P., Bilde, M., Burkhart, J. F., Canonaco, F., Clegg, S. L., Coe, H., Crumeyrolle, S., D’Anna, B., Decesari, S., Gilardoni, S., Fischer, M., Fjaeraa, A. M., Fountoukis, C., George, C., Gomes, L., Halloran, P., Hamburger, T., Harrison, R. M., Herrmann, H., Hoffmann, T., Hoose, C., Hu, M., Hyvärinen, A., Hõrrak, U., Iinuma, Y., Iversen, T., Josipovic, M., Kanakidou, M., Kiendler-Scharr, A., Kirkevåg, A., Kiss, G., Klimont, Z., Kolmonen, P., Komppula, M., Kristjánsson, J.-E., Laakso, L., Laaksonen, A., Labonnote, L., Lanz, V. A., Lehtinen, K. E. J., Rizzo, L. V., Makkonen, R., Manninen, H. E., McMeeking, G., Merikanto, J., Minikin, A., Mirme, S., Morgan, W. T., Nemitz, E., O’Donnell, D., Panwar, T. S., Pawlowska, H., Petzold, A., Pienaar, J. J., Pio, C., Plass-Duelmer, C., Prévôt, A. S. H., Pryor, S., Reddington, C. L., Roberts, G., Rosenfeld, D., Schwarz, J., Seland, Ø., Sellegri, K., Shen, X. J., Shiraiwa, M., Siebert, H., Sierau, B., Simpson, D., Sun, J. Y., Topping, D., Tunved, P., Vaattovaara, P., Vakkari, V., Veefkind, J. P., Visschedijk, A., Vuollekoski, H., Vuolo, R., Wehner, B., Wildt, J., Woodward, S., Worsnop, D. R., van Zadelhoff, G.-J., Zardini, A. A., Zhang, K., van Zyl, P. G., Kerminen, V.-M., S Carslaw, K., and Pandis, S. N.: General overview: European Integrated project on Aerosol Cloud Climate and Air Quality interactions (EUCAARI) - integrating aerosol research from nano to global scales, Atmos. Chem. Phys., 11, 13061-13143, doi:10.5194/acp11-13061-2011, 2011.

Laakso, L., Petäjä, T., Lehtinen, K. E. J., Kulmala, M., Paatero, J., Hõrrak, U., Tammet, H., and Joutsensaari, J.: Ion production rate in a boreal forest based on ion, particle and radiation measurements, Atmos. Chem. Phys., 4, 1933-1943, doi:10.5194/acp-41933-2004, 2004.

Langner, J. and Rodhe, H.: A global three-dimensional model of tropospheric sulfur cycle, J. Atmos. Chem., 13, 225-263, 1991.

Laurent, B., Marticorena, B., Bergametti, G., and Mei, F.: Modeling mineral dust emissions from Chinese and Mongolian deserts, Global Planet. Change, 52, 121-141, doi:10.1016/j.gloplacha.2006.02.012, 2006.

Lin, H. and Leaitch, W. R.: Development of an in-cloud aerosol activation parameterization for climate modelling., in: WMO Workshop on Measurement of Cloud Properties for Forecasts of Weather, Air Quality and Climate, pp. 328-355, Geneva, Switzerland, World Meteorology Organization, 1997.

Lin, S. J. and Rood, R. B.: Multidimensional flux-form semiLagrangian transport schemes, Mon. Weather Rev., 124, 2046- 
2070, 1996.

Liu, X. and Penner, J. E.: Effect of Mount Pinatubo $\mathrm{H}_{2} \mathrm{SO}_{4} / \mathrm{H}_{2} \mathrm{O}$ aerosol on ice nucleation in the upper troposphere using a global chemistry and transport model, J. Geophys. Res., 107, 4141, doi:10.1029/2001JD000455, 2002.

Liu, X., Penner, J. E., and Herzog, M.: Global modeling of aerosol dynamics: Model description, evaluation, and interactions between sulfate and nonsulfate aerosols, J. Geophys. Res., 110, D18206, doi:10.1029/2004JD005674, 2005.

Liu, X., Easter, R. C., Ghan, S. J., Zaveri, R., Rasch, P., Shi, X., Lamarque, J.-F., Gettelman, A., Morrison, H., Vitt, F., Conley, A., Park, S., Neale, R., Hannay, C., Ekman, A. M. L., Hess, P., Mahowald, N., Collins, W., Iacono, M. J., Bretherton, C. S., Flanner, M. G., and Mitchell, D.: Toward a minimal representation of aerosols in climate models: description and evaluation in the Community Atmosphere Model CAM5, Geosci. Model Dev., 5, 709-739, doi:10.5194/gmd-5-709-2012, 2012.

Lohmann, U. and Feichter, J.: Impact of sulfate aerosols on albedo and lifetime of clouds: A sensitivity study with the ECHAM4 GCM, J. Geophys. Res., 102, 13685-13700, doi:10.1029/97JD00631, 1997.

Lohmann, U. and Hoose, C.: Sensitivity studies of different aerosol indirect effects in mixed-phase clouds, Atmos. Chem. Phys., 9, 8917-8934, doi:10.5194/acp-9-8917-2009, 2009.

Lohmann, U. and Roeckner, E.: Design and performance of a new cloud microphysics scheme developed for the ECHAM general circulation model, Climate Dynamics, 12, 557-572, 1996.

Lohmann, U., Stier, P., Hoose, C., Ferrachat, S., Kloster, S., Roeckner, E., and Zhang, J.: Cloud microphysics and aerosol indirect effects in the global climate model ECHAM5-HAM, Atmos. Chem. Phys., 7, 3425-3446, doi:10.5194/acp-7-3425-2007, 2007.

Louis, J. F.: A parametric model of vertical eddy uses in the atmosphere., Bound.-Layer Meteor., 17, 187-202, 1979.

Makkonen, R., Asmi, A., Korhonen, H., Kokkola, H., Järvenoja, S., Räisänen, P., Lehtinen, K. E. J., Laaksonen, A., Kerminen, V.M., Järvinen, H., Lohmann, U., Bennartz, R., Feichter, J., and Kulmala, M.: Sensitivity of aerosol concentrations and cloud properties to nucleation and secondary organic distribution in ECHAM5-HAM global circulation model, Atmos. Chem. Phys., 9, 1747-1766, doi:10.5194/acp-9-1747-2009, 2009.

Mashayekhi, R., Irannejad, P., Feichter, J., and Bidokhti, A. A.: Implementation of a new aerosol HAM model within the Weather Research and Forecasting (WRF) modeling system, Geosci. Model Dev. Discuss., 2, 681-707, doi:10.5194/gmdd-2-6812009, 2009.

Mlawer, E. J., Taubman, S. J., Brown, P. D., Iacono, M. J., and Clough, S. A.: Radiative transfer for inhomogeneous atmospheres: RRTM, a validated correlated-k model for the longwave., J. Geophys. Res., 102, 16663-16682, 1997.

Monahan, E., Spiel, D., and Davidson, K.: A model of marine aerosol generation via whitecaps and wave disruption, in: Oceanic whitecaps and their role in air-sea exchange, edited by: Reidel, D., 167-174, Norwell, Massachusetts, 1986.

Myhre, G., Samset, B. H., Schulz, M., Balkanski, Y., Bauer, S., Berntsen, T. K., Bian, H., Bellouin, N., Chin, M., Diehl, T., Easter, R. C., Feichter, J., Ghan, S. J., Hauglustaine, D., Iversen, T., Kinne, S., Kirkevåg, A., Lamarque, J.-F., Lin, G., Liu, X., Luo, G., Ma, X., Penner, J. E., Rasch, P. J., Seland, Ø., Skeie, R.
B., Stier, P., Takemura, T., Tsigaridis, K., Wang, Z., Xu, L., Yu, H., Yu, F., Yoon, J.-H., Zhang, K., Zhang, H., and Zhou, C.: Radiative forcing of the direct aerosol effect from AeroCom Phase II simulations, Atmos. Chem. Phys. Discuss., 12, 22355-22413, doi:10.5194/acpd-12-22355-2012, 2012.

Ng, N. L., Chhabra, P. S., Chan, A. W. H., Surratt, J. D., Kroll, J. H., Kwan, A. J., McCabe, D. C., Wennberg, P. O., Sorooshian, A., Murphy, S. M., Dalleska, N. F., Flagan, R. C., and Seinfeld, J. H.: Effect of $\mathrm{NO}_{\mathrm{x}}$ level on secondary organic aerosol (SOA) formation from the photooxidation of terpenes, Atmos. Chem. Phys., 7, 5159-5174, doi:10.5194/acp-7-5159-2007, 2007.

Niemeier, U., Timmreck, C., Graf, H.-F., Kinne, S., Rast, S., and Self, S.: Initial fate of fine ash and sulfur from large volcanic eruptions, Atmos. Chem. Phys., 9, 9043-9057, doi:10.5194/acp9-9043-2009, 2009.

Niemeier, U., Schmidt, H., and Timmreck, C.: The dependency of geoengineered sulfate aerosol on the emission strategy, Atmos. Sci. Lett., 12, 189-194, doi:10.1002/asl.304, 2011.

Nightingale, P., Malin, G., Law, C., Watson, A., Liss, P., Liddicoat, M., Boutin, J., and Upstill-Goddard, R.: In situ evaluation of air-sea gas exchange parameterizations using novel conservative and volatile tracers, Global Biogeochem. Cy., 14, 373-387, doi:10.1029/1999GB900091, 2000.

Nilsson, B.: Meteorological influence on aerosol extinction in the 0.2-40-micron wavelength range, Appl. Optics, 18, 3457-3473, doi:10.1364/AO.18.003457, 1979.

Nordeng, T. E.: Extended versions of the convective parametrization scheme at ECMWF and their impact on the mean and transient activity of the model in the tropics, ECMWF Research Department, Technical Momorandum 206, European Centre for Medium-Range Weather Forecast, Reading, UK, 1994.

O'Donnell, D., Tsigaridis, K., and Feichter, J.: Estimating the direct and indirect effects of secondary organic aerosols using ECHAM5-HAM, Atmos. Chem. Phys., 11, 8635-8659, doi:10.5194/acp-11-8635-2011, 2011.

Odum, J. R., T. Hoffman, T., Bowman, F., Collins, D., Flagan, R. C., and Seinfeld, J. H.: Gas/Particle Partitioning and Secondary Organic Aerosol Yields, Environ. Sci. Technol., 30, 2580-2585, doi:10.1021/es950943+, 1996.

Olivier, J., Berdowski, J., Peters, J., Bakker, J., Visschedijk, A., and Bloos, J.: Applications of EDGAR including a description of EDGAR V3.0: reference database with trend data for 19701995, NRP Report 410200 051, RIVM, Bilthoven, The Netherlands, 2005a.

Olivier, J. G. J., van Aardenne, J. A., Dentener, F. J., Pagliari, V., Ganzeveld, L. N., and Peters, J. A. H. W.: Recent trends in global greenhouse gas emissions: regional trends 1970-2000 and spatial distribution of key sources in 2000, Environ. Sci., 2, 81-99, doi:10.1080/15693430500400345, 2005b.

Pankow, J. F.: An absorption model of gas/particle partitioning of organic compounds in the atmosphere, Environ. Sci., 28, 185188, 1994a.

Pankow, J. F.: An absorption model of the gas/particle partitioning involved in the formation of secondary organic aerosol, Environ. Sci., 28, 189-193, 1994b.

Petters, M. D. and Kreidenweis, S. M.: A single parameter representation of hygroscopic growth and cloud condensation nucleus activity, Atmos. Chem. Phys., 7, 1961-1971, doi:10.5194/acp-71961-2007, 2007. 
Pham, M., Müller, J. F., Brasseur, G. P., Granier, C., and Mégie, G.: A three-dimensional study of the tropospheric sulfur cycle, J. Geophys. Res., 100, 26061-26092, doi:10.1029/95JD02095, 1995.

Prigent, C., Tegen, I., Aires, F., Marticorena, B., and Zribi, M.: Estimation of the aerodynamic roughness length in arid and semiarid regions over the globe with the ERS scatterometer, J. Geophys. Res., 110, D09205, doi:10.1029/2004JD005370, 2005.

Pringle, K. J., Tost, H., Message, S., Steil, B., Giannadaki, D., Nenes, A., Fountoukis, C., Stier, P., Vignati, E., and Lelieveld, J.: Description and evaluation of GMXe: a new aerosol submodel for global simulations (v1), Geosci. Model Dev., 3, 391-412, doi:10.5194/gmd-3-391-2010, 2010.

Putaud, J.-P., Dingenen, R. V., Baltensperger, U., Brüggemann, E., Charron, A., Facchini, M. C., Decesari, S., Fuzzi, S., Gehrig, R., Hansson, H. C., Harrison, R. M., Jones, A. M., Laj, P., Lorbeer, G., Maenhaut, W., Mihalopoulos, N., Müller, K., Palmgren, F., Querol, X., Rodriguez, S., Schneider, J., Spindler, G., Brink, H., Tunved, P., Torseth, K., Wehner, B., Weingartner, E., Wiedensohler, A., Wahlin, P., and Raes, F.: A European aerosol phenomenology; physical and chemical characteristics of particulate matter at kerbside, urban, rural and background sites in Europe, Tech. Rep. Report nr. EUR 20411, European Commission, available at http://ccu.ei.jrc.it/ccu, 2003.

Quaas, J., Boucher, O., and Breon, F. M.: Aerosol indirect effects in POLDER satellite data and the Laboratoire de Meteorologie Dynamique-Zoom (LMDZ) general circulation model, J. Geophys. Res., 109, D08205, doi:10.1029/2003JD004317, 2004.

Riipinen, I., Sihto, S.-L., Kulmala, M., Arnold, F., Dal Maso, M., Birmili, W., Saarnio, K., Teinilä, K., Kerminen, V.-M., Laaksonen, A., and Lehtinen, K. E. J.: Connections between atmospheric sulphuric acid and new particle formation during QUEST III-IV campaigns in Heidelberg and Hyytiälä, Atmos. Chem. Phys., 7, 1899-1914, doi:10.5194/acp-7-1899-2007, 2007.

Roeckner, E., Bäuml, G., Bonaventura, L., Brokopf, R., Esch, M., Giorgetta, M., Hagemann, S., Kirchner, I., Kornblueh, L., Manzini, E., Rhodin, A., Schlese, U., Schulzweida, U., and Tompkins, A.: The atmospheric general circulation model ECHAM 5. PART I: model description, MPI Technical Report 349, Max Planck Institute for Meteorology, Hamburg, Germany, 2003.

Roeckner, E., Brokopf, R., Esch, M., Giorgetta, M. A., Hagemann, S., Kornblueh, L., Manzini, E., Schlese, U., and Schulzweida, U.: Sensitivity of Simulated Climate to Horizontal and Vertical Resolution in the ECHAM5 Atmosphere Model, Journal of Climate, 19, 3771-3791, 2006a.

Roeckner, E., Stier, P., Feichter, J., Kloster, S., Esch, M., and Fischer-Bruns, I.: Impact of carbonaceous aerosol emissions on regional climate change, Clim. Dynam., 27, 553-571, doi:10.1007/s00382-006-0147-3, 2006b.

Saathoff, H., Naumann, K.-H., Möhler, O., Jonsson, Å. M., Hallquist, M., Kiendler-Scharr, A., Mentel, Th. F., Tillmann, R., and Schurath, U.: Temperature dependence of yields of secondary organic aerosols from the ozonolysis of $\alpha$-pinene and limonene, Atmos. Chem. Phys., 9, 1551-1577, doi:10.5194/acp-9-15512009, 2009.

Samset, B. H. and Myhre, G.: Vertical dependence of black carbon, sulphate and biomass burning aerosol radiative forcing, Geophys. Res. Lett., 38, L24802, doi:10.1029/2011GL049697, 2011.
Schulz, M., Textor, C., Kinne, S., Balkanski, Y., Bauer, S., Berntsen, T., Berglen, T., Boucher, O., Dentener, F., Guibert, S., Isaksen, I. S. A., Iversen, T., Koch, D., Kirkevåg, A., Liu, X., Montanaro, V., Myhre, G., Penner, J. E., Pitari, G., Reddy, S., Seland, $\varnothing$. ., Stier, P., and Takemura, T.: Radiative forcing by aerosols as derived from the AeroCom present-day and pre-industrial simulations, Atmos. Chem. Phys., 6, 5225-5246, doi:10.5194/acp-65225-2006, 2006.

Schulz, M., Chin, M., and Kinne, S.: The Aerosol Model Comparison Project, AeroCom, Phase II: Clearing Up Diversity, IGAC Newsletter, 2009.

Seinfeld, J. H. and Pandis, S. N.: Atmospheric Chemistry and Physics: From Air Pollution to Climate Change, J. Wiley, New York, 1998.

Shettle, E. P. and Fenn, R. W.: Models of the aerosols of the lower atmosphere and the effects of humidity variations on their optical properties, Tech. rep. project 7670, Air Force Geoph. Lab., Massachusetts, 1979.

Slinn, S. A. and Slinn, W. G. N.: Predictions for particle deposition on natural waters, Atmos. Environ., 14, 1013-1026, 1980.

Smith, M. and Harrison, N.: The sea spray generation function, J. Aerosol Sci., 29, 189-190, doi:10.1016/S0021-8502(98)002808, 1998.

Spracklen, D. V., Pringle, K. J., Carslaw, K. S., Chipperfield, M. P., and Mann, G. W.: A global off-line model of sizeresolved aerosol microphysics: I. Model development and prediction of aerosol properties, Atmos. Chem. Phys., 5, 22272252, doi:10.5194/acp-5-2227-2005, 2005.

Stier, P., Feichter, J., Kinne, S., Kloster, S., Vignati, E., Wilson, J., Ganzeveld, L., Tegen, I., Werner, M., Balkanski, Y., Schulz, M., Boucher, O., Minikin, A., and Petzold, A.: The aerosol-climate model ECHAM5-HAM, Atmos. Chem. Phys., 5, 1125-1156, doi:10.5194/acp-5-1125-2005, 2005.

Stier, P., Feichter, J., Roeckner, E., Kloster, S., and Esch, M.: The evolution of the global aerosol system in a transient climate simulation from 1860 to 2100, Atmos. Chem. Phys., 6, 3059-3076, doi:10.5194/acp-6-3059-2006, 2006.

Stier, P., Seinfeld, J. H., Kinne, S., and Boucher, O.: Aerosol absorption and radiative forcing, Atmos. Chem. Phys., 7, 5237-5261, doi:10.5194/acp-7-5237-2007, 2007.

Stokes, R. H. and Robinson, R. A.: Interactions in aqueous nonelectrolyte solutions. I. Solute-solvent equilibria, J. Phys. Chem., 70, 2126-2130, doi:10.1021/j100879a010, 1966.

Tanre, D., Geleyn, J. F., and Slingo, J. M.: First results of the introduction of an advanced aerosol-radiation interaction in the ECMWF low resolution global model, in: Aerosols and Their Climatic Effects, edited by Gerber, H. and Deepak, A., pp. 133177, A. Deepak, Hampton, Va., 1984.

Tegen, I., Harrison, S. P., Kohfeld, K., Prentice, I. C., Coe, M., and Heimann, M.: Impact of vegetation and preferential source areas on global dust aerosol: Results from a model study, J. Geophys. Res., 107, 4576, doi:10.1029/2001JD000963, 2002.

Textor, C., Schulz, M., Guibert, S., Kinne, S., Balkanski, Y., Bauer, S., Berntsen, T., Berglen, T., Boucher, O., Chin, M., Dentener, F., Diehl, T., Easter, R., Feichter, H., Fillmore, D., Ghan, S., Ginoux, P., Gong, S., Grini, A., Hendricks, J., Horowitz, L., Huang, P., Isaksen, I., Iversen, I., Kloster, S., Koch, D., Kirkevåg, A., Kristjansson, J. E., Krol, M., Lauer, A., Lamarque, J. F., Liu, X., Montanaro, V., Myhre, G., Penner, J., Pitari, G., Reddy, S., Seland, 
Ø., Stier, P., Takemura, T., and Tie, X.: Analysis and quantification of the diversities of aerosol life cycles within AeroCom, Atmos. Chem. Phys., 6, 1777-1813, doi:10.5194/acp-6-1777-2006, 2006.

Textor, C., Schulz, M., Guibert, S., Kinne, S., Balkanski, Y., Bauer, S., Berntsen, T., Berglen, T., Boucher, O., Chin, M., Dentener, F., Diehl, T., Feichter, J., Fillmore, D., Ginoux, P., Gong, S., Grini, A., Hendricks, J., Horowitz, L., Huang, P., Isaksen, I. S. A., Iversen, T., Kloster, S., Koch, D., Kirkevåg, A., Kristjansson, J. E., Krol, M., Lauer, A., Lamarque, J. F., Liu, X., Montanaro, V., Myhre, G., Penner, J. E., Pitari, G., Reddy, M. S., Seland, Ø., Stier, P., Takemura, T., and Tie, X.: The effect of harmonized emissions on aerosol properties in global models an AeroCom experiment, Atmos. Chem. Phys., 7, 4489-4501, doi:10.5194/acp-7-4489-2007, 2007.

Tie, X., Brasseur, G., Emmons, L., Horowitz, L., and Kinnison, D.: Effects of aerosols on tropospheric oxidants: A global model study, J. Geophys. Res., 106, 22931-22964, doi:10.1029/2001JD900206, 2001.

Tiedtke, M.: A comprehensive mass flux scheme for cumulus parameterization in large scale models, Mon. Weather Rev., 117, 1779-1800, 1989.

Timmreck, C., Graf, H. F., Lorenz, S. J., Niemeier, U., Zanchettin, D., Matei, D., Jungclaus, J. H., and Crowley, T. J.: Aerosol size confines climate response to volcanic super-eruptions, Geophys. Res. Lett., 37, L24705, doi:10.1029/2010GL045464, 2010.

Toon, O. B., Pollack, J. B., and Khare, B. N.: The optical constants of several atmospheric aerosol species: Ammonium sulfate, aluminum oxide, and sodium chloride, J. Geophys. Res., 81, 57335748, doi:10.1029/JC081i033p05733, 1976.

Tunved, P., Hansson, H.-C., Kulmala, M., Aalto, P., Viisanen, Y., Karlsson, H., Kristensson, A., Swietlicki, E., Dal Maso, M., Ström, J., and Komppula, M.: One year boundary layer aerosol size distribution data from five nordic background stations, Atmos. Chem. Phys., 3, 2183-2205, doi:10.5194/acp-3-2183-2003, 2003.

Uppala, S. M., KÅllberg, P. W., Simmons, A. J., Andrae, U., Bechtold, V. D. C., Fiorino, M., Gibson, J. K., Haseler, J., Hernandez, A., Kelly, G. A., Li, X., Onogi, K., Saarinen, S., Sokka, N., Allan, R. P., Andersson, E., Arpe, K., Balmaseda, M. A., Beljaars, A. C. M., Berg, L. V. D., Bidlot, J., Bormann, N., Caires, S., Chevallier, F., Dethof, A., Dragosavac, M., Fisher, M., Fuentes, M., Hagemann, S., Hólm, E., Hoskins, B. J., Isaksen, L., Janssen, P. A. E. M., Jenne, R., McNally, A. P., Mahfouf, J.F., Morcrette, J.-J., Rayner, N. A., Saunders, R. W., Simon, P., Sterl, A., Trenberth, K. E., Untch, A., Vasiljevic, D., Viterbo, P., and Woollen, J.: The ERA-40 re-analysis, Q. J. Roy. Meteorol. Soc., 131, 2961-3012, 2005. van der Werf, G. R., Randerson, J. T., Collatz, G. J., Giglio, L., Kasibhatla, P. S., Arellano, A. F., Olsen, S. C., and Kasischke, E. S.: Continental-Scale Partitioning of Fire Emissions During the 1997 to 2001 El Niño/La Niña Period, Science, 303, 73-76, doi:10.1126/science.1090753, 2004.

Vehkamäki, H., Kulmala, M., Napari, I., Lehtinen, K. E. J., Timmreck, C., Noppel, M., and Laaksonen, A.: An improved parameterization for sulfuric acid water nucleation rates for tropospheric and stratospheric conditions, J. Geophys. Res., 107, 4622, doi:10.1029/2002JD002184, 2002.

Verheggen, B., Cozic, J., Weingartner, E., Bower, K., Mertes, S., Connolly, P., Gallagher, M., Flynn, M., Choularton, T., and Baltensperger, U.: Aerosol partitioning between the interstitial and the condensed phase in mixed-phase clouds, J. Geophys. Res., 112, D23202, doi:10.1029/2007JD008714, 2007.

Vignati, E., Wilson, J., and Stier, P.: M7: An efficient size-resolved aerosol microphysics module for large-scale aerosol transport models, J. Geophys. Res., 109, D22202, doi:10.1029/2003JD004485, 2004.

Wexler, A. S. and Clegg, S. L.: Atmospheric aerosol models for systems including the ions $\mathrm{H}^{+}, \mathrm{NH}_{4}^{+}, \mathrm{Na}^{+}, \mathrm{SO}_{4}^{2-}$, $\mathrm{NO}^{3-}, \mathrm{Cl}^{-}, \mathrm{Br}-$, and $\mathrm{H}_{2} \mathrm{O}$, J. Geophys. Res., 107, 4207, doi:10.1029/2001JD000451, 2002.

Wilson, J., Cuvelier, C., and Raes, F.: A modeling study of global mixed aerosol fields, J. Geophys. Res., 106, 34081-34108, 2001.

Zarzycki, C. M. and Bond, T. C.: How much can the vertical distribution of black carbon affect its global direct radiative forcing?, Geophys. Res. Lett., 37, L20807, doi:10.1029/2010GL044555, 2011.

Zaveri, R. A., Easter, R. C., Fast, J. D., and Peters, L. K.: Model for Simulating Aerosol Interactions and Chemistry (MOSAIC), J. Geophys. Res., 113, D13204, doi:10.1029/2007JD008782, 2008.

Zdanovskii, A. B.: New methods for calculating solubilities of electrolytes in multicomponent systems, Zhur. Fiz. Khim., 22, 14751485, 1948.

Zeleznik, F. J.: Thermodynamic properties of the aqueous sulfuric acid system to 350 K, J. Phys. Chem. Ref. Data, 20, 1157-1200, doi:10.1063/1.555899, 1991.

Zhang, K., Wan, H., Wang, B., Zhang, M., Feichter, J., and Liu, X.: Tropospheric aerosol size distributions simulated by three online global aerosol models using the M7 microphysics module, Atmos. Chem. Phys., 10, 6409-6434, doi:10.5194/acp-10-64092010, 2010.

Zhang, K., Feichter, J., Kazil, J., Wan, H., Zhuo, W., Griffiths, A. D., Sartorius, H., Zahorowski, W., Ramonet, M., Schmidt, M., Yver, C., Neubert, R. E. M., and Brunke, E.-G.: Radon activity in the lower troposphere and its impact on ionization rate: a global estimate using different radon emissions, Atmos. Chem. Phys., 11, 7817-7838, doi:10.5194/acp-11-7817-2011, 2011. 